Florida International University FIU Digital Commons

FIU Electronic Theses and Dissertations

University Graduate School

3-28-2018

\title{
Addressing Alcohol and Marijuana use Disparities among Latino Adolescents
}

Jessica Weissman

Florida International University, jweis005@fiu.edu

DOI: 10.25148 /etd.FIDC006555

Follow this and additional works at: https:// digitalcommons.fiu.edu/etd

Part of the Community Health Commons, Community Health and Preventive Medicine Commons, and the Substance Abuse and Addiction Commons

\section{Recommended Citation}

Weissman, Jessica, "Addressing Alcohol and Marijuana use Disparities among Latino Adolescents" (2018). FIU Electronic Theses and Dissertations. 3699.

https://digitalcommons.fiu.edu/etd/3699

This work is brought to you for free and open access by the University Graduate School at FIU Digital Commons. It has been accepted for inclusion in FIU Electronic Theses and Dissertations by an authorized administrator of FIU Digital Commons. For more information, please contact dcc@fiu.edu. 
FLORIDA INTERNATIONAL UNIVERSITY

Miami, Florida

ADDRESSING ALCOHOL AND MARIJUANA USE DISPARITIES

AMONG LATINO ADOLESCENTS

A dissertation submitted in partial fulfillment of

the requirements for the degree of

DOCTOR OF PHILOSOPHY

in

PUBLIC HEALTH

By

Jessica Weissman 


\section{To: Tomas R. Guilarte}

Robert Stempel College of Public Health and Social Work

This dissertation, written by Jessica Weissman, and entitled Addressing Alcohol and Marijuana Use Disparities among Latino Adolescents, having been approved in respect to style and intellectual content, is referred to you for judgment.

We have read this dissertation and recommend that it be approved.

Mario de La Rosa

Jessy G. Dévieux

Changwon Yoo

H. Virginia McCoy, Major Professor

Date of Defense: March 28, 2018

The dissertation of Jessica Weissman has been approved.

Dean Tomas R. Guilarte

Robert Stempel College of Public Health and Social Work

Andrés G. Gil

Vice President for Research and Economic Development and Dean of the University Graduate School

Florida International University, 2018 


\section{ACKNOWLEDGMENTS}

I would like to thank my dissertation committee members for their academic support and personal encouragement. I particularly want to thank my dissertation committee chair/advisor, Dr. H. Virginia McCoy, for inspiring me and encouraging me to stay motivated throughout the entire PhD program. I also thank her for her patience, flexibility, and genuine caring and concern during the $\mathrm{PhD}$ program. She has been a wonderful mentor.

This dissertation would not have been possible without the expert guidance of my dissertation committee_-professors Dr. Mario De La Rosa, Dr. Jessy Deviéux, and Dr. Changwon Yoo - in addition to three very important mentors: Dr. Patria Rojas, Dr. Mary Jo Trepka, and Dr. Mariano Kanamori. I would like to thank Dr. De La Rosa for allowing me to train under his mentorship and with the entire research team at the Center for Research on U.S. Latino HIV/AIDS and Drug Abuse (CRUSADA). His expertise with respect to Latino health disparities has played a significant role in making this dissertation project. I would like to thank Dr. Dévieux for her expertise and support of my dissertation and for her personal support during the $\mathrm{PhD}$ program. I would like to thank Dr. Yoo for his bio-statistical support.

I thank Dr. Patria Rojas for her inspiring passion for working with underserved populations. She has served as a great inspiration and mentor. I thank Dr. Mary Jo Trepka for her tremendous support and mentorship during the dissertation proposal writing process and for motivating, supporting, and training me during the entire $\mathrm{PhD}$ process. She has critically contributed to my success in the $\mathrm{PhD}$ program. I also thank Dr. Mariano Kanamori for his mentorship and for serving as an outstanding role model and a 
source of overall support during my $\mathrm{PhD}$ program. I am grateful for his mentorship throughout this process, and I could not have completed this dissertation project without his support.

I would like to thank CRUSADA (Director: Mario De La Rosa) for providing me with two years (Feb 2015-December 2016) of funding during my PhD program. My twoyear fellowship under award number P20MD002288 from the National Institute on Minority Health and Health Disparities supported me during the dissertation proposal writing process, and allowed me to take advantage of the expert mentorship provided by the generous individuals who are affiliated with CRUSADA: Dr. De La Rosa, Dr. Rojas, Dr. Kanamori, and Dr. Trepka.

I would also like to thank the Chair of the Department of Health Promotion and Disease Prevention (HPDP), Dr. Elena Bastida, as well as the entire faculty and staff within the Department of HPDP. The professors within the Department of HPDP have provided me with incredible mentorship and expertise, leading me to achieve several award and scholarship recognitions and other professional achievements (e.g., scientific publications and presentations), which will no doubt contribute to my successful career in public health. The Department has provided the backbone for my dissertation project and has provided me with the support needed to excel in the PhD program. 
ABSTRACT OF THE DISSERTATION

ADDRESSING ALCOHOL AND MARIJUANA USE DISPARITIES

AMONG LATINO ADOLESCENTS

by

Jessica Weissman

Florida International University, 2018

Miami, Florida

Professor H. Virginia McCoy, Major Professor

In the early 1990s, a series of seminal research studies were published on substance use disorders among Latino adolescents in Miami-Dade County, Florida. Expanding upon these studies, the aims of the present dissertation project were to (1) Determine whether the following adolescents' and parents' characteristics/cultural values are associated with current (past 30 days) or lifetime (ever) alcohol or marijuana use among Latino adolescents: sex, age, country of birth, GPA, family’s socio-economic status, living with both parents, mother's highest level of education, father's highest level of education, Familism Support, Familism Obligations, Familism Referents, Respect, Religion, Traditional Gender Roles, Independence and Self-Reliance; (2) Assess if recreational activities (sports participation, after-school activities and volunteering) moderate the association between Latino adolescents' friends' age, sex, and ethnicity and Latino adolescents' current alcohol or marijuana use and; (3) Assess if recreational activities moderate the association between Latino adolescents' perceptions of friends' alcohol or marijuana use and Latino adolescents' current alcohol or marijuana use. 
This cross-sectional dissertation study used survey data from 193 Latino adolescent males and females $(15.7 \pm 1.6$ years old; $55.4 \%$ females, $44.6 \%$ males $)$ in Miami-Dade County collected in 2016-2017. Analyses included t-tests, chi-square tests and logistic regressions.

Being born in the U.S. increased the risk of current alcohol use. Identifying more strongly with the cultural value Religion decreased the risk of current alcohol use and current marijuana use. Participants who reported having no close friends who use alcohol were less likely to currently (within past 30 days) use alcohol themselves when compared to participants who reported having at least one close friend who uses alcohol. The interaction between participation in sports activities and reporting having friends who use alcohol on outcome currently using alcohol was significant. Participants who reported having no close friends who use marijuana were less likely to currently use marijuana themselves.

Findings from this study suggest that factors contributing to substance use among Latino adolescents throughout the United States may be different than those which play a role among the unique Latino adolescent population in Miami-Dade County. This study further validated what has been shown in the general U.S. population: adolescents who perceive their friends to be using alcohol or marijuana are more likely to use alcohol or marijuana, respectively, themselves. Further research is suggested to determine the role of recreational activities in alcohol and marijuana use among Latino adolescents. 


\section{TABLE OF CONTENTS}

CHAPTER

PAGE

CHAPTER I: INTRODUCTION ......................................................................

Statement of the Problem................................................................................

Alcohol and Marijuana Use among Adolescents in Florida ...............................4

Introduction to Primary Socialization Theory ............................................... 4

The Latino and Adolescent Populations in Miami-Dade County ..........................5

Substance Use Disparities among Latino Adolescents .....................................6

Public Health Significance ......................................................................... 7

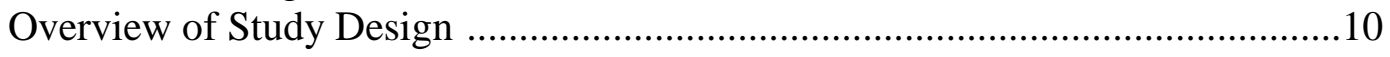

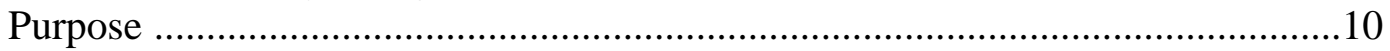

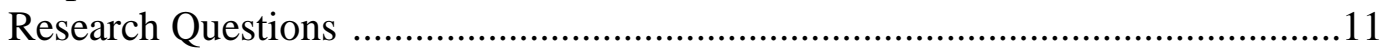

Specific Aims and Hypotheses ..................................................................... 11

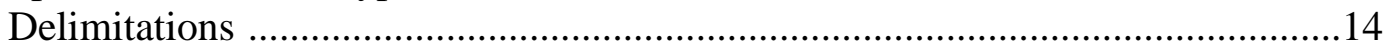

Limitations of Study Design .................................................................. 14

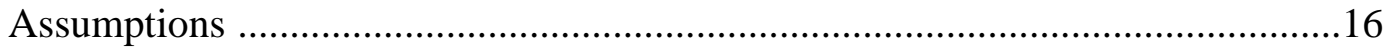

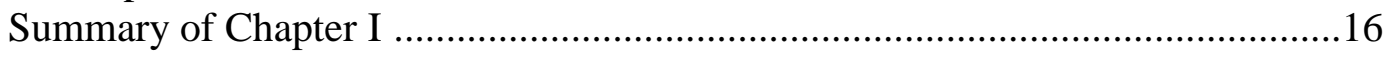

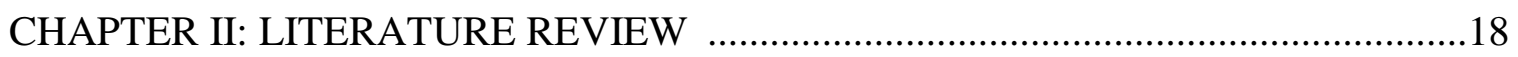

Introduction to Literature Review and Search Strategy ...................................18

Description of Seminal Studies .................................................................19

Consequences of Alcohol Use during Adolescence ........................................22

Consequences of Marijuana Use during Adolescence .......................................24

Factors Associated with Alcohol and Marijuana Use among Adolescents .........25

Role of Cultural Values and Friends' Characteristics .......................................27

Role of Recreational Activities ....................................................................29

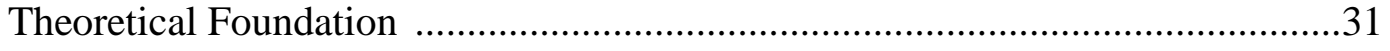

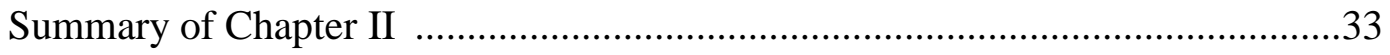

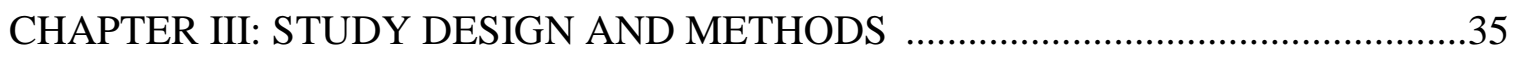

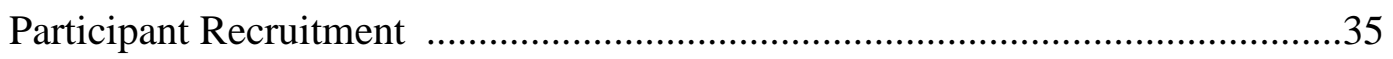

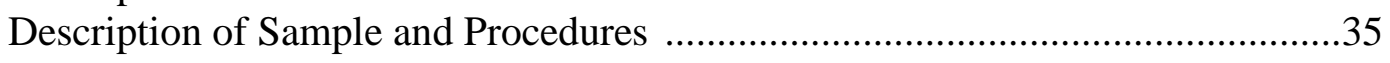

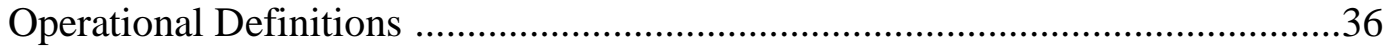

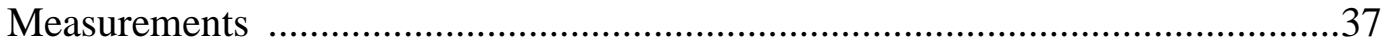

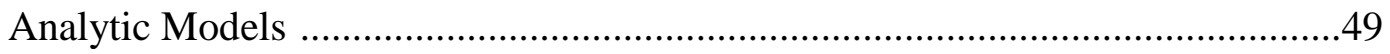

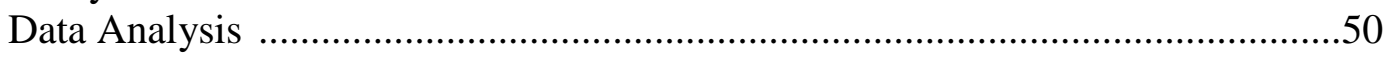

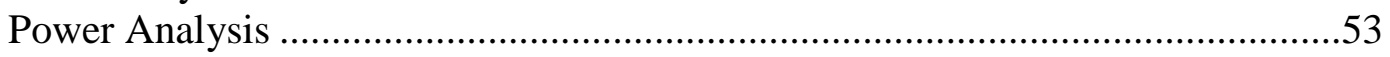

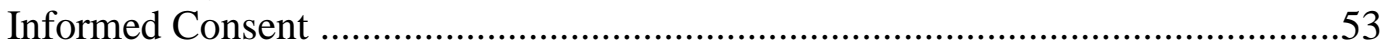

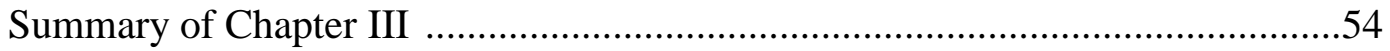




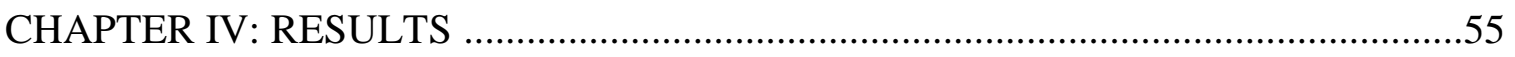

Description of the Sample ..........................................................................55

Perception of Friends' Characteristics ...........................................................57

Recreational Activities ........................................................................59

Latino Cultural Values ................................................................................6

Alcohol and Marijuana Use ................................................................................61

Introduction to Findings of Hypotheses Testing of Hypotheses 1-4 ....................62

Results of Hypothesis Testing (Hypothesis 1: Forward Selection and Backward

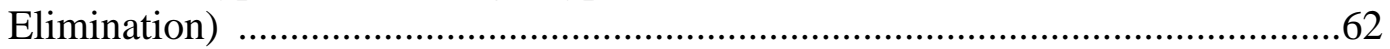

Results of Hypothesis Testing (Hypothesis 2: Forward Selection) ......................64

Results of Hypothesis Testing (Hypothesis 2: Backward Elimination) .................65

Results of Hypothesis Testing (Hypothesis 3: Forward Selection and Backward

Elimination)

Results of Hypothesis Testing (Hypothesis 4: Forward Selection and Backward

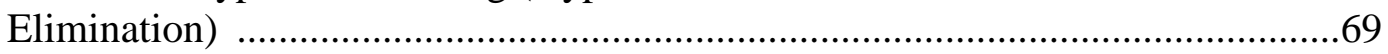

Results of Hypothesis Testing (Hypothesis 5) ……………................................70

Results of Hypothesis Testing (Hypothesis 6) …………...................................71

Results of Hypothesis Testing (Hypothesis 7) ……………...............................72

Results of Hypothesis Testing (Hypothesis 8) …………………………….......74

Summary of Major Findings of Hypothesis Testing ………………......................76

Summary of Chapter IV ……………………………......................................77

CHAPTER V: DISCUSSION/CONCLUSIONS AND FUTURE RESEARCH .............79

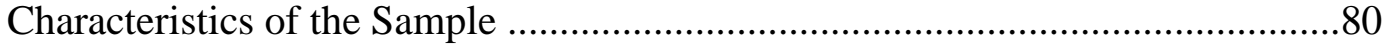

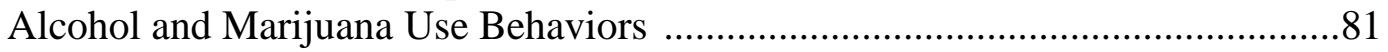

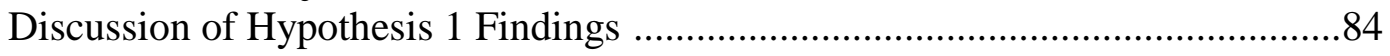

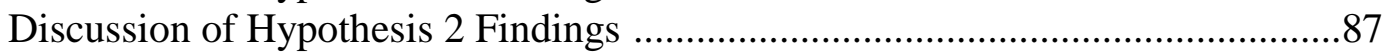

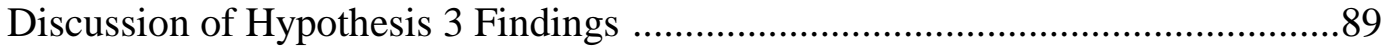

Discussion of Hypothesis 4 Findings ..............................................................99

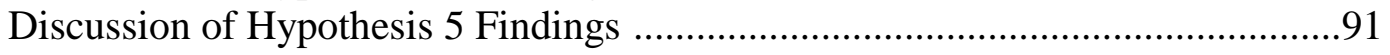

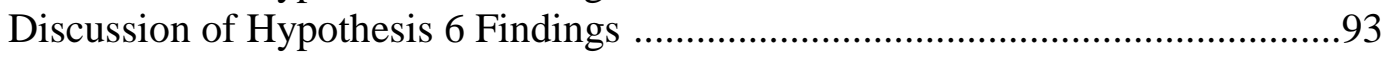

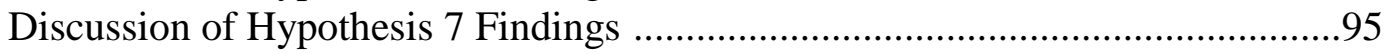

Discussion of Hypothesis 8 Findings ……………….....................................97

Theoretical Implications: Primary Socialization Theory ....................................98

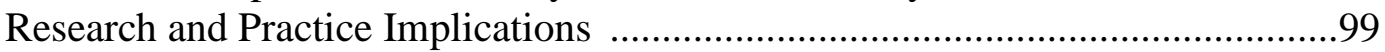

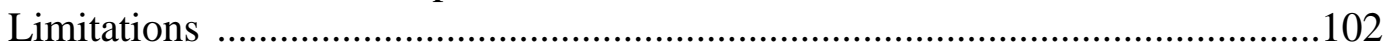

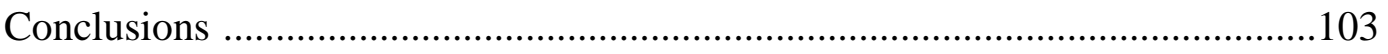

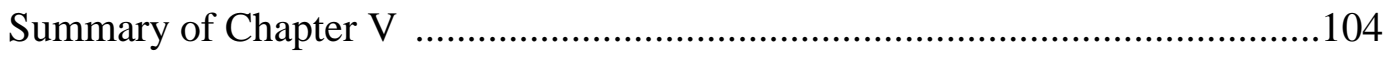

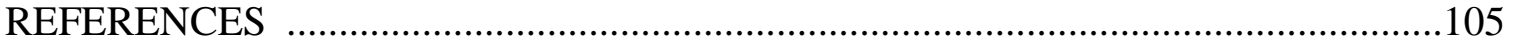

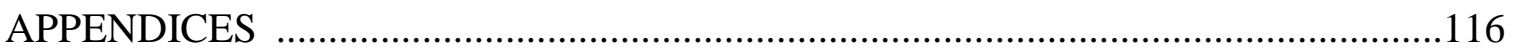

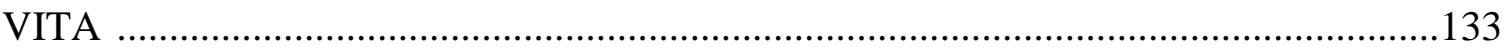




\section{LIST OF TABLES}

TABLE

PAGE

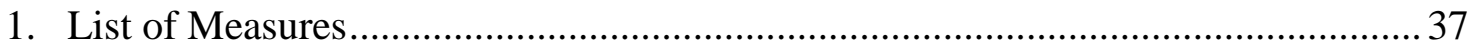

2. Socio-Demographic Characteristics of Participants and their Families, MiamiDade County, Florida 2016-2017

3. Countries of Birth of non-U.S.-born Latino Adolescents, Miami-Dade County, Florida 2016-2017.

4. Recreational Activities Reported by Latino Adolescents, Miami-Dade County, Florida 2016-2017.

5. Means and Standard Deviations of Latino Cultural Values Subscales Reported by Latino Adolescents, Miami-Dade County, Florida 2016-2017

6. Latino Adolescents' Lifetime and Current Use of Alcohol, Miami-Dade County, Florida 2016-2017

7. Latino Adolescents' Lifetime and Current Use of Marijuana, Miami-Dade County, Florida 2016-2017

8. Backward Elimination Logistic Regression Model Summary for Dependent Variable: Current Alcohol Use

9. Backward Elimination Hosmer and Lemeshow Test for Dependent Variable:

Current Alcohol Use 63

10. Backward Elimination Classification Table for Dependent Variable: Current Alcohol Use

11. Backward Elimination, Variables in the Equation for Dependent Variable:

Current Alcohol Use 64

12. Forward Selection Logistic Regression Model Summary for Dependent Variable: Lifetime Alcohol Use

13. Forward Selection Hosmer and Lemeshow Test for Dependent Variable: Lifetime Alcohol Use

14. Forward Selection Classification Table for Dependent Variable: Lifetime Alcohol Use 
15. Forward Selection, Variables in the Equation for Dependent Variable:

Lifetime Alcohol Use.

16. Backward Elimination Logistic Regression Model Summary for Dependent Variable: Lifetime Alcohol Use.

17. Backward Elimination Hosmer and Lemeshow Test for Dependent Variable:

Lifetime Alcohol Use.

18. Backward Elimination Classification Table for Dependent Variable: Lifetime Alcohol Use

19. Backward Elimination, Variables in the Equation for Dependent Variable:

Lifetime Alcohol Use.

20. Backward Elimination Logistic Regression Model Summary for Dependent Variable: Current Marijuana Use.

21. Backward Elimination Hosmer and Lemeshow Test for Dependent Variable: Current Marijuana Use.

22. Backward Elimination Classification Table for Dependent Variable: Current Marijuana Use 68

23. Backward Elimination, Variables in the Equation for Dependent Variable: Current Marijuana Use

24. Backward Elimination Logistic Regression Model Summary for Dependent Variable: Current Marijuana Use.

25. Backward Elimination Hosmer and Lemeshow Test for Dependent Variable: Lifetime Marijuana Use 70

26. Backward Elimination Classification Table for Dependent Variable: Lifetime Marijuana Use.

27. Backward Elimination, Variables in the Equation for Dependent Variable: Lifetime Marijuana Use 70

28. Associations between Latino Adolescents' Current Alcohol Use and Reporting Friends with same Gender, Miami-Dade County, Florida 20162017

29. Associations between Latino Adolescents' Current Alcohol Use and Having Younger Friends, Miami-Dade County, Florida 2016-2017 
30. Associations between Latino Adolescents' Current Alcohol Use and Having Older Friends, Miami-Dade County, Florida 2016-2017

31. Associations between Latino Adolescents' Current Marijuana Use and Reporting Friends with same Gender, Miami-Dade County, Florida 20162017.

32. Associations between Latino Adolescents' Current Marijuana Use and Having Younger Friends, Miami-Dade County, Florida 2016-2017

33. Associations between Latino Adolescents' Current Marijuana Use and Having Older Friends, Miami-Dade County, Florida 2016-2017

34. Associations between Latino Adolescents' Current Alcohol Use and their Perception of Friends' Alcohol Use, Miami-Dade County, Florida 2016-2017...... 73

35. Assessment of Interaction between Perception of Friends' Alcohol Use and Participation in School Sports on Dependent Variable Current Alcohol Use, Miami-Dade County, Florida 2016-2017 73

36. Assessment of Interaction between Perception of Friends' Alcohol Use and Participation in After-school Activities on Dependent Variable Current Alcohol Use, Miami-Dade County, Florida 2016-2017

37. Assessment of Interaction between Perception of Friends' Alcohol Use and Participation in Volunteer Activities on Dependent Variable Current Alcohol Use, Miami-Dade County, Florida 2016-2017 .

38. Associations between Latino Adolescents' Current Marijuana Use and their Perception of Friends' Marijuana Use, Miami-Dade County, Florida 20162017

39. Assessment of Interaction between Perception of Friends' Marijuana Use and Participation in School Sports on Dependent Variable Current Marijuana Use, Miami-Dade County, Florida 2016-2017

40. Assessment of Interaction between Perception of Friends' Marijuana Use and Participation in After-school Activities on Dependent Variable Current Marijuana Use, Miami-Dade County, Florida 2016-2017

41. Assessment of Interaction between Perception of Friends' Marijuana Use and Participation in Volunteer Activities on Dependent Variable Current Marijuana Use, Miami-Dade County, Florida 2016-2017. 


\section{LIST OF FIGURES}

FIGURE

PAGE

1. Prevalence of Alcohol and Marijuana use among High School Adolescents in the U.S., Youth Risk Behavior Surveillance System, 2015 .............................. 7

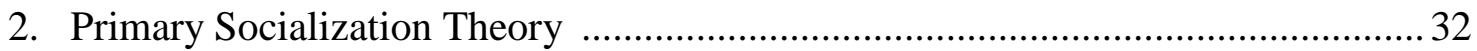

3. Framework Grounded in Primary Socialization Theory ...................................... 33

4. Conceptual Model based on Primary Socialization Theory …............................. 33

5. Analytic Model 1 (Aim 1; Hypotheses 1-4) .................................................. 49

6. Analytic Model 2 (Aim 2; Hypotheses 5-6) ...................................................... 50

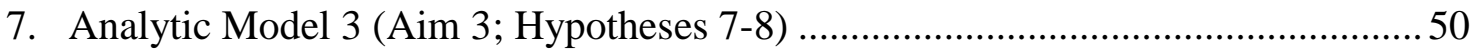

8. Latino Adolescents' Perception of Friends' Age, Sex, and Ethnicity, MiamiDade County, Florida 2016-2017 ............................................................ 58

9. Latino Adolescents' Perception of Friends' Alcohol and Marijuana Use Behaviors, Miami-Dade County, Florida 2016-2017 ....................................... 59

10. Latino Adolescents' Identification with Latino Cultural Value: Familism Support, Miami-Dade County, Florida 2016-2017 125

11. Latino Adolescents' Identification with Latino Cultural Value: Familism Obligations, Miami-Dade County, Florida 2016-2017.

12. Latino Adolescents' Identification with Latino Cultural Value: Familism Referents, Miami-Dade County, Florida 2016-2017

13. Latino Adolescents' Identification with Latino Cultural Value: Respect, Miami-Dade County, Florida 2016-2017

14. Latino Adolescents' Identification with Latino Cultural Value: Religion, Miami-Dade County, Florida 2016-2017

15. Latino Adolescents' Identification with Latino Cultural Value: Traditional Gender Roles, Miami-Dade County, Florida 2016-2017. 
16. Latino Adolescents' Identification with Latino Cultural Value: Independence and Self-Reliance, Miami-Dade County, Florida 2016-2017. 


\section{CHAPTER I: INTRODUCTION}

Statement of the Problem

In the early 1990s, a series of seminal research studies were published on drug and alcohol use among Latino adolescents in Miami-Dade County, Florida. These seminal papers examined the prevalence and risk factors associated with substance abuse and disposition to deviant behaviors, providing the foundation for what is currently understood about Latino adolescent substance use in Miami, Florida (Vega, Zimmerman, Warheit, Apospori, \& Gil, 1993a; Vega, Gil, Warheit, Zimmerman, \& Apospori, 1993b; Vega, Gil, \& Zimmerman, 1993c). In one study of sixth and seventh grade adolescent boys $(\mathrm{N}=6,760)$, Vega et al. (1993a) reported the highest prevalence of early onset of alcohol use among Cubans (41.3\%) and White Non-Hispanics (48.2\%). Cubans (5.1\%) and other Hispanics (5.2\%) had the highest prevalence of illicit drug use (i.e., marijuana, cocaine, PCP). In another study, Vega et al. (1993b) demonstrated associations between acculturation conflicts and disposition to deviant behaviors among sixth and seventh grade Cuban American adolescent boys and girls $(n=1,843)$, most of whom participated in the 1993a seminal study.

A paper published a few years later laid the groundwork for our current understanding of the role of acculturation and peer and familial factors in alcohol use among male Latino adolescents (Gil, Wagner, \& Vega, 2000). In this study, the role of acculturation and familial factors among immigrant Latino adolescent males $(\mathrm{n}=1,051)$ were compared to U.S.-born Latino adolescent males $(n=968)$. Findings revealed a higher report of lifetime alcohol use among those born in the U.S. at three different time 
periods, one year apart (every year for three years). For all participants, years living in the U.S. were positively associated with lifetime alcohol use and past month alcohol use. In addition, the results of two structural equation models indicated that acculturation was associated with alcohol use through acculturation stress and the reduction of two traditional Latino cultural values: Familism and Parental Respect. The present dissertation project explored alcohol and marijuana use among Latino adolescents, expanding upon this foundational work by analyzing current data collected in Miami Dade County, Florida. Moreover, novel contributions of the present dissertation project include (a) comparison of gender differences regarding lifetime and current (past 30 days) use of alcohol and marijuana among a diverse sample of Latino adolescents, (b) the exploration of the role of an in depth (37-item) Latino cultural values scale (Knight et al., 2010), (c) the exploration of the role of recreational activities, and (d) providing an update of the literature since the seminal studies, further advancing current knowledge of Latino adolescent alcohol and marijuana use in Miami-Dade County.

Since these seminal studies were conducted in the 1990's, there have been major changes in the Latino population of Miami-Dade County. For example, in 1990, the total Miami-Dade population was 1,937,094 and Latinos comprised 49.2\% (N =953,407) of the population (Miami-Dade County Department of Planning and Zoning, 2009). In 2015, the Miami-Dade population was comprised of 1,809,150 Latinos (66.4\%) and a total population of 2,724,623 (Miami-Dade County Department of Planning and Zoning, 2009). Moreover, in 1990, most Latinos were of Cuban (59.2\%), Nicaraguan (7.8\%), and Puerto Rican origin (7.6\%; Miami-Dade County Department of Planning and Zoning, 2009). According to the most recent U.S. Census Bureau (2010), the percentage of 
Latinos living in Miami-Dade County who are of Cuban origin has decreased (52.7\%), and the next highest proportion of Latinos are from Nicaragua (4.2\%) and Colombia (4.6\%; U.S. Census Bureau, 2011).

Although (a) the Latino population in Miami-Dade County has changed over the past 25 years and (b) alcohol and substance use are still highly prevalent in the county, very little research has been conducted since the early 1990s. Recent studies have been conducted in other states (i.e., California) and with mostly Mexicans and Puerto Ricans, failing to address the unique Latino population living in Miami-Dade County (Allem, Soto, Baezconde-Garbanati, \& Unger, 2015; Cox Jr, Roblyer, Merten, Shreffler, \& Schwerdtfeger, 2013; Unger, Schwartz, Huh, Soto, \& Baezconde-Garbanati, 2014; Jackson, Rogers, \& Sartor, 2016a). In addition to expanding upon the seminal studies, this dissertation focused on Latino adolescents (13-18 years old) in Miami-Dade County because:

a) When compared to adolescents of other ethnicities, Latino adolescents in the United States (U.S.) report higher prevalence of lifetime alcohol use (Latinos: 72.4\%, Whites: 65.9\%, Blacks: 63.4\%) and marijuana use (Latinos: 48.8\%, Whites: 36.7\%, Blacks: 46.8\%; Kann et al., 2016; Cherpitel, Ye, \& Kerr, 2016);

b) A large proportion of youth in Miami-Dade County, Florida, report current marijuana (10-14 years old: 3.0\%; 15-17 years old: $12.3 \%)$ and alcohol use (10-14 years old: 6.8\%; 15-17 years old: 28.2\%; Florida Department of Children \& Families, 2016); and

c) Latinos experience many health disparities related to marijuana and alcohol use, including barriers to accessing treatment for substance use disorders and higher 
rates of teenage pregnancy (Alegria, Carson, Goncalves, \& Keefe, 2011; Centers for Disease Control and Prevention [CDC], 2016a).

Alcohol and Marijuana Use among Adolescents in Florida

According to the 2016 Florida Youth Substance Abuse Survey (FYSAB), almost half of male and female high school adolescents in Florida aged 11-18 years old have used alcohol at least once during their lifetime (40.2\%), and, of those, $18.6 \%$ consumed an average of 5 or more drinks per day on the days alcohol was consumed in the past 30 days (Florida Department of Children \& Families, 2016). Among 10-14-year-olds, 22.6\% reported ever using alcohol in their lifetime. In addition, marijuana use at least once during their lifetime was reported by $26.3 \%$ of male and female adolescents aged 15-17 years old and 5.7\% of male and female adolescents aged 10-14 years old in Miami-Dade County (Florida Department of Children \& Families, 2016). Among Latino adolescents in Miami-Dade County, $14.5 \%$ reported lifetime alcohol use and 18.6\% reported alcohol use within the past 30 days. In addition, $20.5 \%$ of Latino adolescents reported using marijuana at least once during their lifetime, and $10.7 \%$ reported using marijuana within the past 30 days (Florida Department of Children and Families, 2016).

Introduction to Primary Socialization Theory

Primary Socialization Theory has been used as a guiding framework to determine which factors play a role in alcohol and marijuana use among Latino adolescents (Oetting, Deffenbacher, \& Donnermeyer, 1998; Shin, Lee, \& Hecht, 2016; Kam \& Yang, 
2014; Brook, Lee, Finch, Brown, \& Brook, 2013a; Aspy et al., 2012). Grounded in the premise that virtually all human social behaviors are learned, Primary Socialization Theory posits that drug use and deviant behaviors emerge from interactions with the three primary socialization sources: family, school, and peer clusters (Oetting et al., 1998). This dissertation project was based on an adaptation of Primary Socialization Theory. Detailed information about the adapted theoretical framework is included in the literature review (Chapter II).

The Latino and Adolescent Populations in Miami-Dade County

This dissertation project focused on a unique sample of Latino adolescents and provides valuable information regarding current alcohol and marijuana use (past 30 days) and lifetime (ever) alcohol and marijuana use among Latino adolescents in Miami-Dade County, Florida (Kann et al., 2016). As of July $1^{\text {st }}, 2016$, the population of Miami-Dade County was $2,712,945$, and Latinos comprised $66.8 \%$ of this county's population (U.S. Census Bureau, 2016). Although individuals of Mexican origin comprise most Latinos living in the U.S. (65\% of Latino population), in Miami-Dade County, individuals of Mexican origin only account for $2.1 \%$ of the total population. Most Latinos living in Miami-Dade County are of Cuban origin (52.7\% of Latino population/34.3\% of total population), followed by Colombian (4.6\% of Latino population) and Nicaraguan origin (4.2\%; U.S. Census Bureau, 2011). With respect to the adolescent population in MiamiDade County, as of July $1^{\text {st }}, 2015$, there were 52,155 Latino adolescents between ages 15 19 years old. Persons under 18 years old comprised $20.5 \%$ of the population $(\mathrm{N}=$ 556,153; U.S. Census Bureau, 2016). 
Substance Use Disparities among Latino Adolescents

According to the 2015 Youth Risk Behavior Surveillance System ( $N=15,624$

high school students $9^{\text {th }}-12^{\text {th }}$ grade), a large nationally representative cross-sectional survey conducted every other year, major substance use disparities exist for Latino adolescents in the U.S. (Kann et al., 2016). For example, the prevalence of having ever drunk alcohol was higher among Latino (72.4\%) adolescent students compared to White (65.9\%) and Black (63.4\%) adolescent students, and the prevalence of having drunk alcohol for the first time before age 13 years was higher among Latino adolescent students $(21.8 \%)$ compared to their White (16.7\%) and albeit not much, their Black (21.0\%) counterparts. The prevalence of having ever used marijuana (Latinos: $48.8 \%$; Whites: $36.7 \%$; Blacks 46.8\%) and having tried marijuana before age 13 years was higher among Latino (10.9\%) than White (5.4\%) and Black (10.6\%) students (Figure 1; Kann et al., 2016). 
Figure 1: Prevalence of Alcohol and Marijuana use among High School Adolescents in the U.S., Youth Risk Behavior Surveillance System, 2015

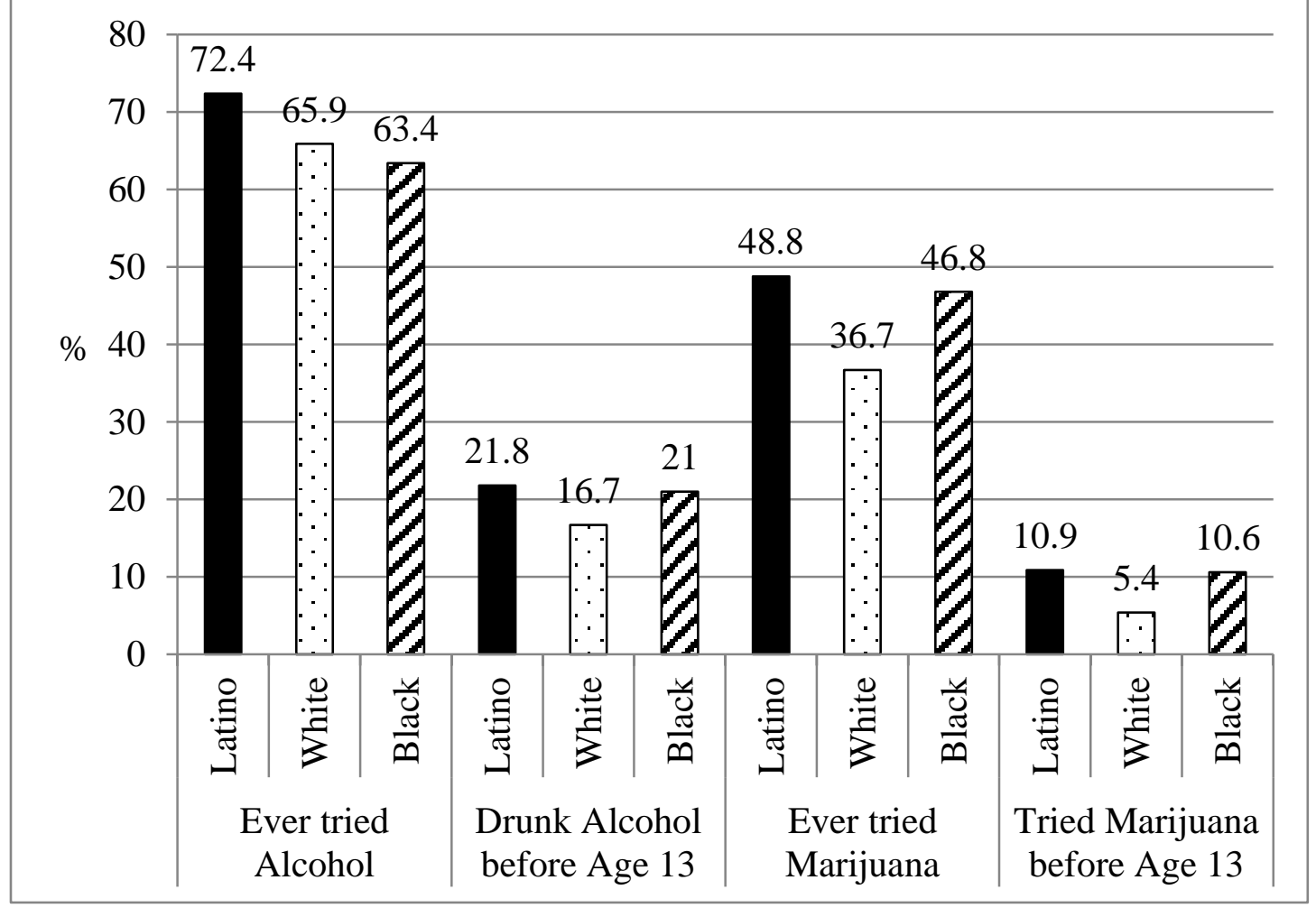

Public Health Significance

The present dissertation expands upon the foundational work on Latino adolescent substance use in Miami-Dade County, Florida by performing analyses using data collected in 2016-2017 in Miami-Dade County on males and females, approximately 25 years since the seminal work (Vega et al., 1993b; Vega et al., 1993c; Vega et al., 1993a). According to a recent report prepared by the National Institute on Alcohol Abuse and Alcoholism's (NIAAA) Alcohol Epidemiologic Data System (AEDS), which utilized data from the National Survey of Drug Use and Health (NSDUH), the Monitoring the Future (MTF) survey, and the Youth Risk Behavior Survey (YRBS), there has been an 
overall declining trend in the prevalence of current alcohol use (past 30 days) among persons in the U.S. ages 12-20 years old between 1991 and 2015 (Chen, Yoon, \& Faden, 2017). This decline has been greater for males than females, and, the most current epidemiological data reveals that there is no significant difference among the sexes (males: 19.8\%; females: 20.8\%) with respect to current alcohol use. Although there have been no significant linear changes from 1991-2015 in lifetime marijuana use (31.3\%$38.6 \%)$ or current marijuana use (14.7\%-21.7\%) among those aged $12-20$ years in the U.S., prevalence remains high among U.S. high school students (CDC, 2016b).

The use of marijuana and alcohol, two of the most commonly used substances by adolescents in the U.S., have important consequences among adolescents, in particular, Latino adolescents (Miech, Johnston, O’Malley, Bachman, \& Schulenberg, 2015; National Institute on Drug Abuse; NIDA 2016). According to the 2016 MTF survey, a nationwide study among adolescent students in the U.S., in $2016(\mathrm{n}=45,473), 43.4 \%$ of $10^{\text {th }}$ graders and $61.2 \%$ of $12^{\text {th }}$ graders reported lifetime use of alcohol (NIDA, 2016). In addition, $19.9 \%$ and $33.2 \%$ of $10^{\text {th }}$ and $12^{\text {th }}$ graders, respectively, reported using alcohol during the past month (NIDA, 2016). Thirty percent of $10^{\text {th }}$ graders and $45 \%$ of $12^{\text {th }}$ graders reported lifetime use of marijuana, and $14 \%$ and $23 \%$ of $10^{\text {th }}$ and $12^{\text {th }}$ graders, respectively, reported using marijuana during the past month (NIDA, 2016). When compared to adolescents of other ethnicities, Latino adolescents in the U.S. report disproportionately higher overall prevalence of lifetime alcohol use (Latinos: 72.4\%, Whites: 65.9\%, Blacks: 63.4\%) and marijuana use (Latinos: 48.8\%, Whites: 36.7\%, Blacks: 46.8\%; Kann et al., 2016; Cherpitel, Ye, \& Kerrc, 2016). 
Marijuana and alcohol use during adolescence is associated with increased likelihood of higher number of absences in school and failing grades in school, and increased risk for HIV and STDs as well as teenage pregnancy (CDC, 2016a). In addition, among Latinos, younger age at first use of alcohol is associated with a higher volume of alcohol consumption during adulthood (Caetano, Mills, Vaeth, \& Reingle, 2014), and age at first use of alcohol may be inversely related to binge drinking among Latinos (Caetano et al., 2014). Furthermore, findings from previous studies suggest that reducing substance use and abuse among Latino adolescents could lead to lower incidence of engaging in criminal behaviors, fighting, unprotected sexual activity, arrest for drunk driving, symptoms of depression and anxiety, and unemployment in adulthood (Brook, Lee, Finch, Seltzer, \& Brook, 2013b; Lee, Brook, Finch, \& Brook, 2015; Brook, Lee, Brown, Finch, \& Brook, 2011; CDC, 2016a).

The present dissertation study explored whether any changes have occurred in the lifetime or current alcohol and marijuana use behaviors among a new cohort of Latino male and female adolescents living in South Florida in 2016 and 2017 as compared to the Latino adolescents living in this county when the seminal studies were reported, during the 1990s (Vega et al., 1993b; Vega et al., 1993c; Vega et al., 1993a). There is a need for research that expands upon the seminal studies and elucidates which potentially modifiable factors (i.e., participation in sports activities) play a role in the onset and current use of alcohol and marijuana among Latino adolescents in Miami-Dade County today, so that more effective substance use prevention and intervention programs can be developed for this population. 
Overview of Study Design

The present cross-sectional study was conducted using a secondary data analysis of survey research data collected between June 2016 and December 2017 as part of the baseline assessment of an HIV prevention intervention study for Latino adolescents, CUÍDATE. A total of 201 males and female Latino adolescents (aged 13-18 years old) were recruited from four Latino-serving community-based organizations in Miami-Dade County, Florida.

\section{Purpose}

The purpose of this dissertation was twofold:

1) to expand upon the seminal work on Latino adolescents conducted in the 1990's in Miami, Fl in order to improve our understanding of the differences between boys and girls with respect to current use and lifetime use of alcohol and marijuana and to determine the associations between adolescents' and parents' socio-demographic characteristics (age, country of birth, GPA, family's socioeconomic status, mother's highest level of education, father's highest level of education), household composition (living with both parents versus not living with both parents), and adolescents' cultural values (Familism Support, Familism Obligations, Familism Referents, Respect, Religion, Traditional Gender Roles, Independence and Self-Reliance) with current alcohol or marijuana use among Latino adolescents'.

2) to improve our understanding of the moderating role of recreational activities on the association between friends' age, sex, ethnicity, and perception of friends' 
alcohol and marijuana use with current alcohol and marijuana use.

Research Questions

The three overarching research questions were:

1) Are there differences in lifetime or current alcohol or marijuana use between boys and girls?

2) Are there associations between Latino adolescents' and adolescents' or parents' socio-demographic characteristics, household composition, or adolescents' cultural values and current alcohol or marijuana use?

3) What is the moderating role of recreational activities with respect to the association between friends' age, sex, ethnicity and perception of their friends' alcohol and marijuana use with current alcohol and marijuana use?

Specific Aims and Hypotheses

After conducting a literature review on the topics of alcohol and marijuana use among Latino adolescents, as described in Chapter II of this dissertation, a critical analysis of the literature led to the development of the specific aims and hypotheses as herein described.

Aim 1: Determine whether the following adolescents' and parents' characteristics are associated with current (past 30 days) or lifetime (ever) alcohol or marijuana use among Latino adolescents: sex, age, country of birth, GPA, family's socio-economic status, 
living with both parents, mother's highest level of education, father's highest level of education and Latino cultural values of Familism Support, Familism Obligations, Familism Referents, Respect, Religion, Traditional Gender Roles, Independence and SelfReliance.

Hypothesis 1: Among Latino adolescents, there is an association between the following characteristics/Latino cultural values and current alcohol use (past 30 days): adolescents' sex, age, country of birth, GPA, family's socio-economic status, living with both parents, mother's highest level of education, father's highest level of education, Familism Support, Familism Obligations, Familism Referents, Respect, Religion, Traditional Gender Roles, Independence and Self-Reliance.

Hypothesis 2: Among Latino adolescents, there is an association between the following characteristics/Latino cultural values and lifetime alcohol use: adolescents' sex, age, country of birth, GPA, family's socio-economic status, living with both parents, mother's highest level of education, father's highest level of education, Familism Support, Familism Obligations, Familism Referents, Respect, Religion, Traditional Gender Roles, Independence and Self-Reliance.

Hypothesis 3: Among Latino adolescents, there is an association between the following characteristics/Latino cultural values and current marijuana use (past 30 days): adolescents' sex, age, country of birth, GPA, family's socio-economic status, living with both parents, mother's highest level of education, father's highest level of education, Familism Support, Familism Obligations, Familism Referents, Respect, Religion, Traditional Gender Roles, Independence and Self-Reliance. 
Hypothesis 4: Among Latino adolescents, there is an association between the following characteristics/Latino cultural values and lifetime marijuana use: adolescents' sex, age, country of birth, GPA, family's socio-economic status, living with both parents, mother's highest level of education, father's highest level of education, Familism Support, Familism Obligations, Familism Referents, Respect, Religion, Traditional Gender Roles, Independence and Self-Reliance.

Aim 2: Assess if recreational activities moderate the association between friends' age, sex, and ethnicity and current alcohol or marijuana use.

Hypothesis 5: Recreational activities moderate the association between friends' age, sex, and ethnicity and current alcohol use.

Hypothesis 6: Recreational activities moderate the association between friends' age, sex, and ethnicity and current marijuana use.

Aim 3: Assess if recreational activities moderate the association between perception of friends' alcohol or marijuana use and current alcohol or marijuana use.

Hypothesis 7: Recreational activities moderate the association between perception of friends' alcohol use and current alcohol use.

Hypothesis 8: Recreational activities moderate the association between perception of friends' marijuana use and current marijuana use. 


\section{Delimitations}

The sample was limited to Latino adolescents aged 13-18 years old who live in Miami-Dade County, Florida. The sample excluded non-Latinos and Latino adolescents younger than 13 years old and older than 18 years old; previous studies have shown that Latino adolescents within the age range of 13-18 years old experience major substance use health disparities compared to their non-Latino 13-18-year-old counterparts (Kann et al., 2016; Cherpitel, Ye, \& Kerrc, 2016). The sample was limited to Miami-Dade County because of the unique population characteristics of the county that make it unlike any other county in the U.S. Specifically, $66.8 \%$ of the population is Latino, and more than half of the Latino population is of Cuban origin (U.S. Census Bureau, 2016). Because (a) there was such scarce recent information in the literature regarding the present dissertation's topics and (b) most research, since the seminal studies, on Latino adolescent substance use has been conducted on adolescents of Mexican or Puerto Rican descent (Acosta, Hospital, Graziano, Morris, \& Wagner, 2015; Roditis, Delucchi, Chang, \& Halpern-Felsher, 2016; Bacio, Lau, \& Mays, 2013), a novel cross-sectional study was performed instead of a longitudinal study.

\section{Limitations of Study Design}

The study's most apparent limitations were the convenience and purposive sampling approach and cross-sectional design, which hindered the ability to make causal inferences and limited generalizability of the findings. The dissertation relied on selfreported measures of sensitive information, which increased the potential for social desirability bias and recall bias. However, the measures used are standardized and have 
been tested for validity and reliability in previous studies (Schofield, Conger, \& Robins, 2015; Zapata Roblyer, Grzywacz, Cervantes, \& Merten, 2016; Knight et al., 2010; Morgan Consoli \& Llamas, 2013; CDC, 2016c; Brener et al., 2002). Moreover, most of the scales used in the present study have been previously used with Latino adolescent populations. Additionally, this dissertation used data collected by experienced Latino facilitators who were extensively trained in culturally appropriate techniques. Cultural adaptations in research with Latinos, such as employing culturally-informed interviewers/facilitators and devising well-adapted questionnaires, have been found to increase participant satisfaction and willingness to disclose sensitive information (De La Rosa, Rahill, Rojas, \& Pinto, 2007).

The survey questions were measured with respect to different time periods. For example, adolescents were asked about the number of times they had at least one drink of alcohol during the past 30 days and whether they currently participate in any volunteer (recreational) activities. This hindered the ability to make causal inferences. In addition, a location effect may have occurred, because surveys were conducted at four different community-based organizations. These locations may have had different influences on participants' responses. For example, because (a) only four community-based organizations were involved and (b) these organizations were located in South MiamiDade County, the sample included in the present dissertation study may not be representative of the entire Miami-Dade County. In contrast, the seminal studies, which were comprised of a larger and more geographically dispersed sample, were more representative of the entire Miami-Dade County (Vega et al., 1993a; Vega et al., 1993b; Vega et al., 1993c). 


\section{Assumptions}

It was assumed that all participants could read and understand the survey instrument and that they responded honestly to the questions. It was additionally assumed that the recall of the participants would be reliable because the survey design was based on recent and current life events rather than events in the distant past. Previous studies have found self-reported data regarding alcohol and marijuana use to be valid and reliable among adolescents including Latino adolescents (CDC, 2015; Brener et al., 2002; Brener, Collins, Kann, Warren, \& Williams, 1995).

\section{Summary of Chapter I}

This chapter described the seminal research studies from the 1990s on substance use among Latino adolescents in Miami-Dade County, Florida. Then, it provided a description of the problems of alcohol and marijuana use among Latino adolescents in Miami-Dade County, Florida. In Florida, most 15-17-year-old adolescents (57.5\%) have reported using alcohol at least once during their lifetime, and $29.4 \%$ have used marijuana. The prevalence of alcohol and marijuana use is higher for Latino adolescents compared to their non-Latino White and Black adolescent counterparts. Marijuana and alcohol use during adolescence is associated with a broad range of consequences, including failing grades in school, and increased risk for STDs. However, previous studies have not addressed the role of recreational activities (i.e., sports participation, after-school activities, volunteer activities), a potentially modifiable factor, in the use of alcohol and marijuana among Latino adolescents. Moreover, most recent research conducted on Latino adolescent substance use has neglected the unique Miami-Dade County Latino 
adolescent population. This chapter presented the general study design, the theoretical framework, overarching research questions, aims and hypotheses, delimitations, limitations, and assumptions of the dissertation project. 


\section{CHAPTER II: LITERATURE REVIEW}

Introduction to Literature Review and Search Strategy

The purpose of Chapter II is to describe the seminal papers from the early 1990s that were conducted in Miami-Dade County and to explore the current literature (past 5 years) to determine what is known about marijuana and alcohol use among Latino adolescents, so that the dissertation project could address an important gap in the current research literature. This would aid in the development and adaptation of more effective alcohol and marijuana prevention and treatment interventions for Latino adolescents. This chapter comprises a comprehensive literature review focused on the following topics:

(a) description of seminal studies in Miami, Florida

(b) consequences of alcohol and marijuana use during adolescence,

(c) factors associated with the use of alcohol and marijuana during adolescence,

(d) the role of cultural values,

(e) the role of friends' characteristics, and

(f) the role of recreational activities.

After each section, a description is provided about how the section relates to the dissertation's study aims. Chapter II concludes with a description of the theoretical foundation of the dissertation and a summary of the chapter. An expanded description of the literature search strategy is provided in Appendix 1. 


\section{Description of Seminal Studies}

In the early 1990s, a series of papers were published on research studies regarding drug and alcohol use among Latino adolescents in Miami-Dade County, Florida. These seminal studies provided the basis for what is currently understood about Latino adolescent substance use in Miami, Florida (Vega et al., 1993a; Vega et al., 1993b; Vega et al., 1993c). Each seminal study analyzed data from subsamples of the same sample of adolescents who were recruited from all 48 middle schools in the Miami-Dade public school system. Data for this longitudinal study were collected every year for three years beginning in the fall of 1990 .

In a 1993 paper, Vega et al. reported prevalence of early onset of alcohol use among sixth and seventh grade adolescent boys $(n=6,760)$. They found the highest prevalence among Cubans (41.3\%) and White, Non-Hispanics (48.2\%; 1993a). Cubans $(5.1 \%)$ and other Hispanics $(5.2 \%)$ had the highest prevalence of illicit drug use (i.e., marijuana, cocaine, PCP).

In another pivotal study, Vega et al., explored relationships between acculturation and delinquent behaviors among Cuban American adolescent males and females in sixth and seventh grade $(\mathrm{n}=1,843)$ and demonstrated that there were, in fact, associations between acculturation conflicts and disposition to deviant behaviors (1993b). The variable respect was negatively correlated with disposition to deviance (-0.32) and delinquency scores (-0.19). The authors concluded that family variables are important influences for creating vulnerability to delinquent behaviors and, once vulnerability is created, acculturation strain variables may play a stronger role in causing the actual behavior (Vega et al., 1993b). The participants from this study were taken from the same 
sample as the Vega et al. 1993a study, both of which came from the first wave of the longitudinal study that was first conducted during the fall semester of 1990 .

Other relevant papers were then published on substance use disorders among Latino adolescents. For example, one such study published in the year 2000 expanded our understanding of the roles of acculturation and peer and familial factors in alcohol use among male Latino adolescents (Gil, Wagner, \& Vega, 2000). In this study, the role of acculturation and familial factors were compared between immigrant Latino adolescent males $(\mathrm{N}=1,051)$ and U.S.-born Latino adolescent males $(\mathrm{N}=968)$ who participated in the seminal studies. Findings revealed a higher report of lifetime alcohol use among those born in the U.S. at all three time periods (yearly for three years). For all participants, years living in the U.S. were positively associated with lifetime alcohol use and past month alcohol use. In addition, the results of two structural equation models indicated that acculturation was associated with alcohol use through acculturation stress and the reduction of traditional Latino values Familism and Parental Respect.

Turner and Lloyd (2003) examined the role of life-time exposure to a wide range of major and potentially traumatic events on drug dependence among multiracial/multiethnic males and females $(n=1803)$ in south Florida, most of whom (93\%) were between ages 19 and 21 years old. The sample was comprised of all female participants from the seminal Vega et al studies (1993a; 1993b), a random sample of 1,273 male participants from the previous studies (Vega et al., 1993a, 1993b), and an additional sample of females who were randomly selected from the same population $\left(6^{\text {th }}\right.$ and $7^{\text {th }}$ graders from the 1990 Miami-Dade County class roster). Findings revealed that, among the 33 adversity items tested, 28 were associated with increased risk of later drug 
dependence after controlling for time, gender, ethnicity, and socioeconomic status. Each adversity item was categorized into one of the following four categories: major life events (e.g., Were you ever abandoned by one or both of your parents?); life traumas (e.g., Were you ever physically abused or injured by a spouse/boyfriend/girlfriend?); witnessed violence (e.g., Have you seen someone else get shot at or attacked with another weapon?); traumatic news (e.g., Have you ever been told that someone you knew had been raped?).

In a more recent paper, Warner et al. (2006) provided a review of the epidemiology of illicit drug use and drug use disorders and the role of culture change on drug abuse among Latinos in the U.S. with a specific emphasis on demographic correlates: nativity, ethnicity, gender, and age. It was determined that among national surveys of adolescent populations, the younger the respondents, the more likely Latinos have higher rates of illicit substance use compared to Whites and Blacks. In addition, among the eighth-grade respondents in the Monitoring the Future study, Latinos reported the highest rates of illicit drug use in the past year since 1992. With respect to nativity, U.S.-born Latinos reported higher rates of experimental drug use, drug abuse, and drug dependence compared to non-U.S.-born Hispanics. There were non-significant differences by gender regarding past month illicit drug use among Latino adolescents (12-17 years old). Last, the following contextual factors were noted as correlates of substance use: weakened ethnic and cultural identity, lower levels of ethnic pride, predominate use of English rather than Spanish, and acculturation gaps between parents and children (Warner et al., 2006). 
The present dissertation project, although cross-sectional in nature, expanded upon the described seminal work and additional studies published over the next few years, providing a current investigation of alcohol and marijuana use among Latino adolescents in Miami-Dade County. Moreover, the present dissertation project additionally included (a) a comparison of gender differences for lifetime and current (past 30 days) use of alcohol and marijuana, (b) the exploration of the role of an in depth (37item) Latino cultural values scale (Knight et al., 2010), and (c) the exploration of the role of recreational activities.

\section{Consequences of Alcohol Use during Adolescence}

The present dissertation study investigated factors associated with current and lifetime alcohol use among Latino adolescents because of the serious and important consequences associated with alcohol use during adolescence. Alcohol consumption during adolescence has been shown to be associated with fighting, arrest for drunk driving, interpersonal victimization (e.g., sexual assault, physical assault, physical abuse; McCart et al., 2012; Temple \& Freeman, 2011), increased likelihood of higher number of absences in school and failing grades in school (CDC, 2015), and risky sexual activity (e.g., sex without a condom, forced sexual intercourse; Le, Behnken, Markham, \& Temple, 2011; Yan, Howard, Beck, Shattuck, \& Hallmark-Kerr, 2010). Alcohol use during adolescence is also associated with other serious health problems including increased risk for HIV and STDs and teenage pregnancy (CDC, 2015; Salas-Wright, Vaughn, Ugalde, \& Todic, 2015). For example, results from a qualitative study with 20 Black and 20 Latino (21-24 years old) men who have sex with men suggest that alcohol 
enabled them to engage in sexual behaviors with other men, enabling them to be more "bold" and to overcome stigma related to homosexuality (Mutchler, McDavitt, \& Gordon, 2014).

Alcohol use may also result in physical violence, mental health problems, and death. For example, a longitudinal study revealed that 11-year-olds who reported using alcohol during the past year were 2.1 times more likely to report low physical aggression during $6^{\text {th }}$ grade with increased physical aggression in $7^{\text {th }}$ and $8^{\text {th }}$ grade (aggression escalators) and 1.9 times more likely to report a high rate of physical aggression across $6^{\text {th }}, 7^{\text {th }}$, and $8^{\text {th }}$ grade (chronic aggressive group; (Maldonado-Molina, Jennings, \& Komro, 2010).

In a cross-sectional study that included a nationally representative sample of adolescent girls, alcohol use was associated with increased risk of responding yes to the question: "During the past 12 months, did you ever seriously consider attempting suicide?" This association was demonstrated across ethnicities and for Latinos only (Le et al., 2011). In addition to suicide risk, according to the CDC, excessive drinking contributes to more than 4,300 deaths among underage ( $<21$ years old) youth in the U.S. every year (CDC, 2015). Because the consequences of alcohol consumption among Latino adolescents are so detrimental, it is important to understand which modifiable factors may play a role in such behavior. The dissertation addressed participation in recreational activities, one such potentially modifiable factor that has not thoroughly been explored in the literature. Although other factors have been shown to be associated with alcohol use among adolescents (i.e., physical fights between parents during childhood, parental divorce/separation, living with older siblings, being overweight), due to the 
limitations of the present study, it was not possible to explore all potential variables among this unique sample of Latino adolescents (Allem Soto, Baezconde-Garbanati, \& Unger, 2015; Jackson et al., 2016a; Wagner, Ritt-Olson, Soto, \& Unger, 2008; Zeller, Becnel, Reiter-Purtill, Peugh, \& Wu, 2016).

\section{Consequences of Marijuana Use during Adolescence}

Marijuana use during adolescence is associated with many devastating problems during both adolescence and throughout the lifetime. The present dissertation study investigated factors associated with current and lifetime marijuana use among Latino adolescents because such significant consequences have been demonstrated to be associated with marijuana use during adolescence. Marijuana use during adolescence has been shown to be associated with engaging in criminal behaviors (Brook et al., 2011; D’Amico et al., 2016), symptoms of depression and anxiety (Brook et al., 2011), lower likelihood of post-secondary educational attainment (Maggs et al., 2015), being unemployed during adulthood (Brook et al., 2013b; Lee et al., 2015), increased tobacco smoking during young adulthood (29-32 years old; Brook, Lee, \& Brook, 2015), anger/hostility during adulthood (32 years old; Pahl, Brook, \& Koppel, 2011), and meeting criteria for a substance use disorder during adulthood (32 years old; Pahl et al., 2011). Chen, Storr, and Anthony (2009) found that compared to people who start using marijuana as adults, those who begin during adolescence are two to four times more likely to have marijuana dependence two years after their first use.

Marijuana use during adolescence may have negative consequences with respect to intimate partner relationships. For example, it has been suggested that marijuana and 
alcohol use may increase Latino adolescents' risk for intimate partner violence (IPV; Jennings, Reingle, Staras, \& Maldonado-Molina, 2012; Temple \& Freeman, 2011). Additionally, a longitudinal study of 1,488 Latino young adults living throughout the U.S. demonstrated that those who reported high-level marijuana use (compared to no marijuana use) during adolescence had twice the risk of being a victim of intimate partner violence or of being both a victim and a perpetrator of intimate partner violence (Jennings et al., 2012). In addition, those who used both alcohol and marijuana during adolescence had almost twice the risk (OR: 1.86) of being both a victim and a perpetrator of intimate partner violence compared to marijuana non-users (Jennings et al., 2012). In another large longitudinal study of adolescents, alcohol use, but not marijuana use, predicted the perpetration of physical violence (Temple, Shorey, Fite, Stuart, \& Le, 2013). The present dissertation sought to determine factors that may play a role in marijuana use among Latino adolescents because of the above-described harmful consequences of marijuana use during adolescence.

Factors Associated with Alcohol and Marijuana Use among Adolescents

Many determinants have been shown to be associated with alcohol and marijuana use among Latino adolescents. The following factors may be associated with an increased likelihood to drink alcohol and to binge drink among Latino adolescents in the U.S.: adverse events during childhood (e.g., physical fights between parents during childhood or parental divorce/separation; Allem et al., 2015; Jackson et al., 2016a), being born in the U.S. (Bacio et al., 2013), and having parents who were born in the U.S. (Bacio et al., 2013). Additional factors that may be associated with an increased likelihood to drink 
alcohol and to binge drink among Latino adolescents in the U.S. include a parent-child acculturation gap (Cox Jr et al., 2013), cultural incongruity between heritage culture and U.S. academic environment (Cano et al., 2015), acculturation stress (Ehlers, Gilder, Criado, \& Caetano, 2009), lower self-esteem (Zamboanga, Schwartz, Hernandez Jarvis, \& Van Tyne, 2009), living with older siblings (Wagner et al., 2008), having a parent with an alcohol use disorder (Hussong, Huang, Serrano, Curran, \& Chassin, 2012), being overweight (Zeller et al., 2016), and having experienced perceived discrimination (Unger et al., 2014; Cheng \& Mallinckrodt, 2015; Kam, Cleveland, \& Hecht, 2010). In contrast, the following factors have been shown to be associated with decreased risk of alcohol drinking among Latino adolescents: living with one's parents (Cacciola \& Nevid, 2014), higher level of Latino acculturation (Unger, 2014; Unger et al., 2014), stronger identification with religion (Escobar \& Vaughan, 2014), and high immigrant concentration in one's own neighborhood (Jackson, Browning, Krivo, Kwan, \& Washington, 2016b).

The following factors have been associated with increased likelihood of smoking marijuana among Latino adolescents: living with cousins (Wagner et al., 2008), perceived discrimination (Unger et al., 2014; Kam et al., 2010), increased exposure to medical marijuana advertisements (D’Amico, Miles, \& Tucker, 2015), lower perceived risk associated with marijuana use (Terry-McElrath, O’Malley, Patrick, \& Miech, 2017), victimization and perpetration of violence (Brady, Tschann, Pasch, Flores, \& Ozer, 2008), lower self-esteem (Zamboanga et al., 2009), lower level of Latino acculturation (Unger et al., 2014), and a weaker identification with one's own religion (Escobar \& Vaughan, 2014). Among the factors that have been associated with alcohol and marijuana 
use among Latino adolescents, the majority (e.g., parental divorce/separation, being born in the U.S., lower level of Latino acculturation) are not factors upon which researchers can intervene and most were conducted with Mexican and Puerto Rican samples. Therefore, this dissertation sought to explore potential modifiable factors that play a role in alcohol and marijuana use among Latino adolescents in Miami-Dade County.

Role of Cultural Values and Friends' Characteristics

The influence of two specific factors, cultural values and perception of friends' substance use behaviors, on Latino adolescents' substance use behaviors have been consistently documented in the literature. However, in general, research has demonstrated that Latino adolescents who are more acculturated with U.S. culture and did not identify strongly with Latino values (e.g., Familismo, an emphasis on having positive family relationships and being dedicated, loyal, and respectful to one's family) tend to have higher rates of substance use than those who are less acculturated with U.S. culture and identify more strongly with Latino values (Carlton-Smith \& Skeer, 2015; DiBello, Gonzales, Young, Rodriguez, \& Neighbors, 2015; Unger et al., 2014; Schwartz et al., 2011; Vega et al., 1993c). Additionally, adolescents, including Latino adolescents, who perceive their friends to be substance users were more likely to use substances themselves (Schofield et al., 2015; Acosta et al., 2015). Acculturation, or "the process by which an individual adopts the practices and values of the dominant culture where he or she lives" (Warner et al., 2006), is typically measured by the following variables: primary language spoken, length of time living in the U.S., cultural preferences, and cultural identity (Carlton-Smith \& Skeer, 2015). Latino adolescents who are more acculturated to 
U.S. culture and who are born in the U.S. have generally reported higher rates of substance use when compared to those who are less acculturated and foreign born, respectively (Carlton-Smith \& Skeer, 2015; Unger et al., 2014). Specific characteristics of Latino cultural values have also been demonstrated to be associated with health outcomes. For example, the Latino cultural value Familism has been shown to be associated with positive outcomes for Latino adolescents, including a protective role in adolescent alcohol use (DiBello et al., 2015). For example, in a study on 623 undergraduate students (53\% female; $18-26$ years old) who met the criteria for heavy drinking ( 4 or 5 drinks during one occasion for men and women, respectively, in the past month), the researchers found that Latinos - who reported higher Familism than their non-Latino counterparts—consumed less alcohol compared to their non-Latino counterparts. Other studies have also confirmed that Familism is protective against drinking alcohol among Latino adolescents (Bacio et al., 2013).

With respect to friends' characteristics, findings from a study by Schofield et al. (2015) indicated that adolescents who associated with what was referred to as deviant peers (e.g., high proportion of friends who used alcohol to get drunk) were at increased risk for early initiation of alcohol, tobacco, and other drugs. This re-confirmed the findings from the seminal study by Vega et al. which revealed that adolescent boys (Cubans, other Hispanics, Blacks, Whites) who perceived their friends to be using alcohol were more likely to report using alcohol themselves (Vega et al., 1993a). In another cross-sectional study among Latino high school students $(\mathrm{N}=371 ; 15-18$ years old), those who reported a greater proportion of nondrinking peers reported significantly less total alcohol drinks in the previous month and less days using alcohol in the previous 
month (Acosta et al., 2015). Furthermore, findings from another cross-sectional study of Latino adolescents in California $(\mathrm{N}=786)$ suggested that those who reported friends using marijuana had $27 \%$ greater odds of using marijuana themselves (Roditis et al., 2016).

Although cultural value and friends' characteristics play a role in alcohol and marijuana use among Latino adolescents, it is difficult to develop alcohol and marijuana use prevention and treatment interventions to influence these two factors. A more feasible option is to explore the role of potentially modifiable factors such as recreational activities as described in the subsequent section and addressed in this dissertation project. In this dissertation, recreational activities (sports activities, volunteer activities, afterschool activities) were assessed as a moderating variable for the association between perception of friends' alcohol and marijuana use and current alcohol and marijuana use. The role of cultural values was also assessed, however, to determine whether what has been found among other Latino subcultures, primarily Mexican and Puerto Rican, was true among the unique Latino adolescent population in Miami-Dade County. Furthermore, the mentioned studies have been primarily conducted in other states in the U.S. and with Latino adolescents primarily of Mexican and Puerto Rican origin and therefore have not addressed the unique Latino population in Miami-Dade County, Florida.

Role of Recreational Activities

The influence of recreational activities on alcohol and marijuana use among Latino adolescents has not been thoroughly examined in the literature. The few studies 
that have attempted to investigate such associations have mostly explored sports participation and have not assessed the role of other recreational activities such as volunteer activities and after-school activities. For example, an analysis of the 2009 Youth Risk Behavior Surveillance System $(\mathrm{N}=16,343)$ revealed a positive correlation between alcohol use and sports participation for male adolescents and a negative correlation between sports participation and marijuana use for female adolescents (Dunn, 2014). Other studies have also demonstrated inconsistent associations between sports participation and alcohol or drug use among adolescents (Mays et al., 2010; Moore \& Werch, 2008; Parent, Bradstreet, Piper, Brace, \& Parkman, 2016). These studies have not provided findings stratified by ethnicity, so it is not clear whether these associations were true for Latino adolescents. In addition, most studies measured school-based sports participation, so it is unknown whether the role of school-based sports differs from the role of sports programs that are not affiliated with schools and whether effects are different for those participating in team sports versus individual sports. However, some previous studies among non-Latino adolescents have indicated that there may be differences among individuals who play different types of sports (e.g., tennis vs. football; Brisola-Santos et al., 2016).

Other recreational activities may also play a role in alcohol and marijuana use among Latino adolescents. Of note, however, no study has comprehensively addressed the role of a wide range of recreational activities in which Latino adolescents may participate, such as sports, volunteer activities, or after-school activities. The present dissertation addressed this gap in the literature. 
Theoretical Foundation

The dissertation was grounded in the Primary Socialization Theory (Figure 2), which has guided previous studies of substance abuse behaviors and other delinquent behaviors (i.e., alcohol use, drug use) among Latino adolescents (Oetting et al., 1998;

Shin et al., 2016; Kam \& Yang, 2014; Brook et al., 2013a; Aspy et al., 2012). However, expanding upon other studies which primarily investigated Latino adolescents of Mexican origin, the present dissertation study was comprised of a unique Miami-Dade County sample of Latino adolescents. Primary Socialization Theory is based on the premise that essentially all human social behaviors are learned, and that drug use and deviant behaviors emerge from interactions with the three primary socialization sources: family, school, and peer clusters (Oetting et al., 1998). Adolescents are supported physically, emotionally, and socially by bonds to the family, school, and peer clusters (Oetting et al., 1998). In addition, the individual's personal characteristics and personality traits do not directly related to drug use, but in nearly all cases, influence drug use only when they affect the interactions between the individuals and the primary socialization sources (Oetting et al., 1998). Therefore, personality traits influence drug use only indirectly (Oetting et al., 1998). The youths' characteristics influence the strength of the bonds with persons who comprise the primary socialization sources who then interact with the adolescent (Oetting et al., 1998). Therefore, the adolescent is an integral part of this reciprocal interactive system (Oetting et al., 1998).

In the present study, correlates of current alcohol and marijuana use were examined, including those that comprise the primary socialization sources of the Primary Socialization Theory: family (e.g., cultural values), school (e.g., recreational activities), 
and peer clusters (e.g., perception of friends' substance use behaviors) (Figure 2).

Recreational activities may play a role in marijuana and alcohol use among Latino adolescents of Caribbean and South American origin; however, this has not been studied thoroughly in the literature (Dunn, 2014; Mays et al., 2010; Moore \& Werch, 2008;

Parent et al., 2016; De la Haye, D’Amico, Miles, Ewing, \& Tucker, 2014). Importantly, most adolescents in the U.S. participate in some recreational activities (e.g., extracurricular activities, sports). For example, nearly half (48.5\%) of Latino high school students participate in at least one sports team overseen by either their school or community groups. Likewise, according to the U.S. Census Bureau, more than half of children between 6 and 17 years old (57\%) participate in at least one after-school extracurricular activity (U.S. Census Bureau, 2014).

Recreational activities may be modifiable factors in an adolescent's life, so it is important to explore the role of recreational activities in alcohol and marijuana use among Latino adolescents. Aims 2 and 3 were based on a conceptual framework grounded in Primary Socialization Theory in which an additional construct, recreational activities, was added to the original theoretical framework (Figures 3 and 4).

Figure 2: Primary Socialization Theory

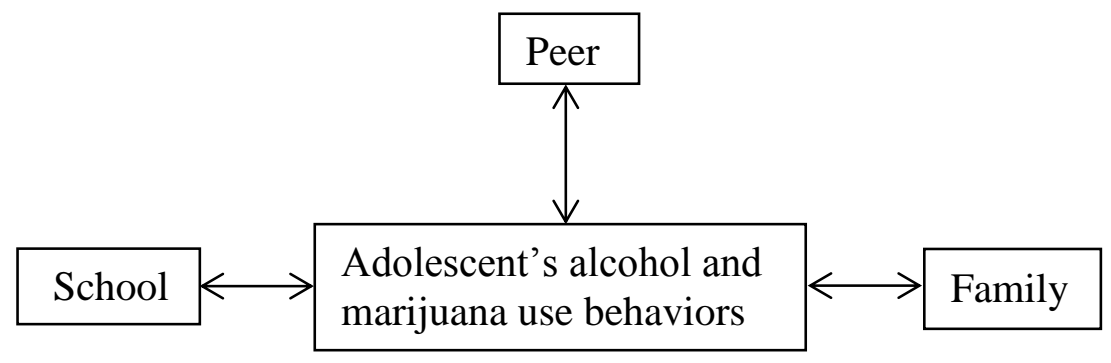


Figure 3: Framework Grounded in Primary Socialization Theory

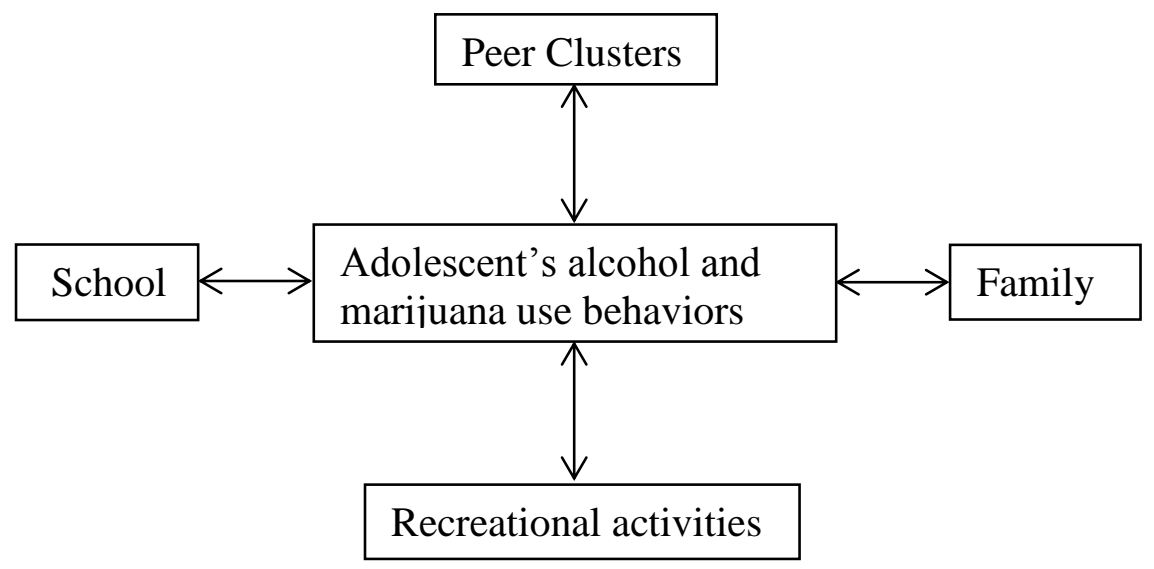

Figure 4: Conceptual Model based on Primary Socialization Theory

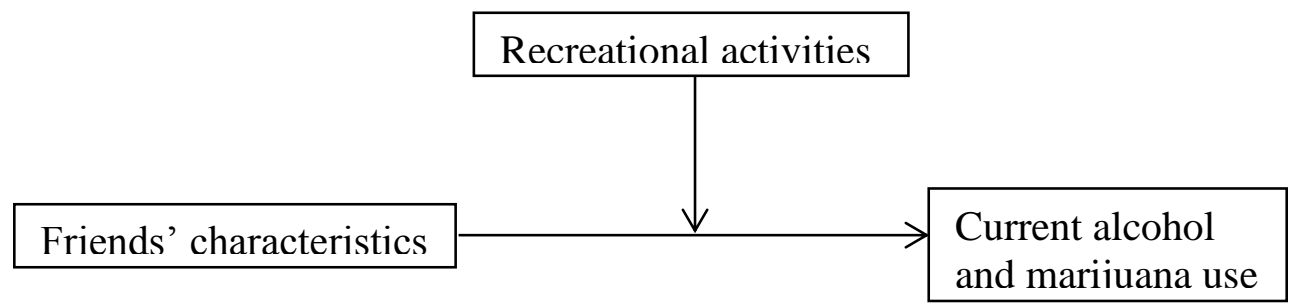

(adapted from Figure 1 in Oetting et al., 1998).

\section{Summary of Chapter II}

The purpose of Chapter II was to describe the seminal work and the most current literature (published within the past five years) on marijuana and alcohol use among Latino adolescents. A series of papers published in the early 1990s provided the foundation for what is currently understood about Latino adolescent substance use in Miami, Florida (Vega et al., 1993b; Vega et al., 1993c; Vega et al., 1993a). However, since these seminal papers, most studies have been conducted in other states, neglecting the unique south Florida Latino adolescent population. 
Consequences of alcohol consumption and marijuana use during adolescence include fighting, arrest for drunk driving, interpersonal victimization (e.g., sexual assault, physical assault, physical abuse; McCart et al., 2012; Temple \& Freeman, 2011), risky sexual activity (Le et al., 2011; Yan et al., 2010), engaging in criminal behaviors (Brook et al., 2011; D'Amico et al., 2016), and symptoms of depression and anxiety (Brook et al., 2011).

Although the role of cultural values and perception of friends' alcohol and marijuana use have been investigated in previous studies (Carlton-Smith \& Skeer, 2015; DiBello et al., 2015; Unger et al., 2014; Schwartz et al., 2011; Schofield et al. 2015; Acosta et al., 2015), recreational activities, a potentially modifiable factor, has not been thoroughly examined in the literature. The present dissertation addressed this gap and was grounded in Primary Socialization Theory (Oetting et al., 1998). An additional suggested primary socialization source, recreational activities, was assessed as a potential moderating variable for the associations between perception of friends' characteristics (age, sex, ethnicity, current alcohol or marijuana) and current alcohol or marijuana use. 


\section{CHAPTER III: STUDY DESIGN AND METHODS}

A secondary analysis was performed using baseline data from the HIV-prevention intervention study, CUÍDATE, herein referred to as the parent study. CUÍDATE was conducted in Miami, FL, to test the effectiveness of an evidence-based HIV prevention intervention among male and female Latino adolescents (13-18 years old) in Miami, FL. Data used for this dissertation project was collected between June 2016 and December 2017.

Participant Recruitment

Participants were recruited in collaboration with four community-based organizations (Care Resource, Connect Familias, Federation of Families, and Latinos United in Action) in Miami-Dade County, FL. These community-based organizations provide a variety of healthcare and other types of services to Latino adolescents such as HIV testing and treatment, STD testing and treatment, lifestyle skills training, and immigration assistance. Two recruitment approaches were implemented: passive (flyers) and active (talking to potential participants and word-of-mouth). Parents provided written informed consent and the adolescent children provided verbal assent.

Description of Sample and Procedures

The sample is composed of male $(n=86)$ and female $(n=107)$ Latino adolescents. Eligibility criteria to participate in the study included self-reporting age of 
13-18 years old, self-identifying as Latino, ability to speak fluent English, and willingness to participate in the study.

Participants completed an electronic survey on laptops provided by the research team at one of the four community-based organizations. Questionnaires were completed using the online survey software REDCap version 7.3.1. Three to six research team members were present during the entire session while the participants completed questionnaires. Participants were instructed to ask a research team member for clarification if any question was unclear.

\section{Operational Definitions}

Latino - Latinos were defined as those individuals who self-identified as being Latino. Self-identifying as a Latino was an inclusion criterion for participation in the parent study.

Adolescent - For the purposes of this dissertation, adolescents were defined as individuals who self-reported being between ages 13 and 18 years old at the time of enrollment. Self-identifying within this age range was also an inclusion criteria for participation in the parent study.

Lifetime alcohol use - If participants responded with any number other than zero to the following question, they were considered as having reported lifetime (ever) alcohol use: During your life, on how many days did you have at least one drink of alcohol? This question was taken from the YRBS (CDC, 2016c).

Current alcohol use - If participants responded with any number other than zero to the following question, they were considered as having reported current alcohol 
use: During the past 30 days, on how many days did you have at least one drink of alcohol? This question was taken from the YRBS (CDC, 2016c).

Lifetime marijuana use - If participants responded with any number other than zero to the following question, they were considered as having reported lifetime (ever) marijuana use: During your life, how many times have you used marijuana? This question was taken from the YRBS (CDC, 2016c).

Current marijuana use - If participants responded with any number other than zero to the following question, they were considered as having reported current marijuana use: During the past 30 days, how many times did you use marijuana?

This question was taken from the YRBS (CDC, 2016c).

Recreational Activities - For the purposes of this dissertation study, recreational activities were defined as a participant's report of participation in any sports activities, after-school activities, or volunteer activities.

Measurements

The following table describes the measurements that were included in this dissertation project.

Table 1: List of Measures

\begin{tabular}{|c|c|c|}
\hline Measure & Description & $\begin{array}{l}\text { Questions used for Dissertation } \\
\text { (Response Options) }\end{array}$ \\
\hline $\begin{array}{l}\text { Lifetime Alcohol } \\
\text { Use }\end{array}$ & $\begin{array}{l}\text { One question about } \\
\text { lifetime alcohol use } \\
\text { from the YRBS } \\
\text { questionnaire was asked } \\
\text { to determine whether } \\
\text { participants ever used }\end{array}$ & $\begin{array}{l}\text {-During your life, on how many } \\
\text { days have you had at least one } \\
\text { drink of alcohol? (0 days, 1-2 days, } \\
\text { 3-9 days, } 10-19 \text { days, } 20-39 \text { days, } \\
\text { 40-99 days, } 100 \text { or more days, } \\
\text { refuse to answer) }\end{array}$ \\
\hline
\end{tabular}




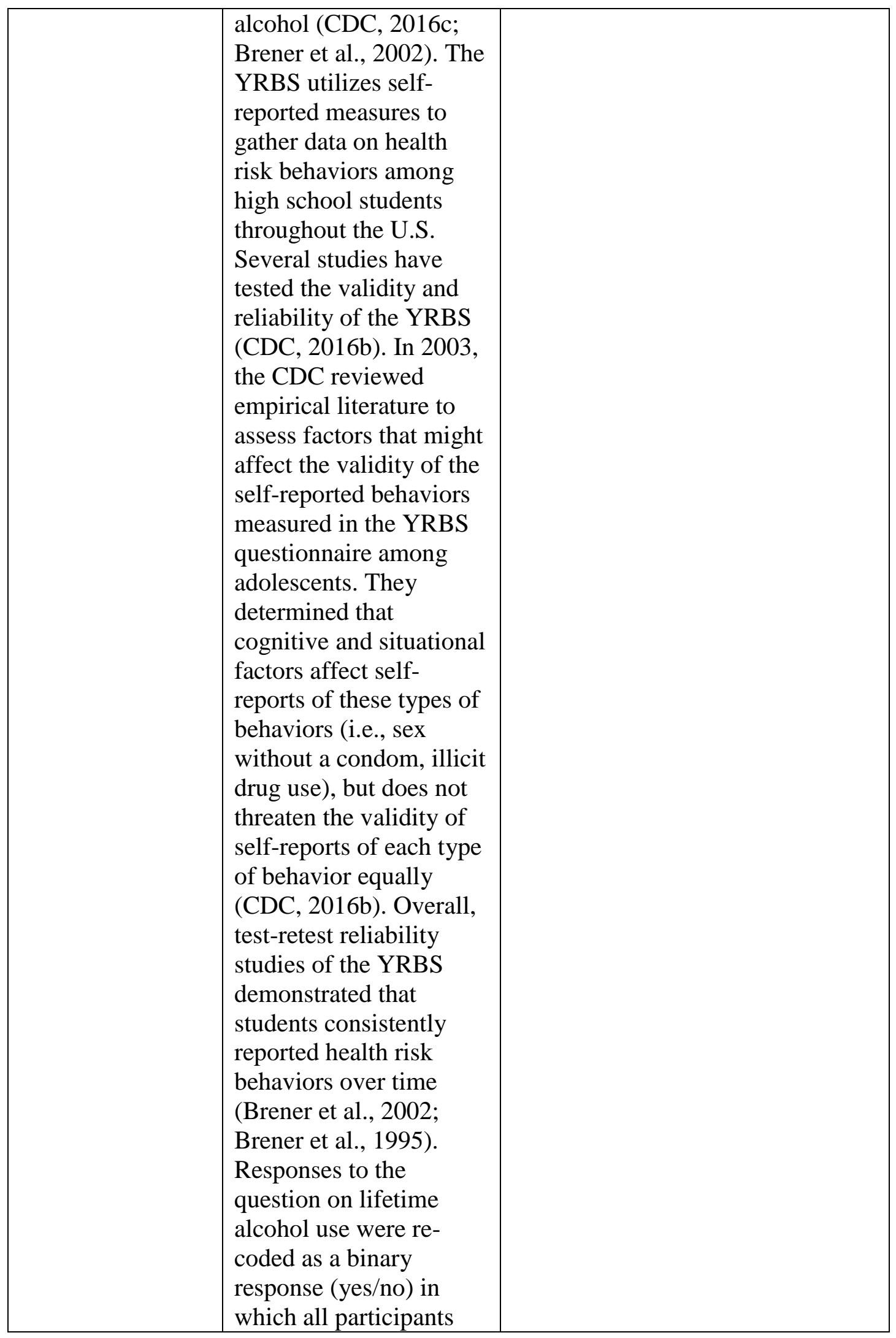




\begin{tabular}{|c|c|c|}
\hline & $\begin{array}{l}\text { who responded with any } \\
\text { number other than zero } \\
\text { were coded as yes (has } \\
\text { used alcohol at least } \\
\text { once during the } \\
\text { lifetime). }\end{array}$ & \\
\hline $\begin{array}{l}\text { Current Alcohol } \\
\text { Use }\end{array}$ & $\begin{array}{l}\text { One question about } \\
\text { current alcohol use from } \\
\text { the YRBS questionnaire } \\
\text { was asked to } \\
\text { participants (CDC, } \\
\text { 2016c; Brener et al., } \\
\text { 2002). Responses to the } \\
\text { question were re-coded } \\
\text { as a binary response } \\
\text { (yes/no) in which all } \\
\text { participants who } \\
\text { responded with any } \\
\text { number other than zero } \\
\text { were coded as yes (has } \\
\text { used alcohol during the } \\
\text { last } 30 \text { days). }\end{array}$ & $\begin{array}{l}\text {-During the past } 30 \text { days, on how } \\
\text { many days did you have at least } \\
\text { one drink of alcohol? A drink is a } \\
\text { can or bottle of beer, a shot of hard } \\
\text { liquor, a mix drink, or a glass of } \\
\text { wine. (0 days, } 1-2 \text { days, } 3-5 \text { days, } \\
6-9 \text { days, } 10-19 \text { days, } 20-29 \text { days, } \\
\text { all } 30 \text { days) }\end{array}$ \\
\hline $\begin{array}{l}\text { Lifetime } \\
\text { Marijuana Use }\end{array}$ & $\begin{array}{l}\text { One question about } \\
\text { lifetime marijuana use } \\
\text { from the YRBS } \\
\text { questionnaire was asked } \\
\text { to participants (CDC, } \\
\text { 2016c; Brener et al., } \\
\text { 2002). Responses to the } \\
\text { question were re-coded } \\
\text { as a binary response } \\
\text { (yes/no) in which all } \\
\text { participants who } \\
\text { responded with any } \\
\text { number other than zero } \\
\text { were coded as yes (has } \\
\text { used marijuana at least } \\
\text { once during the } \\
\text { lifetime). }\end{array}$ & $\begin{array}{l}\text {-During your life, how many times } \\
\text { have you used marijuana? (0 days, } \\
1-2 \text { days, } 3-9 \text { days, } 10-19 \text { days, } 20- \\
39 \text { days, } 40-99 \text { days, } 100 \text { or more } \\
\text { days, refuse to answer) }\end{array}$ \\
\hline $\begin{array}{l}\text { Current Marijuana } \\
\text { Use }\end{array}$ & $\begin{array}{l}\text { One question about } \\
\text { current marijuana use } \\
\text { from the YRBS } \\
\text { questionnaire was asked } \\
\text { to participants (CDC, } \\
\text { 2016c; Brener et al., }\end{array}$ & $\begin{array}{l}\text {-During the past } 30 \text { days, how } \\
\text { many times did you use marijuana? } \\
\text { ( } 0 \text { times, } 1 \text { or } 2 \text { times, } 3-9 \text { times, } \\
10-19 \text { times, } 20-39 \text { times, } 40 \text { or } \\
\text { more times, refuse to answer) }\end{array}$ \\
\hline
\end{tabular}




\begin{tabular}{|c|c|c|}
\hline & $\begin{array}{l}\text { 2002). Responses to the } \\
\text { question were re-coded } \\
\text { as a binary response } \\
\text { (yes/no) in which all } \\
\text { participants who } \\
\text { responded with any } \\
\text { number other than zero } \\
\text { were coded as yes (has } \\
\text { used marijuana during } \\
\text { the last } 30 \text { days). }\end{array}$ & \\
\hline $\begin{array}{l}\text { Sociodemographic } \\
\text { Characteristics } \\
\text { and Household } \\
\text { Composition }\end{array}$ & $\begin{array}{l}\text { The Center for Research } \\
\text { on U.S. Latino } \\
\text { HIV/AIDS and Drug } \\
\text { Abuse (CRUSADA)/C- } \\
\text { SALUD CUÍDATE } \\
\text { demographic instrument } \\
\text { was used to obtain } \\
\text { information about each } \\
\text { participant's age, sex, } \\
\text { country of birth, } \\
\text { family's socioeconomic } \\
\text { status, and with whom } \\
\text { the participant lives } \\
\text { (Kanamori et al., 2016). } \\
\text { Eight of the } 39 \text { total } \\
\text { questions from the } \\
\text { demographic instrument } \\
\text { were included to } \\
\text { determine socio- } \\
\text { demographic } \\
\text { characteristics of the } \\
\text { participants. Age was } \\
\text { calculated as a function } \\
\text { of the date the survey } \\
\text { was conducted and the } \\
\text { reported date of birth } \\
\text { and was rounded to the } \\
\text { nearest whole number } \\
\text { (years). For the } \\
\text { question, who do you } \\
\text { live with, responses } \\
\text { were assigned binary } \\
\text { codes (yes/no) with } \\
\text { respect to living with } \\
\text { both parents. Any }\end{array}$ & $\begin{array}{l}\text {-What is your date of birth? (open- } \\
\text { ended) } \\
\text {-What is your gender? (male, } \\
\text { female, transgender male to female, } \\
\text { transgender female to male, other, } \\
\text { refuse to answer) } \\
\text {-How would you rate your family's } \\
\text { socioeconomic status? (very poor, } \\
\text { poor, lower middle class, upper } \\
\text { middle class, wealthy, other, refuse } \\
\text { to answer) } \\
\text {-How many people live in your } \\
\text { household (including you)? } \\
\text {-Who do you live with? (You can } \\
\text { choose more than one answer: both } \\
\text { my parents, only my mother, only } \\
\text { my father, my partner, my children, } \\
\text { roommates, by myself, refuse to } \\
\text { answer) } \\
\text {-What country were you born in? } \\
\text { (United States, another country, } \\
\text { don't know, refuse to answer) } \\
\text {-What is your mother's highest } \\
\text { level of education? (my mother } \\
\text { never attended school, } 1^{\text {st }} \text { grade, } 2^{\text {nd }} \\
\text { grade, } 3^{\text {rd }} \text { grade, } 4^{\text {th }} \text { grade, } 5^{\text {th }} \\
\text { grade, } 6^{\text {th }} \text { grade, } 7^{\text {th }} \text { grade, } 8^{\text {th }} \\
\text { grade, } 9^{\text {th }} \text { grade, } 10^{\text {th }} \text { grade, } 11^{\text {th }} \\
\text { grade, } 12^{\text {th }} \text { grade, college graduate, } \\
\text { other, don't know, refuse to } \\
\text { answer) } \\
\text {-What is your father's highest level } \\
\text { of education? (same response } \\
\text { options as mother's highest level of } \\
\text { education) }\end{array}$ \\
\hline
\end{tabular}




\begin{tabular}{|c|c|c|}
\hline & $\begin{array}{l}\text { participant who did not } \\
\text { select living with both } \\
\text { parents was considered } \\
\text { not living with both } \\
\text { parents (i.e., living with } \\
\text { mother only) and re- } \\
\text { coded accordingly for } \\
\text { this binary variable. } \\
\text { Participants' country of } \\
\text { birth was re-coded as a } \\
\text { binary response (U.S.- } \\
\text { born versus not U.S.- } \\
\text { born). Responses for } \\
\text { socio-economic status } \\
\text { were collapsed into four } \\
\text { categories: poor, middle } \\
\text { class, wealthy, other. } \\
\text { Mother's and father's } \\
\text { highest level of } \\
\text { education were re-coded } \\
\text { into the following four } \\
\text { categories: } 11^{\text {th }} \text { grade or } \\
\text { less, high school } \\
\text { graduate, college } \\
\text { graduate, don't } \\
\text { know/refuse to answer. }\end{array}$ & \\
\hline $\begin{array}{l}\text { School } \\
\text { Attendance }\end{array}$ & $\begin{array}{l}\text { Three questions from } \\
\text { the CRUSADA/C- } \\
\text { SALUD CUIDATE } \\
\text { demographic instrument } \\
\text { were used to obtain } \\
\text { information regarding } \\
\text { whether the participant } \\
\text { was currently attending } \\
\text { school and if so, his or } \\
\text { her grade level and } \\
\text { grade point average } \\
\text { (GPA). Responses for } \\
\text { current grade level were } \\
\text { collapsed into the } \\
\text { following categories: } \\
6^{\text {th }}-8^{\text {th }} \text { grade, } 9^{\text {th }}-10^{\text {th }} \\
\text { grade, } 11^{\text {th }}-12^{\text {th }} \text { grade, } \\
\text { other. Responses for } \\
\text { GPA were collapsed }\end{array}$ & $\begin{array}{l}\text {-Do you currently attend school? } \\
\text { (yes, no, refuse to answer) } \\
\text {-What is your grade point average } \\
\text { (GPA)? (4.0/A+/97\%-100\%, } \\
\text { 4.0/A/93\%-96\%, 3.7/A-/90\%-92\%, } \\
3.3 / \mathrm{B}+/ 97 \%-89 \%, 3.0 / \mathrm{B} / 83 \%-86 \% \text {, } \\
2.7 / \mathrm{B}-/ 80 \%-82 \%, 2.3 / \mathrm{C}+/ 77 \%- \\
79 \%, 2.0 / \mathrm{C} / 73 \%-76 \%, 1.7 / \mathrm{C}-/ 70 \%- \\
72 \%, 1.3 / \mathrm{D}+/ 67 \%-69 \% \text {, } \\
1.0 / \mathrm{D} / 65 \%-66 \%, 0.0 / \mathrm{F} / \mathrm{Below} 65 \% \text {, } \\
\text { other, refuse to answer, not } \\
\text { applicable) }\end{array}$ \\
\hline
\end{tabular}




\begin{tabular}{|c|c|c|}
\hline & $\begin{array}{l}\text { into the following five } \\
\text { categories: A, B, C, D, } \\
\text { and Missing. }\end{array}$ & \\
\hline $\begin{array}{l}\text { Friends' } \\
\text { Sociodemographic } \\
\text { Characteristics }\end{array}$ & $\begin{array}{l}\text { To determine friends' } \\
\text { sociodemographic } \\
\text { characteristics, four } \\
\text { items from the Peer } \\
\text { Influence Scale were } \\
\text { adapted from Schofield } \\
\text { et al. (2015). This } 8 \text { - } \\
\text { item scale includes } \\
\text { questions about the } \\
\text { participant's } \\
\text { perceptions/observations } \\
\text { of their friends' } \\
\text { sociodemographic } \\
\text { characteristics and } \\
\text { substance use behaviors. } \\
\text { Response options range } \\
\text { from “none" to “more } \\
\text { than } 6 . " \text { This measure } \\
\text { has been used in other } \\
\text { studies with Latino } \\
\text { adolescent samples } \\
\text { (Schofield et al., } 2015 \text {; } \\
\text { Zapata Roblyer et al., } \\
\text { 2016). This measure has } \\
\text { high reliability (5 } \\
\text { grade: } \alpha=.82 ; 7 \text { th } \\
\text { grade: } \alpha=.83 \text {; } \\
\text { Schofield et al., 2015). } \\
\text { The variables from the } \\
\text { friends' characteristics } \\
\text { scale were re-coded into } \\
\text { binary responses } \\
\text { (yes/no). For all } \\
\text { responses other than } \\
\text { zero, participants were } \\
\text { considered to perceive } \\
\text { at least one friend as } \\
\text { possessing the } \\
\text { characteristic and hence } \\
\text { were re-coded as yes } \\
\text { (i.e., being } \\
\text { Latino/Hispanic). }\end{array}$ & $\begin{array}{l}\text {-How many of your closest friends } \\
\text { are the same gender as you? } \\
\text {-How many of your closest friends } \\
\text { are younger than you? } \\
\text {-How many of your closest friends } \\
\text { are older than you? } \\
\text {-How many of your closest friends } \\
\text { are Latino/Hispanic? } \\
\text { (for all of the above: none, } 1,2,3 \text {, } \\
4,5,6 \text {, more than } 6 \text {, don't know, } \\
\text { refuse to answer) }\end{array}$ \\
\hline
\end{tabular}




\begin{tabular}{|c|c|c|}
\hline $\begin{array}{l}\text { Friends' Substance } \\
\text { Use Behaviors }\end{array}$ & $\begin{array}{l}\text { To determine friends' } \\
\text { substance use behaviors, } \\
\text { two items from the Peer } \\
\text { Influence Scale were } \\
\text { adapted from Schofield } \\
\text { et al. (2015). The } \\
\text { variables from the scale } \\
\text { were re-coded into } \\
\text { binary responses } \\
\text { (yes/no). For all } \\
\text { responses other than } \\
\text { zero, participants were } \\
\text { considered to perceive } \\
\text { at least one friend as } \\
\text { possessing the } \\
\text { characteristic and hence } \\
\text { were re-coded as yes } \\
\text { (i.e., drinking alcohol, } \\
\text { using marijuana). }\end{array}$ & $\begin{array}{l}\text {-How many of your closest friends } \\
\text { drink alcohol? } \\
\text {-How many of your closest friends } \\
\text { use marijuana? } \\
\text { (for all of the above: none, } 1,2,3 \text {, } \\
4,5,6 \text {, more than } 6 \text {, don't know, } \\
\text { refuse to answer) }\end{array}$ \\
\hline $\begin{array}{l}\text { Latino Cultural } \\
\text { Value: Familism } \\
\text { Support }\end{array}$ & $\begin{array}{l}\text { The Mexican American } \\
\text { Cultural Values Scale } \\
\text { (Knight et al., 2010) was } \\
\text { used to measure } \\
\text { participants' adherence } \\
\text { to Latino cultural } \\
\text { values. This 37-item } \\
\text { scale measures } \\
\text { adherence to seven } \\
\text { Latino cultural values } \\
\text { (subscales): (a) } \\
\text { Familism Support, (b) } \\
\text { Familism Obligations, } \\
\text { (c) Familism Referents, } \\
\text { (d) Respect, (e) } \\
\text { Religion, (f) Traditional } \\
\text { Gender Roles, and (g) } \\
\text { Independence and Self- } \\
\text { Reliance. The 37-items } \\
\text { (e.g., No matter what, } \\
\text { children should always } \\
\text { treat their parents with } \\
\text { respect) are measured } \\
\text { on a 5-point Likert-type } \\
\text { scale with responses } \\
\text { ranging from "not at all" }\end{array}$ & $\begin{array}{l}\text {-Parents should teach their children } \\
\text { that the family always comes first. } \\
\text {-Family provides a sense of } \\
\text { security because they will always } \\
\text { be there for you. } \\
\text {-It is important to have close } \\
\text { relationships with aunts/uncles, } \\
\text { grandparents, and cousins. } \\
\text {-It is important for family members } \\
\text { to show their love and affection to } \\
\text { one another. } \\
\text {-It is always important to be united } \\
\text { as a family. } \\
\text {-Holidays and celebrations are } \\
\text { important because the whole family } \\
\text { comes together. } \\
\text { (for all of the above: not at all, a } \\
\text { little, somewhat, very much, } \\
\text { completely, refuse to answer). }\end{array}$ \\
\hline
\end{tabular}




\begin{tabular}{|c|c|c|}
\hline & $\begin{array}{l}\text { to "completely." The } \\
\text { scale has been used in } \\
\text { previous studies with } \\
\text { Latino adolescent } \\
\text { samples (Knight et al., } \\
\text { 2010; Morgan Consoli } \\
\text { \& Llamas, 2013). For } \\
\text { the present study, the } \\
\text { role of each of the seven } \\
\text { subscales/cultural values } \\
\text { were assessed as } \\
\text { independent variables. } \\
\text { For each subscale (e.g., } \\
\text { Familism Obligations), } \\
\text { scores for all items (e.g., } \\
\text { Parents should be } \\
\text { willing to make great } \\
\text { sacrifices to make sure } \\
\text { their children have a } \\
\text { better life) were added } \\
\text { and divided by the total } \\
\text { number of questions in } \\
\text { the subscale and the } \\
\text { average was used for } \\
\text { data analysis. } \\
\text { Cronbach's alphas for } \\
\text { the seven subscales are } \\
0.67 \text { (Familism } \\
\text { Support), } 0.65 \\
\text { (Familism Obligations), } \\
\text { 0.61 (Familism } \\
\text { Referents), 0.78 } \\
\text { (Religion), 0.75 } \\
\text { (Respect), 0.73 } \\
\text { (Traditional Gender } \\
\text { Roles), and 0.48 } \\
\text { (Independence and Self- } \\
\text { Reliance; Knight et al., } \\
\text { 2010). }\end{array}$ & \\
\hline $\begin{array}{l}\text { Latino Cultural } \\
\text { Value: Familism } \\
\text { Obligations }\end{array}$ & $\begin{array}{l}\text { The Mexican American } \\
\text { Cultural Values Scale } \\
\text { was used to determine } \\
\text { how strongly } \\
\text { participants agreed with } \\
\text { this cultural value (see }\end{array}$ & $\begin{array}{l}\text {-Children should be taught that it is } \\
\text { their duty to care for their parents } \\
\text { when their parents get old. } \\
\text {-A person should share their home } \\
\text { with relatives if they need a place } \\
\text { to stay. }\end{array}$ \\
\hline
\end{tabular}




\begin{tabular}{|c|c|c|}
\hline & $\begin{array}{l}\text { description above under } \\
\text { Familism Support; } \\
\text { Knight et al., 2010). }\end{array}$ & $\begin{array}{l}\text {-Older kids should take care of and } \\
\text { be role models for their younger } \\
\text { brothers and sisters. } \\
\text {-Parents should be willing to make } \\
\text { great sacrifices to make sure their } \\
\text { children have a better life. } \\
\text {-If a relative is having a hard time } \\
\text { financially, one should help them } \\
\text { out if possible. } \\
\text { (for all of the above: not at all, a } \\
\text { little, somewhat, very much, } \\
\text { completely, refuse to answer). }\end{array}$ \\
\hline $\begin{array}{l}\text { Latino Cultural } \\
\text { Value: Familism } \\
\text { Referents }\end{array}$ & $\begin{array}{l}\text { The Mexican American } \\
\text { Cultural Values Scale } \\
\text { was used to determine } \\
\text { how strongly } \\
\text { participants agreed with } \\
\text { this cultural value (see } \\
\text { description above under } \\
\text { Familism Support; } \\
\text { Knight et al., 2010). }\end{array}$ & $\begin{array}{l}\text {-A person should always think } \\
\text { about their family when making } \\
\text { important decisions. } \\
\text { (for all of the above: not at all, a } \\
\text { little, somewhat, very much, } \\
\text { completely, refuse to answer). }\end{array}$ \\
\hline $\begin{array}{l}\text { Latino Cultural } \\
\text { Value: Respect }\end{array}$ & $\begin{array}{l}\text { The Mexican American } \\
\text { Cultural Values Scale } \\
\text { was used to determine } \\
\text { how strongly } \\
\text { participants agreed with } \\
\text { this cultural value (see } \\
\text { description above under } \\
\text { Familism Support; } \\
\text { Knight et al., 2010). }\end{array}$ & $\begin{array}{l}\text {-No matter what, children should } \\
\text { always treat their parents with } \\
\text { respect. } \\
\text {-Children should respect adult } \\
\text { relatives as if they were parents. } \\
\text {-Children should never question } \\
\text { their parents. } \\
\text {-Children should be on their best } \\
\text { behavior when visiting the homes } \\
\text { of friends or relatives. } \\
\text {-Children should always honor } \\
\text { their parents and never say bad } \\
\text { things about them. } \\
\text {-Children should follow their } \\
\text { parents' rules, even if they think the } \\
\text { rules are unfair. } \\
\text {-It is important for children to } \\
\text { understand that their parents should } \\
\text { have the final say when decisions } \\
\text { are made in the family. } \\
\text {-Children should always be polite } \\
\text { when speaking to any adult. } \\
\text { (for all of the above: not at all, a } \\
\text { little, somewhat, very much, }\end{array}$ \\
\hline
\end{tabular}




\begin{tabular}{|c|c|c|}
\hline & & completely, refuse to answer). \\
\hline $\begin{array}{l}\text { Latino Cultural } \\
\text { Value: Religion }\end{array}$ & $\begin{array}{l}\text { The Mexican American } \\
\text { Cultural Values Scale } \\
\text { was used to determine } \\
\text { how strongly } \\
\text { participants agreed with } \\
\text { this cultural value (see } \\
\text { description above under } \\
\text { Familism Support; } \\
\text { Knight et al., 2010). }\end{array}$ & $\begin{array}{l}\text {-One's belief in God gives inner } \\
\text { strength and meaning to life. } \\
\text {-God is first. Family is second. } \\
\text {-Parents should teach their children } \\
\text { to pray. } \\
\text {-If everything is taken away, one } \\
\text { still has their faith in God. } \\
\text {-It is important to thank God every } \\
\text { day for all one has. } \\
\text {-It is important to follow the Word } \\
\text { of God. } \\
\text {-Religion should be an important } \\
\text { part of one's life. } \\
\text { (for all of the above: not at all, a } \\
\text { little, somewhat, very much, } \\
\text { completely, refuse to answer) }\end{array}$ \\
\hline $\begin{array}{l}\text { Latino Cultural } \\
\text { Value: Traditional } \\
\text { Gender Roles }\end{array}$ & $\begin{array}{l}\text { The Mexican American } \\
\text { Cultural Values Scale } \\
\text { was used to determine } \\
\text { how strongly } \\
\text { participants agreed with } \\
\text { this cultural value (see } \\
\text { description above under } \\
\text { Familism Support; } \\
\text { Knight et al., 2010). }\end{array}$ & $\begin{array}{l}\text {-Men should earn most of the } \\
\text { money for the family so women } \\
\text { can stay home and take care of the } \\
\text { children and the home. } \\
\text {-Families need to watch over and } \\
\text { protect teenage girls more than } \\
\text { teenage boys. } \\
\text {-It is important for the man to have } \\
\text { more power in the family than the } \\
\text { woman. } \\
\text {-Mothers are the main people } \\
\text { responsible for raising children } \\
\text {-A wife should always support her } \\
\text { husband's decisions, even if she } \\
\text { does not agree with him. } \\
\text { (for all of the above: not at all, a } \\
\text { little, somewhat, very much, } \\
\text { completely, refuse to answer) }\end{array}$ \\
\hline $\begin{array}{l}\text { Latino Cultural } \\
\text { Value: } \\
\text { Independence and } \\
\text { Self-Reliance }\end{array}$ & $\begin{array}{l}\text { The Mexican American } \\
\text { Cultural Values Scale } \\
\text { was used to determine } \\
\text { how strongly } \\
\text { participants agreed with } \\
\text { this cultural value (see } \\
\text { description above under } \\
\text { Familism Support; } \\
\text { Knight et al., 2010). }\end{array}$ & $\begin{array}{l}\text {-People should learn how to take } \\
\text { care of themselves and not depend } \\
\text { on others. } \\
\text {-The most important thing parents } \\
\text { can teach their children is to be } \\
\text { independent from others. } \\
\text {-As children get older their parents } \\
\text { should allow them to make their } \\
\text { own decisions. } \\
\text {-When there are problems in life, a }\end{array}$ \\
\hline
\end{tabular}




\begin{tabular}{|c|c|c|}
\hline & & $\begin{array}{l}\text { person can only count on him or } \\
\text { himself. } \\
\text {-Parents should encourage children } \\
\text { to solve their own problems. } \\
\text { (for all of the above: not at all, a } \\
\text { little, somewhat, very much, } \\
\text { completely, refuse to answer) }\end{array}$ \\
\hline $\begin{array}{l}\text { Recreational } \\
\text { activity: School } \\
\text { Sports }\end{array}$ & $\begin{array}{l}\text { Participants were asked } \\
\text { whther they have ever } \\
\text { participated inschool } \\
\text { sports of clubs/teams. } \\
\text { Participants were also } \\
\text { asked to select a school } \\
\text { sport in which they } \\
\text { participate. If they } \\
\text { selected a school sport } \\
\text { in which they } \\
\text { participate, they were } \\
\text { re-coded as being a } \\
\text { current participant in } \\
\text { school sports (yes). } \\
\text { Questions regarding } \\
\text { participation in sports } \\
\text { activities were adapted } \\
\text { from the World Health } \\
\text { Organization's (WHO) } \\
\text { Global Physical Activity } \\
\text { Questionnaire (GPAQ; } \\
\text { Who, 2017). The GPAQ } \\
\text { is a 16-item } \\
\text { questionnaire which } \\
\text { covers intensity, } \\
\text { duration, and frequency } \\
\text { of physical activity and } \\
\text { assesses three physical } \\
\text { activity domains: } \\
\text { occupational physical } \\
\text { activity, transport- } \\
\text { related physical activity, } \\
\text { and physical activity } \\
\text { during discretionary or } \\
\text { leisure time. The WHO } \\
\text { developed the GPAQ to } \\
\text { be used as a } \\
\text { standardized protocol }\end{array}$ & $\begin{array}{l}\text {-Have you (ever) participated in } \\
\text { school sports or physical activity } \\
\text { clubs/teams? (no, yes, don't } \\
\text { know/don't remember, refuse to } \\
\text { answer, not applicable) } \\
\text {-In what school sports or physical } \\
\text { activity clubs do you participate? } \\
\text { (baseball/softball/ catch/pitching, } \\
\text { basketball, bike riding/dirt biking/ } \\
\text { mountain biking, dance, football } \\
\text { (American), running/jogging, } \\
\text { soccer (futbol), swimming, other, } \\
\text { don't know, refuse to answer, not } \\
\text { applicable) }\end{array}$ \\
\hline
\end{tabular}




\begin{tabular}{|c|c|c|}
\hline & $\begin{array}{l}\text { for surveilling physical } \\
\text { activity among } \\
\text { populations. Validity } \\
\text { and reliability of the } \\
\text { GPAQ has been } \\
\text { demonstrated in several } \\
\text { studies (Cleland et al., } \\
\text { 2014; Bull, Maslin, \& } \\
\text { Armstrong, 2009; Chu, } \\
\text { Ng, Koh, Müller- } \\
\text { Riemenschneider, } \\
\text { 2015). }\end{array}$ & \\
\hline $\begin{array}{l}\text { Recreational } \\
\text { activity: } \\
\text { Volunteer } \\
\text { Activities }\end{array}$ & $\begin{array}{l}\text { Participants were asked } \\
\text { whether they are } \\
\text { currently a volunteer. } \\
\text { This question was coded } \\
\text { as a binary variable } \\
\text { (yes/no). Questions } \\
\text { regarding participation } \\
\text { in volunteer activities } \\
\text { were taken from the } \\
\text { CUÍDATE demographic } \\
\text { instrument which is } \\
\text { comprised of a total of } \\
39 \text { questions (Kanamori } \\
\text { et al., 2016). These } \\
\text { questions were selected } \\
\text { from the parent study's } \\
\text { questionnaire because } \\
\text { they addressed items } \\
\text { necessary to test } \\
\text { hypotheses 5-8 of the } \\
\text { dissertation. }\end{array}$ & $\begin{array}{l}\text {-Are you currently a volunteer at } \\
\text { school or anywhere? (yes, no, } \\
\text { refuse to answer) } \\
\text {-If you chose yes, where do you } \\
\text { volunteer? (open-ended response) }\end{array}$ \\
\hline $\begin{array}{l}\text { Recreational } \\
\text { activity: After- } \\
\text { school Activities } \\
\text { or Programs not } \\
\text { related to School }\end{array}$ & $\begin{array}{l}\text { Participant s were asked } \\
\text { whether they currently } \\
\text { participate in any after- } \\
\text { school activities or } \\
\text { programs. This question } \\
\text { was coded as a binary } \\
\text { variable (yes/no). } \\
\text { Questions regarding } \\
\text { participation in after- } \\
\text { school activities were } \\
\text { taken from the } \\
C U I ́ D A T E \text { demographic }\end{array}$ & $\begin{array}{l}\text {-Do you participate in any after- } \\
\text { school activities or programs (not } \\
\text { related to school)? (yes, no, refuse } \\
\text { to answer) } \\
\text {-If you chose yes, please specify } \\
\text { the activity or program. (open- } \\
\text { ended response) }\end{array}$ \\
\hline
\end{tabular}




\begin{tabular}{|l|l|l|}
\hline & $\begin{array}{l}\text { instrument which is } \\
\text { comprised of a total of } \\
39 \text { questions (Kanamori } \\
\text { et al., 2016). These } \\
\text { questions were selected } \\
\text { from the parent study's } \\
\text { questionnaire because } \\
\text { they addressed items } \\
\text { necessary to test } \\
\text { hypotheses 5-8 of the } \\
\text { dissertation. }\end{array}$ & \\
\hline
\end{tabular}

Analytic Models

The conceptual model presented in this Chapter II (Figure 4) has been further developed into analytic models (Figures 5-7) based on the hypotheses which were used to guide the data analysis for this dissertation.

Figure 5: Analytic Model 1 (Aim 1; Hypotheses 1-4)

Independent Variables:
Sex
Age
Country of birth
GPA
Family's socio-economic status
Living with both parents
Familism
Religion
Traditional Gender Roles,
Independence and Self-Reliance


Figure 6: Analytic Model 2 (Aim 2; Hypotheses 5-6)

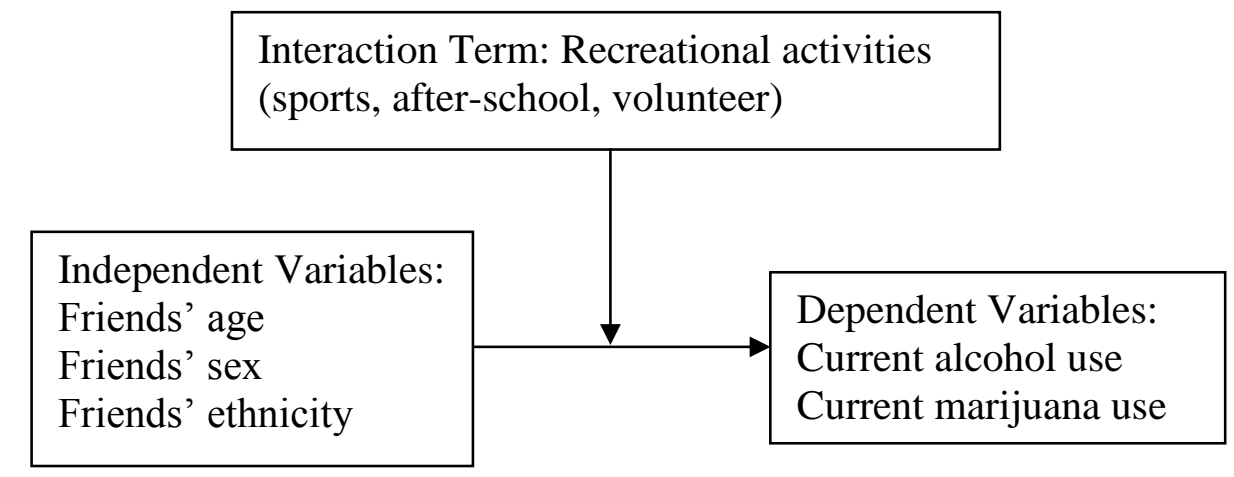

Figure 7: Analytic Model 3 (Aim 3; Hypotheses 7-8)

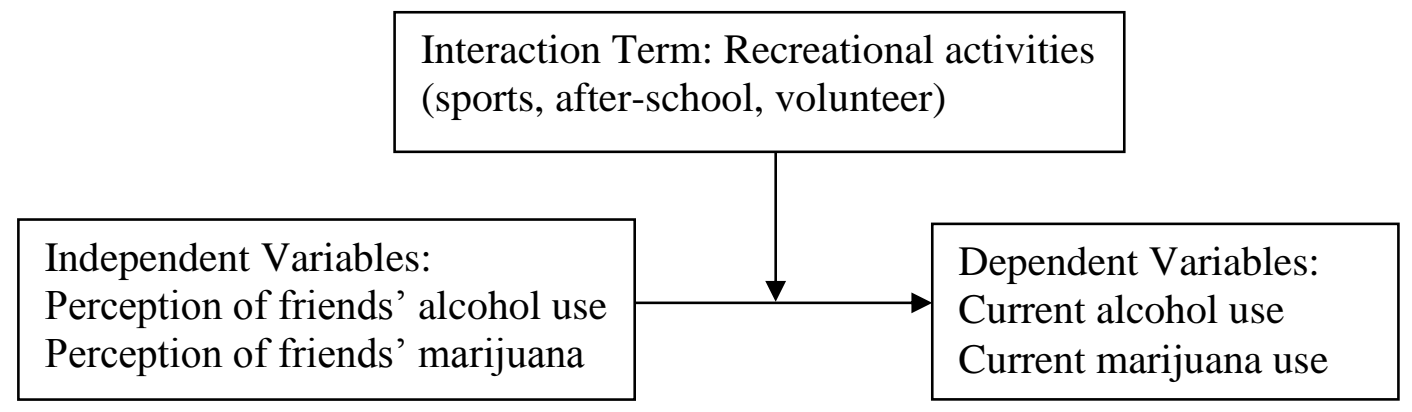

Data Analysis

Data were analyzed using the Statistical Package for Social Sciences (SPSS)

Version 21. To determine socio-demographic characteristics of the sample, means and standard deviations were calculated for continuous variables and percentages were calculated for categorical values. Independent t-tests and chi square tests were used to analyze differences between males and females with respect to socio-demographic characteristics. 
For each Latino cultural value subscale (i.e., Traditional Gender Roles), scores for all items were added to create one composite score for each subscale. For aim 1, multiple logistic regression was performed using both Forward Selection (likelihood ratio) and Backward Elimination (likelihood ratio) techniques. Due to missing data values, 163 of the participants were included in the analyses for the dependent variables lifetime alcohol use, current alcohol use, and current marijuana use, and 162 participants were included in the analyses for the dependent variable lifetime marijuana use. Two variables were removed from the original models due to too many missing responses which would have drastically decreased the sample size: mother's highest level of education and father's highest level of education. In addition, Familism Support, Familism Obligations, and Familism Referents were combined into one composite variable, familism due to multicollinearity and similarity among items in these Latino cultural values subscales (Appendix 2). Therefore, the final models included the following independent variables: sex, age, country of birth, GPA, family’s socioeconomic status, living with both parents Familism, Religion, Traditional Gender Roles, and Independence and Self-Reliance. Dummy variables were created for the two categorical independent variables with more than two categories: socioeconomic status and GPA. The most frequently reported categories (socioeconomic status: middle class; GPA: B) were coded as the reference categories for each variable.

Before performing multiple regression, the data were checked for the following assumptions: dichotomy of dependent variables, at least one independent variable, independent observations, multicollinearity. The data did not violate any assumptions. The dependent variables were dichotomous, and more than one independent variable was 
tested in the model. Observations were all independent, and the dependent variables have mutually exclusive and exhaustive categories (i.e., yes/no). Due to multicollinearity between the Latino cultural values Respect and Familism (VIF > 2.5), Respect was removed from the models (Appendix 2). Significant associations were determined at $p<$ 0.10 . For any regression that did not yield gender or country of birth in the final model, a comparison was performed to compare the full and reduced models based on their deviance in which the significant independent variables from the original regression (forward selection and backward elimination) were entered in in block 1 and gender and/or country of birth were entered in block 2 to test the differences between the models. This would allow for comparison of the findings of the present dissertation study to those of the seminal study which compared U.S.-born Cubans to foreign-born CubanAmericans (Vega et al., 1993c) and to further explore the role of gender to expand upon the work conducted in the seminal studies (Vega et al., 1993a; Vega et al., 1993b; Vega et al., 1993c).

For aims 2 and 3 (hypotheses 5-8), bivariate logistic regression models including one independent variable and one dependent variable were performed. If the independent variable was significantly associated with the dependent variable, a logistic regression model including one independent variable and one potential effect modifier was performed. If the independent variable and the potential effect modifier were significantly associated with the dependent variable, a logistic regression model including the independent variable, the potential effect modifier and the interaction was developed. If the interaction effect was significant, additional logistic regression models stratified by the levels of the potential effect modifier were performed and presented. If the interaction 
effect was not significant, the most parsimonious model was presented. Significant associations were determined at $p<0.10$.

Power Analysis

Power was calculated using GPower 3.1.9.2. A previous study of alcohol use among Latino adolescents demonstrated a significant effect on alcohol use by gender when all other variables were held constant (odds ratio: 2.90) (Zapata Roblyer et al., 2016). Furthermore, based on a survey conducted by the Florida Department of Children and Families in 2014, the proportion of female adolescents in Miami-Dade County that reported having used alcohol in their lifetime was 0.444 (Florida Department of Children \& Families, 2016). Applying that odds ratio to the proportion of adolescent females living in Miami-Dade County that have used alcohol in their lifetime (0.444), it was estimated that a total sample size of 120 would yield a significant effect size between adolescent males and females using logistic regression and power of 0.80 (alpha of 0.05). With regards to the other aims presented in this study, it was not possible to perform an a priori power analysis due to lack of previous similar studies.

\section{Informed Consent}

The parent study and the dissertation study were approved by the Institutional Review Board (IRB) at Florida International University (FIU; IRB Approval Number: FIU-17-0002). Written parental consent and verbal child assent was required prior to participation in the parent study. 


\section{Summary of Chapter III}

Chapter III began with a description of the parent study and the design of the

present study. The present study was a secondary analysis in which web-based surveys were analyzed for 193 male and female Latino adolescents (13-18 years old) in MiamiDade County, FL. Participant recruitment included passive and active strategies from community-based organizations that provide services to Latino adolescents in MiamiDade County. A description of the questions asked to determine participants' lifetime and current use of alcohol and marijuana, participation in recreational activities, Latino cultural values, and friends' characteristics were included. The chapter concluded with a description of the statistical analyses and power analysis. 


\section{CHAPTER IV: RESULTS}

The purpose of Chapter IV is to describe the findings of the study including sociodemographic characteristics of the participants, perception of friends' characteristics (age, sex, ethnicity, and drinking and marijuana use behaviors), participation in recreational activities, participants' identification with Latino cultural values, and lifetime and current use of alcohol and marijuana. In addition, the findings of the hypotheses testing are presented in the present chapter.

\section{Description of the Sample}

Two hundred and one adolescents participated in the parent study, and six were excluded from the analysis because they did not meet inclusion criteria for Latino ethnicity $(n=3)$ or being $13-18$ years old $(n=3)$. In addition, due to (a) the small number of transgender individuals in the sample $(n=2)$, and (b) the need to evaluate this population separately because of their higher risk of drug use (Reisner, Geytak, Parsons, \& Ybarra, 2015; De Pedro, Gilreath, Jackson, \& Esqueda, 2017), the two individuals who reported their sex as transgender were also excluded from the analyses in this study. Among the 193 participants remaining and included here, the majority were female and born in the U.S. The average age was 15.7 years old (mode: 17 years old). All participants attended school, and most were in grades 9-12 and had a grade point average (GPA) equivalent to an A or B grade. Most participants reported their family's socioeconomic status as middle class. Table 2 presents socio-demographic characteristics for males and females including tests of differences between the sexes. 
Table 2: Socio-Demographic Characteristics of Participants and their Families, MiamiDade County, Florida 2016-2017

\begin{tabular}{|c|c|c|c|c|}
\hline & $\begin{array}{c}\text { Males } \\
(n=86) \\
(44.6 \%)\end{array}$ & $\begin{array}{c}\text { Females } \\
(n=107) \\
(55.4 \%)\end{array}$ & $\chi^{2}$ or $\mathrm{t}$ & $\begin{array}{c}\text { Total } \\
(n=193) \\
(100 \%)\end{array}$ \\
\hline Age in years $(M \pm S D)$ & $15.7+1.5$ & $15.6 \pm 1.6$ & 0.823 & $15.7 \pm 1.6$ \\
\hline 13 & $6(7.0)$ & $14(13.1)$ & & $20(10.4)$ \\
\hline 14 & $16(18.6)$ & $18(16.8)$ & & $34(17.6)$ \\
\hline 15 & $14(16.3)$ & $16(15.0)$ & & $20(15.5)$ \\
\hline 16 & $20(23.3)$ & $22(20.6)$ & & $42(21.8)$ \\
\hline 17 & $18(20.9)$ & $27(25.2)$ & & $45(23.3)$ \\
\hline 18 & $12(14.0)$ & $10(9.3)$ & & $22(11.4)$ \\
\hline Country of birth & & & 1.217 & \\
\hline U.S. born & $59(70.2)$ & $67(62.6)$ & & $126(65.3)$ \\
\hline Non-U.S. born & $25(29.8)$ & $40(37.4)$ & & $65(33.7)$ \\
\hline Missing & $2(2.3)$ & $0(0)$ & & $2(1.0)$ \\
\hline Current Grade Level & & & $8.850^{*}$ & \\
\hline $6^{\text {th }}-8^{\text {th }}$ grade & $15(17.4)$ & $25(23.4)$ & & $40(20.7)$ \\
\hline $9^{\text {th }}-10^{\text {th }}$ grade & $37(43.0)$ & $27(25.2)$ & & $64(33.2)$ \\
\hline $11^{\text {th }}-12^{\text {th }}$ grade & $32(37.2)$ & $46(43.0)$ & & $78(40.4)$ \\
\hline Other & $2(2.3)$ & $9(8.4)$ & & $11(5.7)$ \\
\hline Grade Point Average & & & 5.990 & \\
\hline $\mathrm{A}$ & $14(16.3)$ & $30(28.0)$ & & $44(22.8)$ \\
\hline B & $47(54.7)$ & $53(49.5)$ & & $100(51.8)$ \\
\hline $\mathrm{C}$ & $19(22.1)$ & $20(18.7)$ & & $39(20.2)$ \\
\hline $\mathrm{D}$ & $4(4.7)$ & $1(0.9)$ & & $5(2.6)$ \\
\hline Missing & $2(2.3)$ & $3(2.8)$ & & $5(2.6)$ \\
\hline Family's socioeconomic status & & & $7.694 *$ & \\
\hline Poor & $7(8.1)$ & $11(10.3)$ & & $18(9.3)$ \\
\hline Middle class & $67(77.9)$ & $91(85.0)$ & & $158(81.9)$ \\
\hline Wealthy & $8(9.3)$ & $1(0.9)$ & & $9(4.7)$ \\
\hline Other & $4(4.7)$ & $4(3.7)$ & & $8(4.1)$ \\
\hline $\begin{array}{l}\text { Number of people in household }(\mathrm{M} \pm \\
\text { SD) }\end{array}$ & $4.7(1.6)$ & $4.4(1.5)$ & 1.408 & $4.6(1.5)$ \\
\hline Living with both parents & & & 0.174 & \\
\hline Yes & $50(58.1)$ & $59(55.1)$ & & $109(56.5)$ \\
\hline No & $36(41.9)$ & $48(44.9)$ & & $84(43.5)$ \\
\hline Mother's highest level of education & & & 1.214 & \\
\hline $11^{\text {th }}$ grade or less & $9(10.5)$ & $13(12.1)$ & & $22(11.4)$ \\
\hline High school graduate & $22(25.6)$ & $22(20.6)$ & & $44(22.8)$ \\
\hline College graduate & $27(31.4)$ & $41(38.3)$ & & $68(35.2)$ \\
\hline Don't Know/Refuse to Answer & $28(32)$. & $31(29.0)$ & & $59(30.6)$ \\
\hline Father's highest level of education & & & 0.881 & \\
\hline $11^{\text {th }}$ grade or less & $10(11.6)$ & $14(13.1)$ & & $24(12.4)$ \\
\hline High school graduate & $24(27.9)$ & $21(19.6)$ & & $45(23.3)$ \\
\hline
\end{tabular}


Numbers displayed as $\mathrm{n}(\%)$;

${ }^{*} p<0.05$, based on chi square tests or independent sample t-tests of differences between genders

Among those who were born outside of the U.S., the most reported country of birth was Honduras $(n=17)$ followed by Venezuela $(n=13)$ and Cuba $(n=10$; Table 3$)$

Table 3: Countries of Birth of non-U.S.-born Latino Adolescents, Miami-Dade County, Florida 2016-2017

\begin{tabular}{ll}
\hline Country of Birth & Frequency (\%) \\
\hline Argentina & $1(1.5)$ \\
Chile & $2(3.1)$ \\
Colombia & $3(4.6)$ \\
Cuba & $10(15.4)$ \\
Dominican Republic & $5(7.7)$ \\
Ecuador & $6(9.2)$ \\
Guatemala & $1(1.5)$ \\
Honduras & $17(26.2)$ \\
Mexico & $2(3.1)$ \\
Nicaragua & $2(3.1)$ \\
Puerto Rico & $2(3.1)$ \\
Venezuela & $13(20.0)$ \\
Missing & $1(1.5)$ \\
\hline
\end{tabular}

Perceptions of Friends' Characteristics

Participants were asked how many of their closest friends are (a) older, (b) younger, (c) the same gender, and (d) Latino/Hispanic. Most participants reported 
between one and six of their closest friends were the same gender, older, younger, and Latino/Hispanic (Figure 8). In addition, more than half (50.8\%) of participants reported that currently at least one of their closest friend's drinks alcohol. More than two-thirds (38.4\%) reported that currently at least one of their closest friends uses marijuana (Figure 9).

Figure 8: Latino Adolescents' Perception of Friends' Age, Sex, and Ethnicity, MiamiDade County, Florida 2016-2017

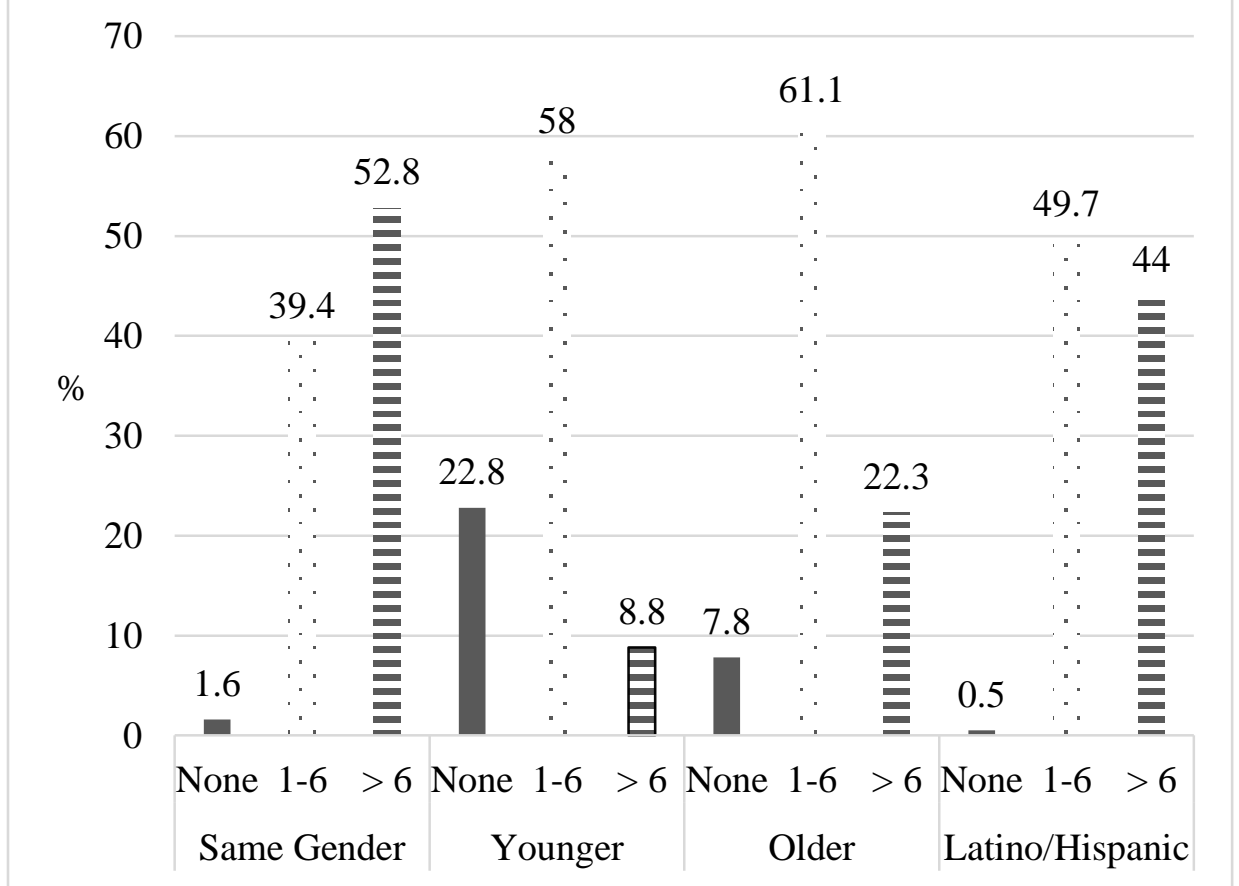

Same Gender: How many of your closest friends are the same gender as you? Younger: How many of your closest friends are younger than you?

Older: How many of your closest friends are older than you?

Latino/Hispanic: How many of your closest friends are Latino/Hispanic? 
Figure 9: Latino Adolescents' Perception of Friends' Alcohol and Marijuana Use Behaviors, Miami-Dade County, Florida 2016-2017

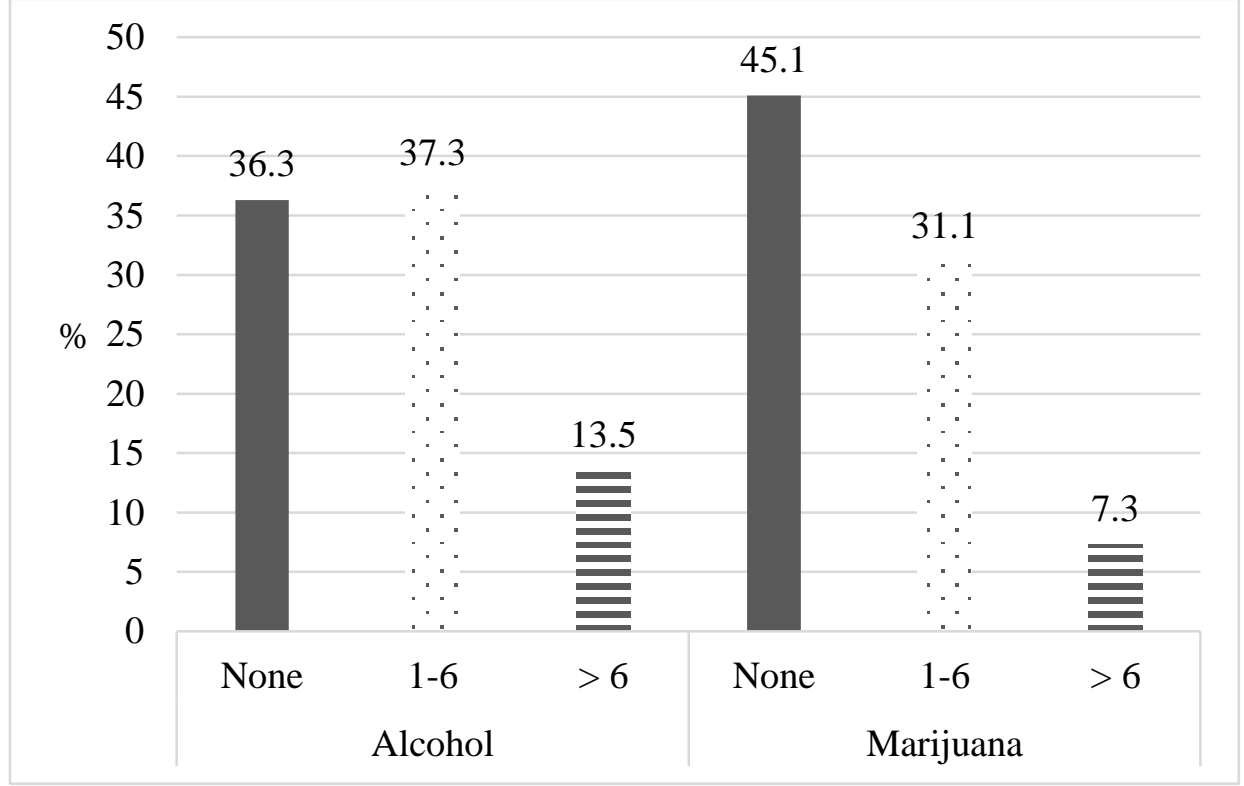

Alcohol: How many of your closest friends drink alcohol?

Marijuana: How many of your closest friends use marijuana?

\section{Recreational Activities}

A total of $135(69.9 \%)$ participants reported participating in at least one type of recreational activity. Approximately one-fifth $(n=37)$ of participants reported that they currently participate in volunteer activities, and almost one-third of participants $(29.5 \%)$ reported participating in any after-school activity or program (not related to school). More than half of participants $(n=120 ; 62.2 \%)$ reported that they have participated in school sports or physical activity clubs/teams. Table 4 presents the specific recreational activities reported by participants of this study. 
Table 4: Recreational Activities Reported by Latino Adolescents, Miami-Dade County, Florida 2016-2017

\begin{tabular}{lll}
\hline & $\mathrm{n}$ & $\%$ \\
\hline Volunteer & 37 & 19.2 \\
-Church & 11 & 5.7 \\
-School & 7 & 3.6 \\
-Other Organizations & 19 & 9.8 \\
-After-school Activities & 57 & 29.5 \\
-Church & 4 & 2.1 \\
-Sports & 44 & 22.8 \\
-Other Activities & 20 & 10.4 \\
Sports & 120 & 62.2 \\
-Basketball/Softball/Catch/Pitching & 11 & 5.7 \\
-Basketball & 40 & 20.7 \\
-Bike Riding/Dirt Biking/Mountain Biking & 3 & 1.6 \\
-Dance & 35 & 18.1 \\
-American Football & 23 & 11.9 \\
-Running/Jogging & 18 & 9.3 \\
-Soccer (Fútbol) & 29 & 15.0 \\
-Swimming & 4 & 2.1 \\
-Other Sports & 25 & 13.0 \\
\hline
\end{tabular}

\section{Latino Cultural Values}

Mean and standard deviation for each cultural values subscale is presented in

Table 5. Participants identified more strongly with the cultural values Familism Support, Familism Obligations, Familism Referents, and Respect and less strongly with the cultural values Religion, Traditional Gender Roles, and Independence and Self-Reliance. Participants' identification with each item that composes each of the seven Latino cultural value sub-scales are presented in Appendix 3. 
Table 5: Means and Standard Deviations of Latino Cultural Values Subscales Reported by Latino Adolescents, Miami-Dade County, Florida 2016-2017

\begin{tabular}{lcc}
\hline & Mean & SD \\
\hline 1. Familism Support & 4.29 & 0.57 \\
2. Familism Obligations & 4.09 & 0.58 \\
3. Familism Referents & 4.13 & 0.95 \\
4. Respect & 4.01 & 0.65 \\
5. Religion & 3.87 & 0.98 \\
6. Traditional Gender Roles & 2.65 & 0.99 \\
7. Independence and Self-Reliance & 3.72 & 0.68 \\
\hline
\end{tabular}

Alcohol and Marijuana Use

More than half of all participants reported they have used alcohol in their lifetime, and almost one-quarter (22.0\%) reported current alcohol use (Table 6). More than onequarter $(28.3 \%)$ of males and females reported lifetime use of marijuana, and $12.9 \%$ and $11.2 \%$ of males and females, respectively, reported current marijuana use (past 30 days; Table 7).

Table 6: Latino Adolescents' Lifetime and Current Use of Alcohol, Miami-Dade County, Florida 2016-2017

\begin{tabular}{lccc}
\hline & $\begin{array}{c}\text { Males } \\
\mathrm{n}(\%)\end{array}$ & $\begin{array}{c}\text { Females } \\
\mathrm{n}(\%)\end{array}$ & $\begin{array}{c}\text { Total } \\
\mathrm{n}(\%)\end{array}$ \\
\hline Ever used alcohol & $45(52.9)$ & $70(65.4)$ & $115(59.9)$ \\
& $16(18.8)$ & $26(24.5)$ & $42(22.0)$ \\
\hline Current alcohol use (past 30 days) & &
\end{tabular}


Table 7: Latino Adolescents' Lifetime and Current Use of Marijuana, Miami-Dade County, Florida 2016-2017

\begin{tabular}{lccc}
\hline & $\begin{array}{c}\text { Males } \\
\mathrm{n}(\%)\end{array}$ & $\begin{array}{c}\text { Females } \\
\mathrm{n}(\%)\end{array}$ & $\begin{array}{c}\text { Total } \\
\mathrm{n}(\%)\end{array}$ \\
\hline Ever used marijuana & $23(27.4)$ & $31(29.0)$ & $54(28.3)$ \\
Current marijuana use (past 30 days) & $11(12.9)$ & $12(11.2)$ & $23(12.0)$ \\
\hline Percentages displayed: \% among all participants & &
\end{tabular}

Percentages displayed: $\%$ among all participants

Introduction to Findings of Hypotheses Testing of Hypotheses 1-4

For Hypotheses 1-4, logistic regression was performed using both forward selection and backward elimination procedures. If the procedures yielded the same final model, then only the results of the backward elimination procedure were reported. The Hosmer and Lemeshow test was performed for all regressions to test the null hypothesis, that the model is a good fit. For the regression models, significance was ascertained at $\mathrm{p}<$ 0.1. If the original logistic regressions (forward selection and backward regression) yielded a final model which did not include gender and/or country of birth, an additional stepwise regression was performed with the independent variables from the final model in block 1 and gender and/or country of birth included in block 2 . If the final models of forward selection and backward elimination techniques yielded different final models (hypothesis 2), then block 1 contained all independent variables from both final models.

Results of Hypothesis Testing (Hypothesis 1: Forward Selection and Backward Elimination)

The forward selection and backward elimination procedures for outcome variable current alcohol use led to the same final model which included the following independent 
variables: country of birth, socioeconomic status, and the Latino cultural value Religion. The forward selection and backward elimination procedures led to the same model. The model explained $9-13 \%$ of the variation in the dependent variable (Table 8). The null hypothesis of the Hosmer and Lemeshow test, that the model is a good fit, was not rejected $\left(\chi^{2}=11.45, p=0.18\right.$; Table 9$)$. The model correctly classified $76.7 \%$ of Latino adolescents (Table 10). Being born in the U.S. increased the risk of current alcohol use (OR: $2.7 ; 95 \%$ CI: 1.17, 6.22), and identifying more strongly with the cultural value Religion decreased the risk of current alcohol use (OR: 0.94; 95\% CI: 0.89, 0.99; Table 11). Reporting a higher socioeconomic status increased the risk of current alcohol use (OR: 2.90; 95\% CI: 0.89, 0.99). Because gender was not significant in the final model, a comparison between the reduced model and the full model was performed based on their deviance with country of birth, socioeconomic status, and Religion entered in block 1 and gender in block 2 . The omnibus test of model coefficients revealed no significant differences between the two models $\left(\chi^{2}=0.02, \mathrm{p}=0.88\right)$.

Table 8: Backward Elimination Logistic Regression Model Summary for Dependent Variable: Current Alcohol Use

\begin{tabular}{llll}
\hline Step & -2 Log likelihood & Cox \& Snell R Square & Nagelkerke R Square \\
\hline 8 & 157.42 & 0.09 & 0.13 \\
\hline
\end{tabular}

Table 9: Backward Elimination Hosmer and Lemeshow Test for Dependent Variable: Current Alcohol Use

\begin{tabular}{llll}
\hline Step & Chi-square & Df & Sig \\
\hline 8 & 11.45 & 8 & 0.18 \\
\hline
\end{tabular}


Table 10: Backward Elimination Classification Table for Dependent Variable: Current Alcohol Use

\begin{tabular}{llll}
\hline Observed & \multicolumn{3}{c}{ Predicted } \\
\hline Step 8 & No & Yes & $\%$ Correct \\
No & 124 & 3 & 97.6 \\
Yes & 35 & 1 & 2.8 \\
Overall \% & & & 76.7 \\
\hline
\end{tabular}

Table 11: Backward Elimination, Variables in the Equation for Dependent Variable: Current Alcohol Use

\begin{tabular}{lccccc}
\hline & B & SE & Wald & Odds Ratio & 95\% CI \\
\hline Country of Birth & 0.99 & 0.43 & 5.41 & 2.70 & $(1.17,6.22)^{* *}$ \\
Socioeconomic status & 1.06 & 0.60 & 3.16 & 2.90 & $(0.90,9.35)^{*}$ \\
Religion & -0.06 & 0.03 & 4.93 & 0.94 & $(0.89,0.99)^{* *}$ \\
& & & & & \\
\hline
\end{tabular}

N/S not significant, $* p$ value $<0.1, * * p$ value $<0.05$.

Results of Hypothesis Testing (Hypothesis 2: Forward Selection)

For hypothesis 2, the final models yielded via the forward selection and backward elimination procedures were different, and therefore both models are presented in this dissertation. Regarding forward selection procedure, the final model for outcome variable lifetime alcohol use included the variables age and Traditional Gender Roles. The model explained 6-9\% of the variation in the dependent variable (Table 12). The null hypothesis of the Hosmer and Lemeshow test, that the model is a good fit, was not rejected $\left(\chi^{2}=\right.$ 3.91, $\mathrm{p}=0.87$; Table 13). The model correctly classified $65.0 \%$ of Latino adolescents (Table 14). Being older increased risk of lifetime alcohol use (OR: 1.23; 95\% CI: 0.99, 1.53; Table 15). Identifying more strongly with the cultural value Traditional Gender Roles decreased risk of lifetime alcohol use (OR: 0.92; 95\% CI: 0.86, 0.98). 
Table 12: Forward Selection Logistic Regression Model Summary for Dependent Variable: Lifetime Alcohol Use

\begin{tabular}{llll}
\hline Step & -2 Log likelihood & Cox \& Snell R Square & Nagelkerke R Square \\
\hline 2 & 206.04 & 0.06 & 0.09 \\
\hline
\end{tabular}

Table 13: Forward Selection Hosmer and Lemeshow Test for Dependent Variable: Lifetime Alcohol Use

\begin{tabular}{llll}
\hline Step & Chi-square & Df & Sig \\
\hline 2 & 3.91 & 8 & 0.87 \\
\hline
\end{tabular}

Table 14: Forward Selection Classification Table for Dependent Variable: Lifetime Alcohol Use

\begin{tabular}{|c|c|c|c|}
\hline Observed & \multicolumn{2}{|c|}{ Predicted } & \\
\hline Step & No & Yes & \% Correct \\
\hline 2 & & & \\
\hline No & 20 & 42 & 32.3 \\
\hline Yes & 15 & 786 & 85.1 \\
\hline Overall \% & & & 65.0 \\
\hline
\end{tabular}

Table 15: Forward Selection, Variables in the Equation for Dependent Variable: Lifetime Alcohol Use

\begin{tabular}{lccccc}
\hline & B & SE & Wald & Odds Ratio & $95 \%$ CI \\
\hline Step 2 & & & & & \\
$\quad$ Age & 0.21 & 0.11 & 3.33 & 1.23 & $(0.99,1.53)^{*}$ \\
$\quad$ Traditional Gender Roles & -0.09 & 0.03 & 6.58 & 0.92 & $(0.86,0.98)^{* *}$ \\
\hline N/S not significant, * $p$ value $<0.1,{ }^{* *} p$ value $<0.05$. & &
\end{tabular}

Results of Hypothesis Testing (Hypothesis 2: Backward Elimination)

After performing the backward elimination procedure, the final model for outcome variable lifetime alcohol use included the following variables: country of birth and the Latino cultural values Religion and Traditional Gender Roles. The model explained $8-11 \%$ of the variation in the dependent variable (Table 16). The null 
hypothesis of the Hosmer and Lemeshow test, that the model is a good fit, was not rejected $\left(\chi^{2}=10.35 \mathrm{p}=0.24\right.$; Table 17$)$. The model correctly classified $63.8 \%$ of Latino adolescents (Table 18). Being born in the U.S. increased the risk of lifetime alcohol use (OR: 2.22; 95\% CI: 1.05, 4.68), and identifying more strongly with the cultural value Religion or Traditional Gender Roles decreased the risk of lifetime alcohol use (Religion: OR: 0.95; 95\% CI: 0.90, 1.0; Traditional Gender Roles: OR: 0.94; 95\% CI: 0.88, 1.01; Table 19). Because gender was not significant in the final model, a comparison between the reduced model and the full model was performed based on their deviance with age, Traditional Gender Roles, Religion, and country of birth entered in block 1 and gender in block 2 . The omnibus test of model coefficients revealed no significant differences between the two models $\left(\chi^{2}=0.02, \mathrm{p}=0.88\right)$.

Table 16: Backward Elimination Logistic Regression Model Summary for Dependent Variable: Lifetime Alcohol Use

\begin{tabular}{llll}
\hline Step & -2 Log likelihood & $\begin{array}{l}\text { Cox \& Snell R } \\
\text { Square }\end{array}$ & $\begin{array}{l}\text { Nagelkerke R } \\
\text { Square }\end{array}$ \\
\hline 8 & 202.41 & 0.08 & 0.11 \\
\hline
\end{tabular}

Table 17: Backward Elimination Hosmer and Lemeshow Test for Dependent Variable: Lifetime Alcohol Use

\begin{tabular}{llll}
\hline Step & Chi-square & Df & Sig \\
\hline 8 & 10.35 & 8 & 0.24 \\
\hline
\end{tabular}


Table 18: Backward Elimination Classification Table for Dependent Variable: Lifetime Alcohol Use

\begin{tabular}{|c|c|c|c|}
\hline Observed & \multicolumn{2}{|c|}{ Predicted } & \\
\hline Step & No & Yes & \% Correct \\
\hline 8 & & & \\
\hline No & 19 & 43 & 30.6 \\
\hline Yes & 16 & 85 & 84.2 \\
\hline Overall \% & & & 63.8 \\
\hline
\end{tabular}

Table 19: Backward Elimination, Variables in the Equation for Dependent Variable: Lifetime Alcohol Use

\begin{tabular}{lccccc}
\hline & B & SE & Wald & Odds Ratio & $95 \%$ CI \\
\hline $\begin{array}{l}\text { Step 8 } \\
\quad \text { Country of Birth }\end{array}$ & 0.80 & 0.38 & 4.34 & 2.22 & $(1.05,4.68)^{* *}$ \\
$\quad \begin{array}{l}\text { Religion } \\
\quad \text { Traditional Gender Roles }\end{array}$ & -0.05 & 0.03 & 3.71 & 0.95 & $(0.90,1.00)^{*}$ \\
& & 0.04 & 2.75 & 0.94 & $(0.88,1.01)^{*}$ \\
\hline N/S not significant, ${ }^{*} p$ value $<0.1, * * p$ value $<0.05$. & &
\end{tabular}

Results of Hypothesis Testing (Hypothesis 3: Forward Selection and Backward Elimination)

The forward selection and backward elimination procedures for outcome variable current marijuana led to the same final model which included the Latino cultural value Religion. The model explained $7-14 \%$ of the variation in the dependent variable (Table 20). The null hypothesis of the Hosmer and Lemeshow test, that the model is a good fit, was not rejected $\left(\chi^{2}=4.25, p=0.75\right.$; Table 21$)$. The model correctly classified $88.3 \%$ of Latino adolescents (Table 22). Identifying more strongly with the cultural value Religion decreased the risk of current marijuana use (OR: 0.90; 95\% CI: 0.84, 0.96; Table 23). Because both gender and country of birth were not significant in the final model, a a comparison between the reduced model and the full model was performed based on their 
deviance was performed with Religion in block 1 and gender and country of birth in block 2 . The omnibus test of model coefficients revealed no significant differences between the two models $\left(\chi^{2}=1.37, \mathrm{p}=0.51\right)$.

Table 20: Backward Elimination Logistic Regression Model Summary for Dependent Variable: Current Marijuana Use

\begin{tabular}{llll}
\hline Step & -2 Log likelihood & $\begin{array}{l}\text { Cox \& Snell R } \\
\text { Square }\end{array}$ & $\begin{array}{l}\text { Nagelkerke R } \\
\text { Square }\end{array}$ \\
\hline 10 & 105.66 & 0.07 & 0.14 \\
\hline
\end{tabular}

Table 21: Backward Elimination Hosmer and Lemeshow Test for Dependent Variable: Current Marijuana Use

\begin{tabular}{llll}
\hline Step & Chi-square & Df & Sig \\
\hline 10 & 4.25 & 7 & 0.75 \\
\hline
\end{tabular}

Table 22: Backward Elimination Classification Table for Dependent Variable: Current Marijuana Use

\begin{tabular}{llll}
\hline Observed & \multicolumn{3}{c}{ Predicted } \\
\hline Step & No & Yes & $\%$ Correct \\
\hline 10 & & & \\
No & 144 & 0 & 100 \\
Yes & 19 & & 0.0 \\
Overall \% & & & 88.3 \\
\hline
\end{tabular}

Table 23: Backward Elimination, Variables in the Equation for Dependent Variable: Current Marijuana Use

\begin{tabular}{lccccc}
\hline & B & SE & Wald & $\begin{array}{c}\text { Odds } \\
\text { Ratio }\end{array}$ & $95 \%$ CI \\
\hline $\begin{array}{l}\text { Step 10 } \\
\text { Religion }\end{array}$ & -0.11 & 0.03 & 11.17 & 0.90 & $(0.84,0.96)^{* *}$ \\
\hline
\end{tabular}

N/S not significant, ${ }^{*} p$ value $<0.1,{ }^{* *} p$ value $<0.05$. 
Results of Hypothesis Testing (Hypothesis 4: Forward Selection and Backward Elimination)

The final models of forward selection and backward elimination procedures for outcome variable lifetime marijuana use led to the same final model which included the cultural values Religion and Independence and Self-Reliance. The model explained 8$11 \%$ of the variation in the dependent variable (Table 24$)$. The null hypothesis of the Hosmer and Lemeshow test, that the model is a good fit, was not rejected $\left(\chi^{2}=3.04, p=\right.$ 0.93; Table 25). The model correctly classified $74.7 \%$ of Latino adolescents (Table 26). Identifying more strongly with the cultural value Religion decreased the risk of current marijuana use (OR: 0.93; 95\% CI: 0.88, 0.98; Table 27). Identifying more strongly with the cultural value Independence and Self-Reliance increased the risk of current marijuana use (OR: 1.15; 95\% CI: 1.02, 1.30; Table 27). Because both gender and country of birth were not significant in the final model, a comparison between the reduced model and the full model was performed based on their deviance with Independence and Self Reliance and Religion in block 1 and gender and country of birth in block 2 . The omnibus test of model coefficients revealed no significant differences between the two models $\left(\chi^{2}=0.19\right.$, $\mathrm{p}=0.91)$

Table 24: Backward Elimination Logistic Regression Model Summary for Dependent Variable: Lifetime Marijuana Use

\begin{tabular}{llll}
\hline Step & -2 Log likelihood & $\begin{array}{l}\text { Cox \& Snell R } \\
\text { Square }\end{array}$ & $\begin{array}{l}\text { Nagelkerke R } \\
\text { Square }\end{array}$ \\
\hline 9 & 178.61 & 0.08 & 0.11 \\
\hline
\end{tabular}


Table 25: Backward Elimination Hosmer and Lemeshow Test for Dependent Variable: Lifetime Marijuana Use

\begin{tabular}{llll}
\hline Step & Chi-square & Df & Sig \\
\hline 9 & 3.04 & 8 & 0.93 \\
\hline
\end{tabular}

Table 26: Backward Elimination Classification Table for Dependent Variable: Lifetime Marijuana Use

\begin{tabular}{|c|c|c|c|}
\hline Observed & \multicolumn{2}{|c|}{ Predicted } & \\
\hline Step & No & Yes & $\%$ Correct \\
\hline \multicolumn{4}{|l|}{9} \\
\hline No & 114 & 3 & 97.4 \\
\hline Yes & 38 & 7 & 15.6 \\
\hline Overall \% & & & 74.7 \\
\hline
\end{tabular}

Table 27: Backward Elimination, Variables in the Equation for Dependent Variable: Lifetime Marijuana Use

\begin{tabular}{lccccc}
\hline & B & SE & Wald & Odds Ratio & $95 \%$ CI \\
\hline $\begin{array}{l}\text { Step 9 } \\
\quad \text { Religion }\end{array}$ & -0.07 & 0.03 & 8.63 & 0.93 & $(0.88,0.98)^{* *}$ \\
$\quad \begin{array}{l}\text { Independence and Self- } \\
\quad \text { Reliance }\end{array}$ & 1.14 & 0.06 & 4.87 & 1.15 & $(1.02,1.30)^{* *}$ \\
\hline N/S not significant, ${ }^{*} p$ value $<0.1, * * p$ value $<0.05$. & & &
\end{tabular}

Results of Hypothesis Testing (Hypothesis 5)

There were no significant associations between current alcohol use and perception of friends' age or sex (Tables 28-30). Associations between current alcohol use and perception of having Latino friends could not be tested because only one participant reported that none of their closest friends are Latino. 
Table 28: Associations between Latino Adolescents' Current Alcohol Use and Reporting Friends with same Gender, Miami-Dade County, Florida 2016-2017

\begin{tabular}{lccccc}
\hline & B & SE & Wald & Odds Ratio & $95 \%$ CI \\
\hline Opposite sex $^{\mathrm{a}}$ & 1.99 & 1.24 & 2.58 & 7.32 & $(0.65,82.86) \mathrm{N} / \mathrm{S}$ \\
\hline N/S not significant, ${ }^{*} p$ value $<0.1, * *$ & $p$ value $<0.05$.
\end{tabular}

${ }^{a}$ Opposite sex: How many of your closes friends are the same gender as you?

Table 29: Associations between Latino Adolescents' Current Alcohol Use and Having Younger Friends, Miami-Dade County, Florida 2016-2017

\begin{tabular}{lccccc}
\hline & B & SE & Wald & Odds Ratio & $95 \%$ CI \\
\hline Younger $^{\mathrm{a}}$ & 0.18 & 0.41 & 0.20 & 1.20 & $(0.54,2.68) \mathrm{N} / \mathrm{S}$ \\
\hline $\begin{array}{l}\text { N/S not significant, }{ }^{*} p \text { value }<0.1, * * \\
\text { a }\end{array}$ value $<0.05$. \\
${ }^{\mathrm{a}}$ Younger: How many of your closes friends are younger that you?
\end{tabular}

Table 30: Associations between Latino Adolescents' Current Alcohol Use and Having Older Friends, Miami-Dade County, Florida 2016-2017

\begin{tabular}{lccccc}
\hline B & SE & Wald & Odds Ratio & $95 \%$ CI \\
\hline Older $^{\text {a }}$ & -0.64 & 0.78 & 0.68 & 0.52 & $(0.11,2.44) \mathrm{N} / \mathrm{S}$ \\
\hline N/S not significant, ${ }^{*} p$ value & $<0.1, * *$ & $p$ value $<0.05$. \\
a Older: How many of your closest friends are older than you? &
\end{tabular}

Results of Hypothesis Testing (Hypothesis 6)

There were no significant associations between current marijuana use and perception of friends' age or sex (Tables 31-33). Associations between current marijuana use and perception of having Latino friends could not be tested because only one participant reported that none of their closest friends are Latino. 
Table 31: Associations between Latino Adolescents' Current Marijuana Use and Reporting Friends with same Gender, Miami-Dade County, Florida 2016-2017

\begin{tabular}{lccccc}
\hline & B & SE & Wald & Odds Ratio & $95 \%$ CI \\
\hline${\text { Opposite } \operatorname{sex}^{\mathrm{a}}}^{1.37}$ & $\begin{array}{c}1.2 \\
5\end{array}$ & 1.21 & 3.95 & $(0.34,45.55) \mathrm{N} / \mathrm{S}$ \\
\hline
\end{tabular}

N/S not significant, ${ }^{*} p$ value $<0.1,{ }^{*} * p$ value $<0.05$.

${ }^{a}$ Opposite sex: How many of your closes friends are the same gender as you?

Table 32: Associations between Latino Adolescents' Current Marijuana Use and Having Younger Friends, Miami-Dade County, Florida 2016-2017

\begin{tabular}{|c|c|c|c|c|c|}
\hline & $\mathrm{B}$ & $\mathrm{SE}$ & Wald & Odds Ratio & $95 \% \mathrm{CI}$ \\
\hline Younger $^{\mathrm{a}}$ & 0.05 & 0.55 & 0.01 & 0.93 & $(0.36,3.11) \mathrm{N} / \mathrm{S}$ \\
\hline
\end{tabular}

Table 33: Associations between Latino Adolescents' Current Marijuana Use and Having Older Friends, Miami-Dade County, Florida 2016-2017

\begin{tabular}{cccccc}
\hline & B & SE & Wald & Odds Ratio & $95 \%$ CI \\
\hline Older $^{\text {a }}$ & 0.19 & 0.80 & 0.06 & 1.21 & $(0.25,5.81) \mathrm{N} / \mathrm{S}$ \\
\hline
\end{tabular}

$\mathrm{N} / \mathrm{S}$ not significant, $* p$ value $<0.1, * * p$ value $<0.05$.

${ }^{\mathrm{a}}$ Older: How many of your closest friends are older than you?

Results of Hypothesis Testing (Hypothesis 7)

Participants who reported having no close friends who use alcohol were less likely to currently (within past 30 days) use alcohol themselves when compared to participants who reported having at least one close friend who uses alcohol (OR: 0.21; CI: 0.08, 0.53; Table 34). The interaction between friends not using alcohol and participation in sports activities was significant (Table 35). The interaction between friends not using alcohol and participation in after-school activities or volunteer activities were not significant (Table 36 and 37). 
Table 34: Associations between Latino Adolescents' Current Alcohol Use and their Perception of Friends' Alcohol Use, Miami-Dade County, Florida 2016-2017

\begin{tabular}{cccccc}
\hline & B & SE & Wald & Odds Ratio & $95 \%$ CI \\
\hline Friends don't use alcohol $^{\mathrm{a}}$ & -1.58 & 0.48 & 10.88 & 0.21 & $(0.08,0.53)^{* *}$ \\
\hline
\end{tabular}

N/S not significant, ${ }^{*} p$ value $<0.1, * * p$ value $<0.05$.

${ }^{\mathrm{a}}$ Friends don't use alcohol: How many of your closest friends drink alcohol?

Table 35: Assessment of Interaction between Perception of Friends' Alcohol Use and Participation in School Sports on Dependent Variable Current Alcohol Use, Miami-Dade County, Florida 2016-2017

\begin{tabular}{lccccc}
\hline & B & SE & Wald & Odds Ratio & 95\% CI \\
\hline $\begin{array}{l}\text { Friends don't use } \\
\text { alcohol }^{\mathrm{a}}\end{array}$ & 0.17 & 0.74 & 0.05 & 1.19 & $(0.28,5.10) \mathrm{N} / \mathrm{S}$ \\
School sports $^{\mathrm{b}}$ & -1.36 & 0.91 & 2.23 & 0.26 & $(0.04,1.53) \mathrm{N} / \mathrm{S}$ \\
$\begin{array}{l}\text { Friends don't use alcohol } \\
\text { x School sports }\end{array}$ & 2.20 & 1.07 & 4.25 & 9.06 & $(1.11,73.62)^{* *}$ \\
\hline
\end{tabular}

N/S not significant, $* p$ value $<0.1, * * p$ value $<0.05$.

${ }^{a}$ Friends don't use alcohol: How many of your closest friends drink alcohol?

${ }^{\mathrm{b}}$ School sports: Responses to participating in school sports were binary (yes no)

Table 36: Assessment of Interaction between Perception of Friends' Alcohol Use and Participation in After-school Activities on Dependent Variable Current Alcohol Use, Miami-Dade County, Florida 2016-2017

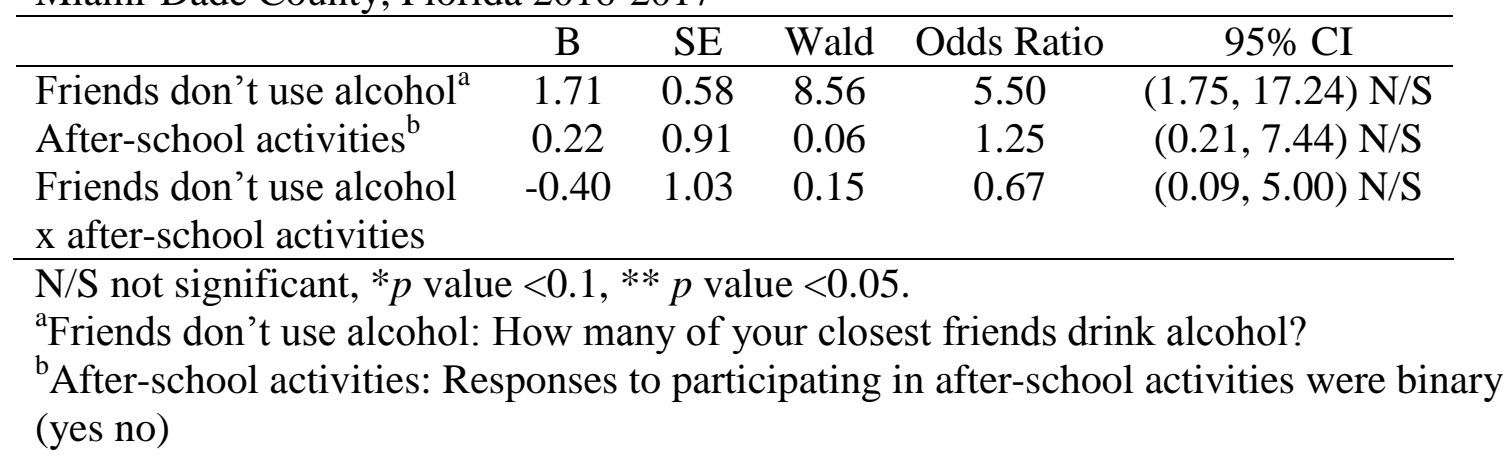


Table 37: Assessment of Interaction between Perception of Friends' Alcohol Use and Participation in Volunteer Activities on Dependent Variable Current Alcohol Use, Miami-Dade County, Florida 2016-2017

\begin{tabular}{lccccc}
\hline & $\mathrm{B}$ & $\mathrm{SE}$ & Wald & Odds Ratio & $95 \% \mathrm{CI}$ \\
\hline $\begin{array}{l}\text { Friends don't use } \\
\text { alcohol }^{\mathrm{a}}\end{array}$ & 1.17 & 0.50 & 5.49 & 3.21 & $(1.21,8.54,--)^{*}$ \\
Volunteer activities $^{\mathrm{b}}$ & -19.19 & 9748.23 & 0.00 & 0.00 & $(0.00,--) \mathrm{N} / \mathrm{S}$ \\
$\begin{array}{l}\text { Friends don't use alcohol } \\
\text { x volunteer activities }\end{array}$ & 19.68 & 9748.23 & 0.00 & & $(0.00,--) \mathrm{N} / \mathrm{S}$ \\
\hline
\end{tabular}

N/S not significant, ${ }^{*} p$ value $<0.1, * * p$ value $<0.05$.

${ }^{a}$ Friends don't use alcohol: How many of your closest friends drink alcohol?

${ }^{\mathrm{b}}$ Volunteer activities: Responses to participating in volunteer activities were binary (yes no)

Results of Hypothesis Testing (Hypothesis 8)

Participants who reported having no close friends who use marijuana were less likely to currently (within past 30 days) use marijuana themselves when compared to participants who reported having at least one close friend who uses marijuana (OR: 0.04;

CI: 0.01, 0.28; Table 38). The interactions between recreational activities (i.e., volunteer, sports participation, after-school) and perception of friends' marijuana use were not testable due to sample size restrictions (Tables 39-41).

Table 38: Associations between Latino Adolescents' Current Marijuana Use and their Perception of Friends' Marijuana Use, Miami-Dade County, Florida 2016-2017

\begin{tabular}{lccccc}
\hline & B & SE & Wald & Odds Ratio & $95 \%$ CI \\
\hline Friends don't use marijuana $^{\mathrm{a}}$ & -3.32 & 1.04 & 10.16 & 0.04 & $(0.01,0.28)^{* *}$ \\
\hline N/S not significant, $* p$ value $^{*}<0.1, * * p$ value & $<0.05$ & & &
\end{tabular}
N/S not significant, ${ }^{*} p$ value $<0.1, * * p$ value $<0.05$.

${ }^{\mathrm{a}}$ Friends don't use marijuana: How many of your closest friends use marijuana? 
Table 39: Assessment of Interaction between Perception of Friends' Marijuana Use and Participation in Sports Activities on Dependent Variable Current Marijuana Use, MiamiDade County, Florida 2016-2017

\begin{tabular}{lccccc}
\hline & B & SE & Wald & Odds Ratio & $95 \%$ CI \\
\hline $\begin{array}{l}\text { Friends don't use } \\
\text { marijuana }^{\mathrm{a}}\end{array}$ & 0.00 & 12230.33 & 0.00 & 1.00 & $(0.00,--) \mathrm{N} / \mathrm{S}$ \\
$\begin{array}{l}\text { School sports } \\
\text { Friends don't use }\end{array}$ & 17.23 & 7735.14 & 0.00 & 30480652.22 & $(0.00,--) \mathrm{N} / \mathrm{S}$ \\
marijuana x school sports & 3.25 & 12230.33 & 0.00 & 25.74 & $(0.00,--) \mathrm{N} / \mathrm{S}$ \\
\hline
\end{tabular}

N/S not significant, $* p$ value $<0.1, * * p$ value $<0.05$.

${ }^{\mathrm{a}}$ Friends don't use marijuana: How many of your closest friends use marijuana?

${ }^{\mathrm{b}}$ School sports: Responses to participating in school sports were binary (yes no)

Table 40: Assessment of Interaction between Perception of Friends' Marijuana Use and Participation in After-school Activities on Dependent Variable Current Marijuana Use, Miami-Dade County, Florida 2016-2017

\begin{tabular}{lccccc}
\hline & B & SE & Wald & Odds Ratio & $95 \%$ CI \\
\hline $\begin{array}{l}\text { Friends don't use } \\
\text { marijuana }^{\text {a }}\end{array}$ & 2.79 & 1.06 & 6.85 & 16.23 & $(0.82,25.88)^{* *}$ \\
$\begin{array}{l}\text { After-school activities } \\
\text { Friends don't use }\end{array}$ & -17.13 & 7735.14 & 0.00 & 0.00 & $(0.00,--)$ N/S \\
$\begin{array}{l}\text { marijuana x after-school } \\
\text { activities }\end{array}$ & 17.59 & 7735.14 & 0.00 & 43560569.07 & $(0.00,--)$ N/S \\
\hline
\end{tabular}

N/S not significant, $* p$ value $<0.1, * * p$ value $<0.05$.

${ }^{a}$ Friends don't use marijuana: How many of your closest friends use marijuana?

${ }^{\mathrm{b}}$ After-school activities: Responses to participating in after-school activities were binary (yes no) 
Table 41: Assessment of Interaction between Perception of Friends' Marijuana Use and Participation in Volunteer Activities on Dependent Variable Current Marijuana Use, Miami-Dade County, Florida 2016-2017

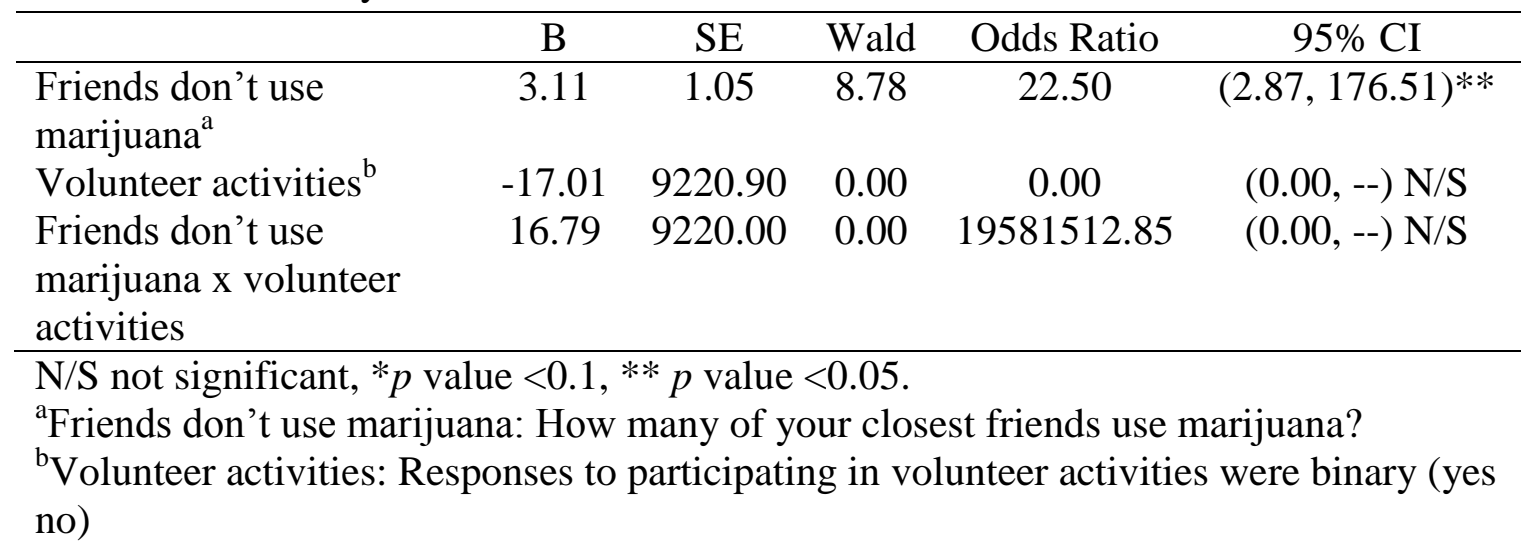

Summary of Major Findings of Hypothesis Testing

Being born in the U.S. increased the risk of current alcohol use. Identifying more strongly with the cultural value Religion decreased the risk of current alcohol use. Reporting a higher socioeconomic status increased the risk of current alcohol use (OR: 2.90; 95\% CI: 0.89, 0.99). Using the forward selection technique of multiple regression, being older increased the risk of lifetime alcohol use and identifying more strongly with the cultural value Traditional Gender Roles decreased the risk of lifetime alcohol use. With the backward elimination technique, findings revealed that being born in the U.S. increased the risk of lifetime alcohol use and identifying more strongly with the cultural value Religion or Traditional Gender Roles decreased risk of current alcohol use.

Identifying more strongly with the cultural value Religion decreased the risk of current marijuana use. Identifying more strongly with the cultural value Religion decreased risk of lifetime marijuana use. Identifying more strongly with the cultural value Independence and Self-Reliance increased risk of lifetime marijuana use. 
There were no significant associations between current alcohol or marijuana use and perception of friends' age or sex. Associations between current alcohol or marijuana use and perception of having Latino friends could not be tested because only one participant reported that none of their closest friends are Latino.

Participants who reported having no close friends who use alcohol were less likely to currently (within past 30 days) use alcohol themselves when compared to participants who reported having at least one close friend who uses alcohol. The interaction between participation in sports activities and reporting having friends who use alcohol on the dependent variable currently using alcohol was significant. Neither afterschool activities nor volunteer activities significantly moderated the association between current alcohol use with perception of friends' alcohol use.

Participants who reported having no close friends who use marijuana were less likely to currently (within past 30 days) use marijuana themselves when compared to participants who reported having at least one close friend who uses marijuana. It was not possible to test the interactions between recreational activities (i.e., volunteer, sports participation, after-school) and perception of friends' marijuana use due to sample size restriction.

\section{Summary of Chapter IV}

Chapter IV presented the findings of the present dissertation project. One hundred ninety-three adolescents (females: $55.4 \%$; mean age: $15.7 \pm 1.6$ years old) participated in the study. Most participants reported having at least one friend who drinks alcohol 
(63.7\%), and at least one friend who uses marijuana (54.9\%). More than half of the participants $(n=120 ; 62.2 \%)$ reported that they have participated in school sports.

Most (59.9\%) participants have used alcohol in their lifetime; among those, $36.5 \%$ have used alcohol in the past 30 days. About one-fourth (28.3\%) of participants have used marijuana, $42.6 \%$ of whom used marijuana in the past 30 days.

Participants who reported that at least one of their closest friend's drinks alcohol or uses marijuana were more likely, within the past 30 days, to have used alcohol or marijuana themselves, respectively. There was an interaction effect between perception of friends drinking alcohol and sports participation with current alcohol use. Participation in after-school activities or volunteer activities did not moderate the association between current alcohol use and perception of friends' alcohol use. Recreational activities (i.e., volunteer activities, sports participation, after-school) as a potential moderator for the association between current marijuana use with perception of friends' marijuana use was not significant. 


\section{CHAPTER V: DISCUSSION/CONCLUSIONS AND FUTURE RESEARCH}

Since the seminal studies on alcohol and marijuana use among Latino adolescents in Miami-Dade County, Florida were conducted in the early 1990s, there have not been many studies on the topic that focus on Latino adolescents living in this county (Vega et

al., 1993b; Vega et al., 1993c; Vega et al.,1993a). The present dissertation expanded upon the seminal work, contributing to the current body of literature. More than 20 years have passed since these seminal studies and the Latino and general population in Miami-Dade County have changed over the years (Miami-Dade County Department of Planning and Zoning, 2009). Accordingly, it was important to conduct a study to investigate factors which play a role in present day alcohol and marijuana use among Latino adolescents in Miami-Dade County, Florida (Miami-Dade County Department of Planning and Zoning, 2009). In addition, the present dissertation project made new contributions to the literature by (a) exploring the role of recreational activities, a potentially modifiable factor, on alcohol and marijuana use among Latino adolescents, (b) exploring differences regarding alcohol and marijuana use between male and female Latino adolescents in Miami-Dade County, and (c) exploring the role of an in depth (37-item) Latino cultural values scale in Latino adolescent substance (alcohol and marijuana) use (Knight et al., 2010).

The purpose of this chapter is to summarize the findings of the dissertation and provide explanations for the findings with respect to previous literature including the seminal studies. Theoretical implications, practice implications, future research directions, and conclusions are also presented in this chapter. 
Characteristics of the Sample

This study tested hypotheses related to alcohol and marijuana use among a diverse at-risk population: Latino adolescents in Miami-Dade County, Florida. Unlike most of the Latino population living in the U.S., who are primarily of Mexican (65\%) origin, most Latinos living in Miami-Dade County, Florida, are of Cuban origin $52.7 \%$ of Latino population/34.3\% of total population), followed by Colombian origin (4.6\% of Latino population; U.S. Census Bureau, 2011). In the present sample, 65 participants were born outside of the United States. Among those, the most frequently reported countries of birth were Honduras $(n=17)$, Venezuela $(n=13)$, and Cuba $(n=10)$. This diversity represents the unique Latino population in Miami-Dade County, Florida that is unlike any other county in the U.S. As such, the present dissertation project is unique given that most studies of Latino substance abuse, since the seminal studies, have focused on Mexican and Puerto Rican populations (Acosta et al., 2015; Roditis et al., 2016; Bacio et al., 2013).

About half of participants (50.8\%) reported that at least one of their closest friend's drinks alcohol, and $38.4 \%$ of participants reported at least one of their closest friends uses marijuana. This is an important finding given that previous studies (Schofield et al., 2015; Acosta et al., 2015), and the present dissertation, have shown that adolescents who perceive their friends to be using substances are more likely to be using substances themselves. Future alcohol and marijuana prevention intervention studies should consider group-based alcohol interventions using snowball sampling in which high risk adolescents recruit their high-risk friends to participate in the intervention. 
Most participants $(n=135 ; 69.9 \%)$ reported participating in at least one type of recreational activity (i.e., sports participation, after-school activities, volunteer activities). Therefore, given their social nature and high prevalence within this sample, recreational activities may play a role in alcohol and marijuana use among Latino adolescents, but this has not been thoroughly explored in the literature. Of note, according to the YRBS, 48.5\% (CI: 46.1-50.9) of Latino high school students play on at least one sports team (run by their school or community group) whereas $62.2 \%$ of the present Latino sample reported participating in sports activities. (Kann et al., 2016). This discrepancy may be due to details of questions asked to participants. Specifically, the present study asked separate questions about participation in school sports versus participation in after-school activities or programs (not related to school) which may have included league sports for example. In contrast, the YRBS did not differentiate between school sports and afterschool activities. In addition, differences in Latino subpopulations between the present study (mostly Honduran, Venezuelan, Cuban) and nationally representative studies such as the YRBS (mostly Mexican) may explain differences in study findings.

Alcohol and Marijuana Use Behaviors

The finding that more than half (59.9\%) of participants have used alcohol in their lifetime is higher than the Florida Department of Children and Families data, which revealed that $52.0 \%$ of male and female adolescents in Florida aged 15-17 years old have used alcohol at least once during their lifetime (Florida Department of Children \& Families, 2016). Among the participants in this dissertation who have ever used alcohol, $36.5 \%$ reported using alcohol within the past 30 days. Importantly, for the $63.5 \%$ of 
participants who have not used alcohol within the past 30 days, it is not known how many times alcohol has been used in total during the entire lifespan. Nonetheless, the large percentage of adolescents in the present study who reported using alcohol is quite concerning considering that, according to the National Institute on Alcohol Abuse and Alcoholism (NIAAA), youth who begin drinking before age 15 are four times more likely to develop alcohol dependence at some time in their lives compared with those who begin at age 20 or older (Grant \& Dawson, 1997; NIAAA, 2003).

In one of the early seminal studies among sixth and seventh grade adolescents (n $=6,760$ ) by Vega et al. (1993a), findings revealed a prevalence of lifetime alcohol use of 41.3\% among Cuban and 31.2\% among other Hispanic males. A higher percentage of lifetime alcohol use was found among males (52.9\%) and females (65.4\%) in the present dissertation study. However, the sample in the present study were older and comprised a larger age span then the previous work. In addition, the present study was conducted approximately 25 years after the seminal study and the sample was comprised of a diverse group of Latinos, not only Cubans. Another strength of the present study was the inclusion of both males and females and hence the ability to compare alcohol use among sexes.

More than one-fourth (28.3\%) of the present dissertation's participants have used marijuana — higher than findings based on Florida Department of Children and Families data, which show that marijuana use at least once during their lifetime was reported by 26.3\% of male and female adolescents aged 15-17 years old (Florida Department of Children \& Families, 2016). Perhaps the percentage in the present study is higher due to the larger age range defined by the inclusion criteria which allowed older adolescents to 
participate in the study. Among those who have ever used marijuana, $42.6 \%$ reported using marijuana within the past 30 days. Among the $57.4 \%$ of participants who have not used marijuana within the past 30 days, it is not known how many times marijuana has been used during the entire lifespan. Of note, smoking marijuana before age 18 years old is a health hazard which can lead to cognitive impairments (Becker, Collins, \& Luciana, 2014).

In this dissertation, $12.9 \%$ and $11.2 \%$ of males and females, respectively, reported current marijuana use (past 30 days) and there were no significant differences between the sexes, which is consistent with the YRBS (Kann et al., 2016). According to the YRBS, Latino male and female high school students report the same (no significant difference) prevalence of ever using marijuana (males: 46.0\%, CI: 42.4-49.8; females: 45.3\%, CI: 41.7-48.9) and current marijuana use (past 30 days; males: 25.5\%, CI: 22.728.6; females: 23.5\%, CI: 19.7-27.7; Kann et al., 2016). The much lower reported percentage of marijuana use in the present dissertation study may be due to the unique subpopulations of Latinos who live in Miami-Dade County, Florida which is much different from the Latinos throughout the rest of the U.S. The high stigmatizing attitude associated with marijuana use and drug addiction among Latinos may also play a role, and stigmatizing attitudes may differ between Latino subpopulations (Florez et al., 2015; Kulesza et al., 2016). It is possible that the diverse Latino population in Miami-Dade County has stronger stigmatizing attitudes toward marijuana use as compared to Latinos throughout the rest of the U.S. In addition, the present study included participants as young as 13 years old whereas the YRBS is comprised of only high school students. In a 2006 paper by Warner et al., a review was conducted of the epidemiology of illicit drug 
use and drug use disorders among Latinos in the U.S. Findings revealed that there were non-significant differences regarding illicit drug use between Latino adolescent boys versus girls (12-17 years old). Accordingly, the present dissertation study confirms that there are no differences in marijuana use between Latino adolescent boys and girls. Future studies with larger sample sizes should compare lifetime and current alcohol and marijuana use between boys and girls by country of birth and developmental age ranges (i.e., 13-15 years old and 16-18 years old).

The following discussion sections explore the factors found to be associated with Latino adolescent alcohol and marijuana use in the present dissertation study, seeking to fill gaps in the current body of literature.

\section{Discussion of Hypothesis 1 Findings}

It was hypothesized, among Latino adolescents, that there would be an association between current alcohol use (past 30 days) and the adolescents' sex, age, country of birth, GPA, family's socio-economic status, living with both parents, mother's highest level of education, father's highest level of education, and the following Latino cultural values: Familism Support, Familism Obligations, Familism Referents, Respect, Religion, Traditional Gender Roles, Independence and Self-Reliance. Being born in the U.S. increased the risk of current alcohol use. This is similar to the finding of one of the seminal studies on adolescent boys in which foreign-born Cuban-American students had significantly lower levels of lifetime alcohol use than U.S.-born students (Vega et al., 1993c). Higher rates of alcohol use among U.S. born adolescents was also found in the seminal study among Latino adolescent boys (Gil, Wagner, \& Vega, 2000). In the 2006 
review paper on drug use among Hispanics, Warner et al. also noted that being born in the U.S. has consistently been associated with higher rates of experimental drug use. In a more recent study of Cuban, Mexican, and Puerto Rican adolescents in the U.S., the authors revealed that U.S.-born adolescents have higher rates of alcohol use (Bacio et al., 2013). The present dissertation study expanded upon the seminal work and the more recent work by including a more diverse sample of Latino adolescents.

For the present sample of Latino adolescents in Miami-Dade County, only one Latino cultural value/subscale was protective against current alcohol use: Religion. The protective effect of religion has also been noted in other recent studies of adolescents and college students (Escobar \& Vaughan, 2014; Jankowski et al., 2015). Interestingly, in contrast with the seminal studies and more recent studies among Mexican and Puerto Rican adolescents, Familism is a protective factor against alcohol use among adolescents (Gil, Wagner, \& Vega, 2000; Lac et al., 2011; Prado et al., 2009; Santisteban, Coatsworth, Briones, Kurtines, \& Szapocznik, 2012). However, this was not shown in the present dissertation study. One potential explanation for this finding is the unknown generational status of the U.S.-born adolescent and the unknown age of migration to the U.S. of the non-U.S. born adolescents. In the present dissertation, it is possible that most U.S.-born adolescents were fourth or fifth generation Americans, for example. In addition, the non-U.S. born adolescents may have immigrated to the U.S. at very young ages. In the future, researchers should explore whether generational status plays a moderating role for the associations between country of birth and Familism using structural equation modeling. In addition, due to multicollinearity among the three Familism subscales (Familism Support, Familism Obligations, Familism Referents), 
these three subscales were combined into one composite variable: Familism. In the future, to reduce the possible dilution effect of combining three subscales, investigators should conduct studies with larger sample sizes so the Familism subscales could be analyzed separately. Moreover, using factor analysis, researchers should analyze whether specific items within each Familism subscale play a role in alcohol and marijuana use among Latino adolescents in Miami-Dade County.

Reporting a higher socioeconomic status (i.e., rich) increased the risk of current alcohol use. This finding is different from a recent systematic review that investigated associations between adolescent alcohol use and several measures of socioeconomic status (e.g., parents' education) and found that the majority of studies showed no relationship between socioeconomic status and alcohol use (Kwok \& Yuan, 2016). However, the present study was unique in that it was the first to investigate the role of socioeconomic status on alcohol use among a diverse group of Latino adolescents.

The role of living with both parents versus just one or none has not been explored in the Latino adolescent social science literature. However, some studies have shown that parental divorce increases an adolescent's risk for alcohol use (Waldron et al., 2014; Jackson et al., 2016a; McCutcheon et al., 2017; Allem et al., 2015). Hence, it was expected that living with one or neither parent would also be associated with a greater risk for current alcohol use. However, this was not the case in the present study. Perhaps this was a result of parents never having been married and therefore never getting divorced. If this is the case, then the adolescents who reported not living with both parents may not suffer the adverse health effects that have been demonstrated among adolescents who have experienced a parental divorce. Moreover, it is possible that 
participants in the present study lived with other positive male and female role models such as older siblings or grandparents, and this in turn promoted more positive wellbeing among the participants. Future studies should explore whether other persons such as stepparents play a protective role against alcohol and marijuana use among Latino adolescents in Miami-Dade County. Through the influence of familial factors and the role of Familismo, other persons such as step-parents may play a role in alcohol and marijuana use among Latino adolescents (Gil, Wagner, \& Vega, 2000; Lac et al., 2011; Prado et al., 2009; Santisteban, Coatsworth, Briones, Kurtines, \& Szapocznik, 2012). Additional quantitative studies with larger sample sizes are needed to determine the roles of living with one step parent and one biological parent versus both or one or neither biological parent(s). Future qualitative studies should further explore the role of family living situation on substance use among Latino adolescents in Miami-Dade County. The role of living with other immediate and extended family members should also be explored in future studies.

A strength of this dissertation study was the ability to compare current alcohol use between boys and girls. Interestingly, current alcohol use was similar (no significant difference) between boys and girls. In addition, there were no significant differences in deviance between the reduced model (country of birth, socioeconomic status, Religion) and the full model (country of birth, socioeconomic status, Religion, sex).

Discussion of Hypothesis 2 Findings

Hypothesis 2 stated that among Latino adolescents, there is an association between lifetime alcohol use (past 30 days) and the adolescents' sex, age, country of 
birth, GPA, family's socio-economic status, living with both parents, mother's highest level of education, father's highest level of education, and the following Latino cultural values: Familism Support, Familism Obligations, Familism Referents, Respect, Religion, Traditional Gender Roles, Independence and Self-Reliance.

When forward selection was performed, being older increased the risk of lifetime alcohol use. This finding was expected given the older one becomes, the more likely it is that an individual has consumed alcohol at least one time. Identifying more strongly with the cultural value Traditional Gender Roles decreased risk of lifetime alcohol use. Future studies should explore underlying mechanisms for this significant finding.

When backward elimination was used, being born in the U.S. increased the risk of lifetime alcohol use. This finding is similar to that of the seminal study on adolescent boys in which foreign-born Cuban-American students were shown to have significantly lower levels of lifetime alcohol use than U.S.-born students (Vega et al., 1993c). More recent studies have also shown Latino adolescents who are more acculturated to U.S. culture and who are born in the U.S. generally have higher rates of substance use when compared to those who are less acculturated and foreign born, respectively (CarltonSmith \& Skeer, 2015; Unger et al., 2014).

Identifying more strongly with the cultural value Religion or Traditional Gender Roles decreased risk of lifetime alcohol use. Religion has been shown to serve as a protective factor against alcohol use in other studies of adolescents and college students (Escobar \& Vaughan, 2014; Jankowski et al., 2015). The role of the Latino cultural value Traditional Gender Roles on alcohol use among adolescents has not yet been explored in 
the literature. Therefore, this finding makes a significant contribution to the literature and should be explored further in future studies.

There was no significant difference between boys and girls for the dependent variable lifetime alcohol use. Furthermore, when the test of differences in deviance between the reduced model (age, country of birth, Traditional Gender Roles, Religion) and the full model (age, country of birth, Traditional Gender Roles, Religion, sex) was performed, there were no significant differences between the models.

Discussion of Hypothesis 3 Findings

Hypothesis 3 predicted that among Latino adolescents, there is an association between current marijuana use (past 30 days) and the adolescents' sex, age, country of birth, GPA, family's socio-economic status, living with both parents, mother's highest level of education, father's highest level of education, and the following Latino cultural values: Familism Support, Familism Obligations, Familism Referents, Respect, Religion, Traditional Gender Roles, Independence and Self-Reliance.

Identifying more strongly with the cultural value Religion decreased risk of current marijuana use. This is in accordance with other studies on adolescents, which have shown inverse relationships between marijuana use and religiosity (Miller, Davies, \& Greenwald, 2000; Hodge, Cardena, \& Montoya, 2001). It is plausible that the adolescents who participated in the present dissertation have formed positive social networks around religion (e.g., at church) and the members of these social networks discourse marijuana use among members of the network. It is also possible that 
participating in religion-based activities keeps adolescents busy, so they do not have time or inclination to smoke marijuana.

A strength of this dissertation study was the ability to compare current marijuana use between sexes, but findings revealed no such significant differences. Moreover, when the test of differences in deviance between the reduced model (Religion) and the full model (country of birth, Religion, sex) was performed, there were no significant differences between the models.

Discussion of Hypothesis 4 Findings

Hypothesis 4 postulated that among Latino adolescents, there would be an association between lifetime marijuana use (past 30 days) and the adolescents' sex, age, country of birth, GPA, family's socio-economic status, living with both parents, mother's highest level of education, father's highest level of education, and the following Latino cultural values: Familism Support, Familism Obligations, Familism Referents, Respect, Religion, Traditional Gender Roles, Independence and Self-Reliance.

In addition to the protective role of the cultural value Religion on marijuana use (both current and lifetime), the cultural value Independence and Self-Reliance also played a role on lifetime marijuana use among Latino adolescents. Identifying more strongly with this value increased risk of lifetime marijuana use. A literature search of marijuana use among Latino adolescents did not reveal any studies on the role of the Latino cultural value Independence and Self-Reliance on marijuana use. This subscale, composed of five questions (i.e., As children get older their parents should allow them to make their own decisions.), has not yet been tested with a diverse Latino adolescent sample. However, 
due to the high stigmatizing attitude associated with marijuana use and drug addiction among Latinos, it is not surprising that the Latino adolescents who identified more strongly with being independent and self-reliant, a value that is not traditionally of high value in Latino culture, would be at increased risk of lifetime marijuana use (Florez et al., 2015; Kulesza et al., 2016).

There was no difference in reported lifetime marijuana use between boys and girls, and the test of differences in deviance between the reduced model (Religion, Independence and Self-Reliance) and the full model (Religion, Independence and SelfReliance, sex, country of birth) revealed no significant differences between the models.

Discussion of Hypothesis 5 Findings

Because there were no associations between current alcohol use and perception of friends' age or sex, it was not possible to test Hypothesis 5, which postulated that recreational activities would moderate the association between friends' age, sex, or ethnicity and current alcohol use. It was thought that Latino adolescents with older or younger friends may be more or less likely to use alcohol, and if this were the case, specific peer-to-peer interventions could be suggested for alcohol use prevention programs among Latino adolescents. However, this was not the case for the present sample of Latino adolescents. Nonetheless, this was the first study of Latino adolescents to assess associations between perception of friends' age and current alcohol use and hence fills an important gap in the current body of scientific literature.

Because previous studies have demonstrated differences regarding alcohol use prevalence between male and female adolescents (Kann et al., 2016), there may be 
differences in alcohol use among Latinos who have more male or female friends.

However, this was tested in the present study and it was not demonstrated to be the case. Nonetheless, no other study has assessed this association among Latino adolescents and, hence, an important gap in the literature has been filled by this dissertation.

The association between current alcohol use and ethnicity could not be tested due to the small number of participants $(n=1)$ who reported none of their closest friends being Latino. However, before the dissertation was conducted, it seemed plausible that Latinos who primarily associate with other Latinos may be less likely to use alcohol, because associating mostly with Latinos could slow down the U.S. acculturation process and less (U.S.) acculturated Latinos are less likely to use alcohol (Carlton-Smith \& Skeer, 2015; DiBello et al., 2015; Unger et al., 2014; Schwartz et al., 2011). However, it is also possible that Latinos who primarily interact with other Latinos may be more likely to use alcohol, because Latino adolescents report higher prevalence of having ever drunk alcohol (72.4\%) compared to their White (65.9\%) and Black (63.4\%) adolescent counterparts (Kann et al., 2016). Additional research is needed to determine whether and how ethnicity of friends plays a role in alcohol use among Latino adolescents.

Although the role of recreational activities as a moderator for the association between current alcohol use and friends' age or sex could not be tested, it is worthwhile to investigate the potential impact of recreational activities on alcohol use among Latino adolescents in a future study. The few previous relevant studies in this field have mostly addressed sports participation and have not assessed how other recreational activities, such as volunteer activities and after-school activities, influence alcohol use in this population (Dunn, 2014; Mays et al., 2010; Moore \& Werch, 2008; Parent et al., 2016). 
Moreover, these studies have not provided findings stratified by ethnicity, so it is not clear whether the findings are relevant to Latino adolescents. If recreational activities play a role in Latino adolescent alcohol use, interventions could be tailored accordingly — thus, they may be more effective at preventing alcohol use in this population. For example, if Latino adolescents who volunteer at church are more likely to drink alcohol, then perhaps social networks who encourage alcohol use have been built around church. If so, then alcohol use prevention interventions could be administered at church.

\section{Discussion of Hypothesis 6 Findings}

Hypothesis 6 suggested that recreational activities would moderate the association between current marijuana use and friends' age, sex, and ethnicity. There were no associations between current marijuana use and perception of friends' age or sex; ethnicity could not be tested due to the small number of participants $(n=1)$ who reported none of their closest friends being Latino.

It was postulated that Latino adolescents with older or younger friends may be more or less likely to use marijuana, and if this were the case, peer-based interventions could be suggested for marijuana use prevention programs among Latino adolescents. However, this was not the case for the present sample. Nonetheless, this was the first study of Latino adolescents to assess associations between friends' age and current marijuana use; thus, the present study fills an important gap in the current body of scientific literature. 
Because there may be differences in underlying factors associated with marijuana use between Latino adolescent males versus females, there may be differences in marijuana use among Latinos who have more male or female friends. This should be tested in future studies, so that, if associations are found, underlying mechanisms could be explored and more culturally appropriate marijuana prevention programs could be developed.

Associations between current marijuana use and perception of friends' ethnicity could not be tested due to the small number of participants $(n=1)$ who reported none of their closest friends being Latino. However, it is plausible that Latinos who primarily interact with other Latinos may be less likely to use marijuana, because interacting mostly with Latinos could slow down the U.S. acculturation process and Latinos who are less acculturated with the U.S. are less likely to use marijuana (Carlton-Smith \& Skeer, 2015; DiBello et al., 2015; Unger et al., 2014; Schwartz et al., 2011). However, it is also possible that Latinos who primarily interact with other Latinos may be more likely to use marijuana, because according to the 2015 Youth Risk Behavior Surveillance System (N = 15,624 high school students), the prevalence of having ever used marijuana was higher among Latino (10.9\%) than White (5.4\%) and Black (10.6\%) adolescents (Kann et al., 2016). Hence, additional research is needed to determine whether and how ethnicity of friends plays a role in marijuana use among Latino adolescents.

Although the role of recreational activities as a moderator for the association between current marijuana use and friends' age or sex could not be tested, recreational activities may play a role in marijuana use among Latino adolescents and, hence, further research is warranted. In the present study, $19.2 \%$ of participants reported participating in 
volunteer activities and 29.5\% reported participating in after-school activities. Moreover, $62.2 \%$ reported participating in sports activities. Therefore, the majority of Latino adolescents are participating in recreational activities, and this may play a role in their marijuana use. If future studies indicate that certain recreational activities are protective against marijuana use while other activities increase risk for using marijuana, interventions could target such recreational activities (e.g., football practice, church volunteer time). However, the role of recreational activities in current marijuana use is understudied and warrants further research.

Previous studies have indicated that social-networks play a role in adolescent marijuana use. Therefore, recreational activities, due to their social nature, may also play a role in marijuana use among Latino adolescents. For example, in a recently published qualitative study of adolescent marijuana use in a Latino seasonal farmworker community in Miami-Dade County, (mother) participants' reported 'You don't have to go very far to find it (marijuana). They have it (marijuana) in schools, even the security has them and they sell it." One mother also stated "When I ask him why he did it (use marijuana), he says it was peer pressure, and to feel accepted in groups" (Kanamori et al., 2016). Accordingly, social networks based around recreational activities may play a role in marijuana use among Latino adolescents.

\section{Discussion of Hypothesis 7 Findings}

Hypothesis 7 postulated that recreational activities would moderate the association between perception of friends' alcohol use and current alcohol use. This hypothesis was mostly not supported in the present study. Findings showed that the 
participants who reported having no close friends who use alcohol were less likely to be currently (within past 30 days) using alcohol themselves, which is in-line with other studies on Latino adolescents (Bacio et al., 2013). However, there was no interaction effect between perception of friends' alcohol use with participation in after-school activities. Volunteer activities could not be tested due to sample size restriction.

Based on the extensive a priori literature review (Chapter II), it seemed plausible that recreational activities may play a role in adolescent alcohol use behaviors. Previous studies have shown associations between alcohol and sports participation (Mays et al., 2010; Moore \& Werch, 2008; Parent et al., 2016). However, these studies did not provide findings stratified by ethnicity, so it was not clear whether these associations were true for Latino adolescents. Furthermore, other types of recreational activities, such as volunteer work, had never been assessed in the literature. This dissertation study was the first to attempt to assess the role of a wide range of recreational activities as moderators for the association between current alcohol use and perception of friends' alcohol use among Latino adolescents_-addressing an important gap in the literature.

There was an interaction effect between perception of friends' alcohol use and sports participation. Future studies should explore whether this interaction is true for all types of sports activities or only, for example, team sports. Underlying mechanisms of the role of sports participation should also be explored so that more effective alcohol use prevention interventions can be created for Latino adolescents. For example, a nationally representative study of $10^{\text {th }}$ graders $(n=19,678,16.0 \%$ Latino) found that overweight Latino adolescents had a higher odds of reporting alcohol use compared to their healthy weight Latino adolescent counterparts (Zeller et al., 2016). Due to the well-established 
association between exercise (i.e., sports participation) and body weight, body weight may play a role in this interaction effect. Because volunteer activities could not be tested due to the small number of participants involved in volunteer activities, additional research with larger sample sizes should be conducted. Moreover, although the interaction between perception of friends' alcohol use and after-school activities was not significant on the outcome current alcohol use, future studies should consider investigating this relationship further considering the present dissertation was the first to assess such a relationship in a diverse Latino adolescent population.

\section{Discussion of Hypothesis 8 Findings}

Hypothesis 8 postulated that recreational activities would moderate the association between current marijuana use and perception of friends' marijuana use. This hypothesis could not be tested due to sample size restriction. However, findings revealed that participants who reported having no close friends who use marijuana were less likely to currently (within past 30 days) use marijuana themselves, which is in-line with other studies that found Latino adolescents to be more likely to use marijuana if their friends use marijuana (Bacio et al., 2013). Although it was not possible to test Hypothesis 8 in the present study, future studies with larger sample sizes should address this gap in the literature. If studies find that particular types of recreational activities play a role in marijuana use among Latino adolescents, interventions could be tailored to this population, yielding more successful results. In addition, if recreational activities play a role, underlying mechanisms should be explored. For example, a recent national representative study of $10^{\text {th }}$ graders $(n=19,678,16.0 \%$ Latino) found that overweight 
Latino adolescents had lower odds of using marijuana as compared to their healthy weight Latino adolescent counterparts (Zeller et al., 2016). There is a clear association between sports participation/exercise and body weight and therefore, body weight may play a role in any potential associations between recreational activities and marijuana use.

Theoretical Implications: Primary Socialization Theory

This dissertation was grounded in Primary Socialization Theory, which has guided previous studies of substance abuse behaviors among Latino adolescents (e.g., violence; Oetting et al., 1998; Shin et al., 2016; Kam \& Yang, 2014; Brook et al., 2013a; Aspy et al., 2012). Primary Socialization Theory posits that drug use and deviant behaviors emerge from interactions with the three primary socialization sources: family, school, and peer clusters (Oetting et al., 1998). This dissertation examined correlates of current alcohol and marijuana use, including those that comprise the primary socialization sources of the Primary Socialization Theory: family (e.g., cultural values), school (e.g., GPA), and peer clusters (e.g., perception of friends' substance use behaviors). Recreational activities were tested as an additional construct (primary socialization source).

This dissertation partially supported the theoretical framework. Current alcohol and marijuana use were associated with perception of having close friends who drink alcohol (peer clusters construct). However, the construct of family, represented by cultural values, living with both parents, and socioeconomic status, was only partially supported. Parental living arrangement (living with both parents) and socioeconomic status were not associated with current alcohol or marijuana use. The school construct 
(GPA) was not associated with alcohol or marijuana use. However, several of the Latino cultural values (family construct) played a role in lifetime and current alcohol and marijuana use. Moreover, this dissertation advances the Primary Socialization Theory by providing information on the theory's implication among a unique and diverse Latino adolescent population in Miami-Dade County, Florida.

Because the Primary Socialization Theory was only partially supported in this study, in the future, researchers should consider investigating other theories that may lead to a better understanding of the factors which play a role in alcohol and marijuana use among Latino adolescents in Miami-Dade County. For example, the Theory of Gender and Power (Lopez, Chesney-Lind, \& Foley, 2012; Rosenbaum, Zenilman, Wingood, \& DiClemente, 2016) or Problem Behavior Theory (Alexander, Obong'o, Chavan, Vander Weg, \& Ward, 2017; Jessor \& Jessor, 1977) may be used to guide additional research among this population.

Research and Practice Implications

Practitioners and researchers who work with the Latino adolescent population in Miami-Dade County should note that perception of friends' alcohol and marijuana use was significantly associated with current alcohol and marijuana use. This finding is inline with other studies of adolescents and has several clinical and research implications (Schofield et al., 2015; Acosta et al., 2015; Roditis et al., 2016). Future longitudinal studies should assess whether perceiving friends to be using substances leads to substance use among Latino adolescents in Miami-Dade County. Furthermore, although it is difficult to develop alcohol and marijuana use prevention and treatment interventions to 
influence perception of friends' substance use behaviors, this knowledge may be used to develop more effective interventions. For example, it may be worthwhile to consider providing alcohol and marijuana prevention interventions in group settings-using stepwise and social network sampling in which adolescents recruit their friends to participate in the intervention. Another suggestion is to consider incorporating peer pressure negotiation skills into alcohol and marijuana prevention programs. There is existing evidence that group prevention programs may be effective among adolescents. For example, according to a recent meta-analysis, previous studies have shown that school-based marijuana prevention programs are effective (Lize et al., 2017) among middle school students. Therefore, providing such interventions in a group setting could be a cost-effective strategy for preventing alcohol and marijuana use.

The findings of this dissertation revealed that only one Latino cultural subscale/value, Religion, was associated with all four outcome variables: current alcohol use, lifetime alcohol use, current marijuana use, lifetime marijuana use. Accordingly, future qualitative studies (i.e.,focus groups) should explore underlying mechanisms by which Religion plays such a role. Discovering the underlying mechanisms for the protective role of Religion could lead to the development of more successful substance use prevention programs among Latino adolescents in Miami-Dade County. With respect to the additional Latino subscales/cultural values, future research should assess the role of specific items within the subscales using factor analysis, to more specifically address the role of cultural values on substance use in this population.

As explained in detail in Chapters I and II of this dissertation, it is important to explore the role of potentially modifiable factors that may play a role in alcohol and 
marijuana use among adolescents. In this dissertation, it was found that most $(n=135$; $69.9 \%$ ) of the adolescents reported participating in at least one type of recreational activity. Although the role of recreational activities was mostly not demonstrated to be significant in the present dissertation study, it is suggested that future studies further investigate the role of recreational activities. One possible mechanism in which recreational activities may play a role is via peer pressure; members of adolescents' social networks — based around recreational activities — pressure other members to use alcohol or marijuana. Another underlying factor is increased access to substances. By participating in recreational activities, adolescents may have more access to certain substances. Future longitudinal studies should determine whether participation in specific recreational activities leads to alcohol or marijuana use among Latino adolescents in Miami-Dade County.

Although several interventions have demonstrated efficacy for preventing or decreasing alcohol and marijuana use among Latino adolescents, alcohol and substance abuse service utilization has been demonstrated to be lower among Latino alcohol users when compared to their White non-Latino counterparts- potentially reflecting underlying disparities in health care access for Hispanics and language and cultural barriers such as perceived stigma to utilizing substance abuse treatment services (Chartier \& Caetano, 2011; Cummings, Wen, \& Druss, 2011; Mulvaney-Day, DeAngelo, Chen, Cook, \& Alegria, 2012; Zemore et al., 2014; Zemore, Mulia, Ye, Borges, \& Greenfield, 2009). In a large cross-sectional study of U.S. adolescents who participated in the National Survey of Drug Use and Health (NSDUH) between 2001-2008, treatment rates among adolescents with substance use disorders were significantly lower for Blacks and 
Hispanics than Whites $(p<0.05)$; Hispanics were significantly less likely than Whites to receive any substance use disorder treatment $(p<0.05)$, treatment in a medical setting $(p$ $<0.01)$, and treatment in a self-help group ( $p<0.05$; Cummings et al., 2011). An understanding of factors that play a role in alcohol and marijuana use among Latino adolescents may help improve service utilization among Latino adolescents. For example, if a majority of Latino adolescents are participating in a specific volunteer activity and that volunteer activity is associated with alcohol or marijuana use, then prevention programs and studies could perhaps be implemented at that volunteer activity's location. Nonetheless, further research is warranted to determine the potential role of recreational activities in the alcohol and marijuana use of Latino adolescents.

\section{Limitations}

Due to sample size restrictions, it was not possible to stratify analyses according to developmental age ranges (i.e., 13-15 years old, 16-18 years old). Another limitation of the sample size was the inability to stratify participants by those living with biological parents versus those living with non-biological parents. Participants who reported living with one biological parent and one non-biological parent $(n=6)$ were coded as not living with both parents. In total, six participants reported living with a step-father and no participants reported living with a step-mother. Due to sample size restrictions and the option to select as many countries as possible, it was additionally not possible to stratify analyses based on self-reported countries of origin (i.e., only Cuban, Cuban-American, American-Nicaraguan, Mexican-Nicaraguan etc.). Stratification of analyses by frequency 
of drinking during the lifetime or during the past 30 days was also not possible due to sample size limitations.

The present dissertation study was conducted via a secondary analysis using baseline data from an HIV-prevention intervention study. Due to the nature of secondary data analyses, it was not possible to determine additional factors that may be related to alcohol and marijuana use such as actual peer substance use and actual family (i.e., mother, father) use of marijuana and alcohol. For example, the influence of peers' alcohol and marijuana use were measured via questions regarding participants' perceptions of friends' alcohol and marijuana use (i.e., How many of your closest friends drink alcohol?) and not their friends' actual alcohol or marijuana use. Perceptions may not be accurate representations of actual alcohol and marijuana use.

\section{Conclusions}

Findings from this dissertation project suggest that (a) what is known about Latino adolescents throughout the U.S. may not always be relevant to the unique Latino adolescent population that comprises Miami-Dade County, Florida and (b) some Latino cultural values may still play a role in substance use among Latino adolescents but not all Latino cultural values play a role (Vega et al., 1993b; Vega et al., 1993c; Vega et al., 1993a). With respect to recreational activities, the present findings showed that having no close friends who use alcohol decreased the risk of currently (within past 30 days) using alcohol among Latino adolescents. Findings also revealed that participants who reported having no close friends who use marijuana were less likely to currently use marijuana themselves. Future research with large sample sizes of Latino adolescents in Miami-Dade 
County should investigate the potential role of recreational activities on the alcohol and marijuana use behaviors of adolescents.

\section{Summary of Chapter V}

This chapter summarized the findings of the dissertation and provided explanations for the findings within the context of previous studies. A discussion of the theory implications and the research and practice implications were also provided in this chapter. Last, conclusions about this dissertation project were presented in light of the seminal studies and more recent previously published studies. 


\section{REFERENCES}

Acosta, S. L., Hospital, M. M., Graziano, J. N., Morris, S., \& Wagner, E. F. (2015). Pathways to drinking among Hispanic/Latino adolescents: Perceived discrimination, ethnic identity, and peer affiliations. Journal of Ethnicity in Substance Abuse, 143(3), 270-286.

Alegria, M., Carson, N. J., Goncalves, M., \& Keefe, K. (2011). Disparities in treatment for substance use disorders and co-occurring disorders for ethnic/racial minority youth. Journal of the American Academy of Child and Adolescent Psychiatry, 50(1), 22-31.

Alexander, A. C., Obong'o, C. O., Chavan, P., Vander Weg, M. W., \& Ward, K. D. (2018). Applying the Problem Behavior Theory to adolescent drug use among a cross-sectional sample of boys participating in a community-based youth organization. Substance Use \& Misuse, 53(4), 610-621.

Allem, J-P., Soto, D. W., Baezconde-Garbanati, L., \& Unger, J. B. (2015). Adverse childhood experiences and substance use among Hispanic emerging adults in Southern California. Addictive behaviors, 50, 199-204.

Aspy, C. B., Vesely, S. K., Oman, R. F., Tolma, E., Rodine, S., Marshall, L., \& Fluhr, J. (2012). School-related assets and youth risk behaviors: alcohol consumption and sexual activity. Journal of School Health, 82(1), 3-10.

Bacio, G. A., Lau, A. S., \& Mays, V. M. (2013). Drinking initiation and problematic drinking among Latino adolescents: Explanations of the immigrant paradox. Psychology of Addictive Behaviors, 27, 14-22.

Becker, M. P., Collins, P. F., Luciana, M. (2014). Neurocognition in college-aged daily marijuana users. Journal of Clinical and Experimental Neuropsychology, 36(4), 379-398.

Brady, S. S., Tschann, J. M., Pasch, L. A., Flores, E., \& Ozer, E. J. (2008). Violence involvement, substance use, and sexual activity among Mexican American and European American adolescents. Journal of Adolescent Health, 43(3), 285-295.

Brener, N. D., Collins, J. L., Kann, L., Warren, C. W., \& Williams, B. I. (1995). Reliability of the Youth Risk Behavior Survey questionnaire. American Journal of Epidemiology, 141, 575-80.

Brener, N. D., Kann, L., McManus, T., Kinchen, S. A., Sundberg, E. C., \& Ross, J. G. (2002). Reliability of the 1999 Youth Risk Behavior Survey questionnaire. Journal of Adolescent Health, 31(4), 336-342. 
Brisola-Santos, M. B., Gallinaro, J. G., Gil, F., Sampaio-Junior, B., Marin, M. C., de Andrade, A. G., . . . Castaldelli-Maia, J. M. (2016). Prevalence and correlates of cannabis use among athletes-A systematic review. The American Journal on Addictions, 25(7), 518-528.

Brook, J. S., Lee, J. Y., Brown, E. N., Finch, S. J., \& Brook, D. W. (2011). Developmental trajectories of marijuana use from adolescence to adulthood: personality and social role outcomes: Psychological Reports, 108(2), 339-357.

Brook, J. S., Lee, J. Y., Finch, S. J., Brown, E. N., \& Brook, D. W. (2013a). Long term consequences of membership in trajectory groups of delinquent behavior in an urban sample: Violence, drug use, interpersonal and neighborhood attributes. Aggressive Behavior, 39(6), 440-452.

Brook, J. S., Lee, J. Y., Finch, S. J., Seltzer, N., \& Brook, D. W. (2013b). Adult work commitment, financial stability, and social environment as related to trajectories of marijuana use beginning in adolescence. Substance Abuse, 34(3), 298-305.

Brook, J. S., Lee, J. Y., \& Brook, D. W. (2015). Trajectories of marijuana use beginning in adolescence predict dependence in adulthood. Substance Abuse 36(4), 470-477.

Bull, F. C., Maslin, T. S., \& Armstrong, T. (2009). Global physical activity questionnaire (GPAQ): Nine country reliability and validity study. Journal of Physical Activity and Health, 6(6), 790-804.

Cacciola, E. E. T., \& Nevid, J. S. (2014). Alcohol consumption in relation to residence status and ethnicity in college students. Psychology of Addictive Behaviors, 28(4), 1278-1283.

Caetano, R., Mills, B. A., Vaeth, P. A. C., \& Reingle, J. (2014). Age at first drink, drinking, binge drinking and DSM-5 alcohol use disorder among Hispanic national groups in the U.S. Alcoholism, Clinical and Experimental Research, $38(5), 1381-1389$.

Cano, M. A., Vaughan, E. L., de Dios, M. A., Castro, Y., Roncancio, A. M., \& Ojeda, L. (2015). Alcohol use severity among Hispanic emerging adults in higher education. Substance Use \& Misuse, (50)11, 1412-1420.

Carlton-Smith, A. R., \& Skeer, M. R. (2015). Differences in adolescent substance use by Hispanic subgroup: What we know and what we need to find out. Journal of Ethnicity in Substance Abuse, 14(4), 340-350.

Centers for Disease Control and Prevention. (2015). Fact sheets - Underage Drinking. Retrieved from https://www.cdc.gov/alchohol/fact-sheets/underage-Drinking.htm. 
Centers for Disease Control and Prevention. (2016a). Sexually Transmitted Disease Surveillance 2015. Atlanta: U.S. Department of Health and Human Services.

Centers for Disease Control and Prevention (2016b). Youth Risk Behavior Surveillance United States, 2015. Retrieved from https://www.cdc.gov/healthyyouth/data/yrbs/pdf/2015/ss6506_updated.pdf.

Centers for Disease Control and Prevention. (2016c). Adolescent and School Health. Retrieved from http://www.cdc.gov/healthyyouth/data/yrbs/questionnaires.htm

Chartier, K. G., \& Caetano, R. (2011). Trends in alcohol services utilization from 19911992 to 2001-2002: Ethnic group differences in the U.S. population. Alcoholism, Clinical and Experimental Research, 35(8), 1485-1497.

Chen, C. M., Yoon, Y-H., \& Faden, V. B. National Institute on Alcohol Abuse and Alcoholism. (2017). Trends in Underage Drinking in the United States, 19912015 (Surveillance Report No. 107). Retrieved from https://pubs.niaaa.nih.gov/publications/surveillance107/Underage15.htm.

Chen, C. Y., Storr, C. L., \& Anthony, J. C. (2009). Early-onset drug use and risk for drug dependence problems. Addictive Behaviors, 34(3), 319-322.

Cheng, H-L., \& Mallinckrodt, B. (2015). Racial/ethnic discrimination, posttraumatic stress symptoms, and alcohol problems in a longitudinal study of Hispanic/Latino college students. Journal of Counseling Psychology, 62(1), 38-49.

Cherpitel, C. J., Ye, Y., \& Kerr, W. (2016). Relationship of usual volume and heavy consumption to risk of alcohol-related injury: Racial/ethnic disparities in four U.S. national alcohol surveys. Journal of Studies on Alcohol and Drugs, 77(1), 58-67.

Chu, A. H., Ng, N. G., Koh, D., Müller-Riemenschneider, F. (2015). Reliability and validity of the self- and interviewer-administered versions of the global physical activity questionnaire (GPAQ). PLOS ONE, 10(9), e0136944.

Cleland, C. K., Hunter, R. F., Kee, F., Cupples, M. E., Sallis, J. F., Tully, M. A. (2014). Validity of the Global Physical Activity Questionnaire (GPAQ) in assessing levels and change in moderate-vigorous physical activity and sedentary behaviour. BMC Public Health, 14, 1255. Doi: 10.1186/1471-2458-14-1255

Cox Jr, R. B., Roblyer, M. Z., Merten, M. J., Shreffler, K. M., \& Schwerdtfeger, K. L. (2013). Do parent-child acculturation gaps affect early adolescent Latino alcohol use? A study of the probability and extent of use. Substance Abuse Treatment, Prevention, and Policy, 8(4), Doi:10.1186/1747-597X-8-4. 
Cummings, J. R., Wen, M. H., \& Druss, B. G. (2011). Racial/ethnic differences in treatment for substance use disorders among U.S. adolescents. Journal of the American Academy of Child and Adolescent Psychiatry, 50(12), 1265-1274.

D’Amico, E. J., Miles, J. N. V., \& Tucker, J. S. (2015). Gateway to curiosity: Medical marijuana ads and intention and use during middle school. Psychology of Addictive Behaviors, 39(3), 613-619.

D’Amico, E. J., Tucker, J. S., Miles, J. N. V., Ewing, B. A., Shih, R. A., \& Pedersen, E. R. (2016). Alcohol and marijuana use trajectories in a diverse longitudinal sample of adolescents: examining use patterns from age 11 to 17 years. Addiction, $111(10), 1825-1835$.

De la Haye, K., D’Amico, E. J., Miles, J. N. V., Ewing, B., \& Tucker, J. S. (2014). Covariance among multiple health risk behaviors in adolescence. PLoS ONE, 9(5), e98141.

De La Rosa, M., Rahill, G. J., Rojas, P., \& Pinto, E. (2007). Cultural adaptations in data collections: Field experiences. Journal of Ethnicity in Substance Abuse, 6(2), 163180 .

De Pedro, K. T., Gilreath, T. D., Jackson, C., \& Esqueda, M. C. (2017). Substance use among transgender students in California public middle and high schools. The Journal of School Health, 87(5), 303-309.

DiBello, A. N., Gonzales, R., Young, C. M., Rodriguez, L. M., \& Neighbors, C. (2015). Blood is thicker than booze: Examining the role of familism and gender in alcohol use and related consequences among Hispanic college students. Journal of Ethnicity in Substance Abuse, 2, 1-15.

Dunn, M. S. (2014). Association between physical activity and substance use behaviors among high school students participating in the 2009 youth risk behaviors survey. Psychological Reports: Disability and Trauma, 114(3), 675-685.

Ehlers, C. L., Gilder, D. A., Criado, J. R., \& Caetano, R. (2009). Acculturation stress, anxiety disorders, and alcohol dependences in a select population of young adult Mexican Americans. Journal of Addiction Medicine, 3(4), 227-233.

Escobar, O. S., \& Vaughan, E. L. (2014). Public religiosity, religious importance, and substance use among Latino emerging adults. Substance Use \& Misuse, 49(10), $1317-1325$. 
Florez, K. R., Pitkin Derose, K., Breslau, J., Griffin, B. A., Haas, A. C., Kanouse, D. E.,...Williams, F. V. (2015). Acculturation and drug addiction stigma among Latino and African Americans: An examination of a church-based sample. Journal of Immigrant and Minority Health, 17(6), 1607-1614.

Florida Department of Children \& Families. (2016). 2016 Florida Youth Substance Abuse Survey. Retrieved from http://www.dcf.state.fl.us/programs/samh/publications/fysas/2016Survey/countytables/Miami-Dade.pdf.

Gil, A. G., Wagner, E. F., \& Vega, W. A. (2000). Acculturation, familism, and alcohol use among Latino adolescent males: Longitudinal relations. Journal of Community Psychology, 28(4), 443-458.

Grant, B. F., \& Dawson, D. A. (1997). Age of onset of alcohol use and its association with DSM-IV alcohol abuse and dependence: Results from the National Longitudinal Alcohol Epidemiologic Survey. Journal of Substance Abuse 9, 103 110.

Hodge, D., Cardenas, P., \& Montoya, H. (2001). Substance use: Spirituality and religious participation as protective factors among rural youths. Social Work Research, 25(3), 153-161.

Hussong, A. M., Huang, W., Serrano, D., Curran, P. J., \& Chassin, L. (2012). Testing whether and when parent alcoholism uniquely affects various forms of adolescent substance use. Journal of Abnormal Child Psychology, 40(8), 1265-1276.

Jackson, K. M., Rogers, M. L., \& Sartor, C. E. (2016a). Parental divorce and initiation of alcohol use in early adolescence. Psychology of Addictive Behaviors, 30(4), 450461.

Jackson, L. A., Browning, C. R., Krivo, L. J., Kwan, M-P., \& Washington, H. M. (2016b). The role of immigrant concentration within and beyond residential neighborhoods in adolescent alcohol use. Journal of Youth and Adolescence, 45, 17-34.

Jankowski, P. J., Hardy, S. A., Zamboanga, B. L., Ham, L. S., Schwartz, S. J., Kim, S. Y., \& Cano, M. A. (2015). Religiousness and levels of hazardous alcohol use: A latent profile analysis

Jennings, W. G., Reingle, J. M., Staras, S. A. S., \& Maldonado-Molina, M. M. (2012). Substance use as a risk factor for intimate partner violence overlap: Generational differences among Hispanic young adults. International Criminal Justice Review, 22(2), 139-152. 
Jessor, R., \& Jessor, S. L. (1977). Problem behavior and psychosocial development: A longitudinal study of youth. New York, New York: Academic Press.

Kam, J. A., Cleveland, M. J., \& Hecht, M. L. (2010). Applying general strain theory to examine perceived discrimination's indirect relation to Mexican-Heritage youth's alcohol, cigarette, and marijuana use. Prevention Science, 11(4).

Doi:10.1007/s11121-010-0180-7.

Kam, J. A., \& Yang, S. (2014). Explicating how parent-child communication increases Latino and European American early adolescents' intentions to intervene in a friend's substance use. Prevention Science, 15, 536-546.

Kanamori, M., Weissman, J., De La Rosa, M., Trepka, M. J., Rojas, P., Cano, M. A., Melton, J., \& Unterberger A. (2016). Latino Mother/Daughter Dyadic Attachment as a Mediator for Substance Use Disorder and Emotional Abuse. Journal of Immigrant and Minority Health, 18, 896-903.

Kann, L., McManus, T., Harris, W. A, Shankline, S. L., Flint, K. H., Hawkins, J., . . Zaza, S. (2016). Youth Risk Behavior Surveillance — United States, 2015. Morbidity and Mortality Weekly Report, 65(6).

Knight, G. P., Gonzales, N. A., Saenz, D. S., Bonds, D. D., Germán, M., Deardorff, J., . . . Updegraff, K. A. (2010). The Mexican American cultural values scale for adolescents and adults. The Journal of Early Adolescence, 30(3), 444-481.

Kulesza, M., Matsuda, M., Ramirez, J. J.., Werntz, B. A., Teachman, B. A., \& Lindgren, K. P. (2016). Towards greater understanding of addiction stigma: Intersectionality with race/ethnicity and gender. Drug and Alcohol Dependence, 169, 85-91.

Kwok, K. H., \& Yuan, S. N. (2016). Parental socioeconomic status and binge drinking in adolescents: A systematic review. The American Journal on Addictions. Doi: 10.1111/ajad.12461

Lac, A., Unger, J. B., Basáñez, T., Ritt-Olson, A., Soto, D. W., \& Baezconde-Garbanati, L. (2011). Marijuana use among Latino adolescents: Gender differences in protective familial factors. Substance Use and Misuse, 46(5), 644-655.

Le, Y-C. L., Behnken, M. P., Markham, C. M., \& Temple, J. R. (2011). Alcohol use as a potential mediator of forced sexual intercourse and suicidality among African American, Caucasian, and Hispanic high school girls. Journal of Adolescent Health, 49(4), 437-439.

Lee, J. Y., Brook, J. S., Finch, S. J., \& Brook, D. W. (2015). Trajectories of marijuana use from adolescence to adulthood predicting unemployment in the mid-thirties. American Journal on Addictions, 24(5), 452-459. 
Lize, S. E., Iachini, A. L., Tang, W., Tucker, J., Seay, K. D., Clone, S., . . Browne, T. (2017). A meta-analysis of the effectiveness of interactive middle school cannabis prevention programs. Prevention Science, 18(1), 50-60.

Lopez, V., Chesney-Lind, M., \& Foley, J. (2012). Relationship power, control, and dating violence among Latina girls. Violence Against Women, 18(6), 681-690.

Maggs, J. L., Staff, J., Kloska, D. D., Patrick, M. E., O’Malley, P. M., \& Schulenberg, J. (2015). Predicting young adult degree attainment by late adolescent marijuana use. Journal of Adolescent Health, 57(2), 205-211.

Maldonado-Molina, M. M., Jennings, W. G., \& Komro, K. A. (2010). Effects of alcohol on trajectories of physical aggression among urban youth: An application of latent trajectory modeling. Journal of Youth and Adolescence, 39(9), 1012-1026.

Mays, D., Thompson, N., Kushner, H. I., Mays II, D. D., Farmer, D., \& Windle, M. (2010). Sports-specific factors, perceived peer drinking, and alcohol-related behaviors among adolescents participating in school-based sports in Southwest Georgia. Addictive Behaviors, 35(3), 235-241.

McCart, M. R., Zajac, K., Kofler, M. J., Smith, D. W., Saunders, B. E., \& Kilpatrick, D. G. (2012). Longitudinal examination of PTSD symptoms and problematic alcohol use as risk factors for adolescent victimization. Journal of Clinical Child and Adolescent Psychology, 41(6), 822-836.

McCutcheon, V. V., Agrawal, A., Kuo, S. I., Su, J., Dick, D. M., Meyers, J. M., . . . Bucholz, K. K. (2017). Associations of parental alcohol use disorders and parental separation with offspring initiation of alcohol, cigarette, and cannabis use and sexual debut in high-risk families. Addiction. Doi: 10.1111/add.14003.

Miami-Dade County Department of Planning and Zoning. (2009) Miami Dade County Facts. Retrieved from http://www.miamidade.gov/planning/library/reports/2009miami-dade-county-facts.pdf.

Miech, R. A., Johnston, L. D., O’Malley, P. M., Bachman, J. G., \& Schulenberg, J. E. (2015). Monitoring the future national survey results on drug use, 1975-2014: Volume I, Secondary school students. Ann Arbor, MI: Institute for Social Research, The University of Michigan. Doi:10.1037/e567272009-001.

Miller, L., Davies, M., \& Greenwald, S. (2000). Religiosity and substance us and abuse among adolescents in the national comorbidity survey. Journal of the American Academy of Child \& Adolescent Psychiatry, 39(9), 1190-1197. 
Moore, M. J., \& Werch, C. (2008). Relationship between vigorous exercise frequency and substance use among first-year drinking college students. Journal of American College Health, 56(6), 686-690.

Morgan Consoli, M. L., \& Llamas, J. D. (2013). The relationship between Mexican American cultural values and resilience among Mexican American college students: a mixed methods study. Journal of Counseling Psychology, 60(4), 61724.

Mulvaney-Day, N., DeAngelo, D., Chen, C., Cook, B., \& Alegria, M. (2012). Unmet need for treatment for substance use disorders across race and ethnicity. Drug and Alcohol Dependence, 12(Suppl 1), S44-S50.

Mutchler, M. G., McDavitt, B., \& Gordon, K. K. (2014). "Becoming Bold”: Alcohol use and sexual exploration among Black and Latino young men who have sex with men (YMSM). Journal of Sex Research, 51(6), 696-710.

National Institute on Alcohol Abuse and Alcoholism. (2003). Alcohol Alert. Retrieved from https://pubs.niaaa.nih.gov/publications/aa59.htm.

National Institute on Drug Abuse. (2016). Monitoring the Future Study: Trends in Prevalence of Various Drugs. Retrieved from https://www.drugabuse.gov/trendsstatistics/monitoring-future/monitoring-future-study-trends-in-prevalence-variousdrugs.

Oetting, E. R., Deffenbacher, J. L., \& Donnermeyer, \& J. F. (1998). Primary socialization Theory: The role played by personal traits in the etiology of drug use and deviance II. Substance Use \& Misuse, 33(6), 1337-1366.

Pahl, K., Brook, J. S., \& Koppel, J. (2011). Trajectories of marijuana use and psychological adjustment among urban African American and Puerto Rican women. Psychological Medicine 41(8), 1775-1783.

Parent, M. C., Bradstreet, T. C., Piper, M., Brace, T., \& Parkman, T. J. (2016). Racial disparities in substance use by sport participation among high school students. Journal of Studies on Alcohol and Drugs, 77(6), 980-985.

Prado, G. J., Schwartz, S. J., Maldonado-Molina, M., Huang, S., Pantin, H. M., Lopez, B., \& Szapocznik, J. (2009). Ecodevelopmental x Intrapersonal Risk: Substance use and sexual behavior in Hispanic adolescents. Health Education and Behavior, 36(1), 45-61.

Reisner, S. L., Grektak, E. A., Parsons, J. T., Ybarra, M. L. (2015). Gender minority social stress in adolescence: Disparities in adolescent bullying and substance use by gender identity. Journal of Sex Research, 52(3), 243-256. 
Roditis, M. K., Delucchi, K., Chang, A., \& Halpern-Felsher, B. (2016). Perceptions of social norms and exposure to pro-marijuana messages are associated with adolescent marijuana use. Preventive Medicine, 93, 171-176.

Rosenbaum, J. E., Zenilman, J., Wingood, R. E., \& DiClemente, R. (2016). Predicting unprotected sex and unplanned pregnancy among Urban African-American adolescent girls using the Theory of Gender and Power. Journal of Urban Health, 93(3), 493-510.

Salas-Wright, C. P., Vaughn, M. G., Ugalde, J., \& Todic, J. (2015). Substance use and teen pregnancy in the United States: Evidence from the NSDUH 2002-2012. Addictive Behaviors, 45, 218-225.

Santisteban, D. A., Coatsworth, J. D., Briones, E., Kurtines, W., Szapocznik, J. (2012). Beyond acculturation: An investigation of the relationship of familism and parenting behavior problems in Hispanic youth. Family Process, 51(4), 470-482.

Schofield, T. J., Conger, R. D., \& Robins, R. W. (2015). Early adolescent substance use in Mexican origin families: Peer selection, peer influence, and parental monitoring. Drug and Alcohol Dependence, 15, 129-135.

Schwartz, S. J., Weisskirch, R. S., Zamboanga, B. L., Castillo, L. G., Ham, L. S., Huynh, Q- L., . . Cano, M. A. (2011). Dimensions of acculturation: Associations with health risk behaviors among college students from immigrant families. Journal of Counseling Psychology, 58(1), 27-41.

Shin, Y., Lee, J-K., \& Hecht, M. L. (2016). Exploring parental influence on the progression of alcohol use in Mexican-heritage youth: A latent transition analysis. Prevention Science, 17, 188-198.

Temple, J. R., \& Freeman, D. H. (2011). Dating violence and substance use among ethnically diverse adults. Journal of Interpersonal Violence, 26(4), 701-718.

Temple, J. R., Shorey, R. C., Fite, P., Stuart, G., \& Le, V. D. (2013). Substance use as a longitudinal predictor of the perpetration of teen dating violence. Journal of Youth and Adolescence, 42(4), 596-606.

Terry-McElrath, Y. M., O’Malley, P. M., Patrick, M. E., \& Miech, R. A. (2017). Risk is still relevant: Time varying associations between perceived risk and marijuana use among US $12^{\text {th }}$ grade students from 1991 to 2016. Addictive Behaviors, 74, 13-19.

Turner, R. J., \& Lloyd, D. A. (2003). Cumulative adversity and drug dependence in young adults: Racial/ethnic contrasts. Addiction, 98, 305-315. 
Unger, J. B. (2014). Cultural influences on substance use among Hispanic adolescents and young adults: Findings from Project RED. Child Development Perspectives, $8(1), 48-53$.

Unger, J. B., Schwartz, S. J., Huh, J., Soto, D. W., \& Baezconde-Garbanati, L. (2014). Acculturation and perceived discrimination: Predictors of substance use trajectories from adolescence to emerging adulthood among Hispanics. Addictive Behaviors, 39(9), 1293-1296.

United States Census Bureau. (2011). Decennial Census 2000 and 2010. Miami-Dade County, Department of Planning and Zoning.

United States Census Bureau (2014). Nearly 6 Out of 10 Children Participate in Extracurricular Activities, Census Bureau Reports. Retrieved from https://www.census.gov/newsroom/press-releases/2014/cb14-224.html

United States Census Bureau (2016). Quick Facts Miami-Dade County, Florida. Retrieved from https://www.census.gov/quickfacts/table/POP815215/12086.

Vega, W. A., Zimmerman, R. S., Warheit, G. J., Apospori, E., \& Gil, A. G. (1993a). Risk factors for early adolescent drug use in four ethnic and racial groups. American Journal of Public Health, 83(2), 185-189.

Vega, W. A., Gil, A. A., Warheit, G. J., Zimmerman, R. S., \& Apospori, E. (1993b). Acculturation and delinquent behavior among Cuban American adolescents: Toward an empirical model. American Journal of Community Psychology, 21(1), $113-125$.

Vega, W. A., Gil, A. G., \& Zimmerman, R. S. (1993c). Patterns of drug use among Cuban-American, African-American, and White Non-Hispanic Boys. American Journal of Public Health, 83(2), 257-259.

Wagner, K. D., Ritt-Olson, A., Soto, D. W., \& Unger, J. B. (2008). Variation in family structure among urban adolescents and its effects on drug use. Substance Use \& Misuse, 43(7), 936-951.

Waldron, M., Vaughan, E. L., Bucholz, K. K., Lynskey, M. T., Sartor, C. E., Duncan, A. E., . . Heath, A. C. (2014). Risks for early substance involvement associated with parental alcoholism and parental separation in an adolescent female cohort. Drug and Alcohol Dependence, 1(138), 130-136.

Warner, L. A., Valdez, A., Vega, W., De la Rosa, M., Turner, R. J., \& Canino, G. (2006). Hispanic drug abuse in an evolving cultural context: An agenda for research. Drug and Alcohol Dependence, 85, S8-S16. 
World Health Organization (2017). Global Physical Activity Surveillance. Retrieved from http://www.who.int/chp/steps/GPAQ/en/.

Yan, F. A., Howard, D. E., Beck, K. H., Shattuck, T., \& Hallmark-Kerr, M. (2010). Psychosocial correlated of physical dating violence victimization among Latino early adolescents. Journal of Interpersonal Violence, 25(5), 808-831.

Zamboanga, B. L., Schwartz, S. J., Hernandez Jarvis, L., \& Van Tyne, K. (2009). Acculturation and substance use among Hispanic early adolescents: Investigating the mediating roles of acculturative stress and self-esteem. Journal of Primary Prevention, 30, 315-333.

Zapata Roblyer, M. I., Grzywacz, J. G., Cervantes, R. C., \& Merten, M. J. (2016). Stress and alcohol, cigarette, and marijuana use among Latino adolescents in families with undocumented immigrants. Journal of Child and Family Studies, 25, 475487.

Zeller, M. H., Becnel, J., Reiter-Purtill, J., Peugh, J., \& Wu, Y. (2016). Associations among excess weight status and tobacco, alcohol, and illicit drug use in a large national sample of early adolescent youth. Prevention Science, 17(4), 483-492.

Zemore, S. E., Mulia, N., Ye, Y., Borges, G., \& Greenfield, T. K. (2009). Gender, acculturation, and other barriers to alcohol treatment utilization among Latinos in three national alcohol surveys. Journal of Substance Abuse Treatment, 36(4), 446456.

Zemore, S. E., Murphy, R. D., Mulia, N., Gilbert, P. A., Martinez, P., Bond, J., \& Polcin, D. L. (2014). A moderating role for gender in racial/ethnic disparities in alcohol services utilization: Results from the 2000-2010 National Alcohol Surveys. Alcoholism, Clinical and Experimental Research, 38(8), 2286-2296. 
APPENDICES 
Appendix 1 - Literature Review Search Strategy 
Literature Review Search Strategy

The literature review included pre-determined search terms using PUBMED to describe the desired race/ethnicity, age group, and marijuana and alcohol use behaviors. The search was conducted between June 2016-June 2017. PUBMED is a service of the U.S. National Library of Medicine that provides free access to MEDLINE, the National Library of Medicine's database of indexed citations and abstracts to science and medical journals; new citations are added to MEDLINE every day (National Institutes of Health, 2016).

The following terms were used to search for race/ethnicity and country of origin: "Hispanic" OR "Hispanics" OR "Latino" OR "Latinos" OR "Latina” OR "Latinas" OR "Latin" OR "Latin" OR “Cuban AND America” OR "Cuban-American" OR "Cuban American" OR "Cuban Americans" OR "Cuban-Americans" OR "Mexican AND America" OR "Mexican-American" OR "Mexican American" OR "Mexican-Americans" OR "Mexican Americans" OR "Colombian AND America" OR "Colombian-American" OR "Colombian American" OR "Colombian-Americans" OR "Colombian Americans" OR "Dominican AND America" OR "Dominican-American" OR "Dominican American" OR "Dominican-Americans" OR "Dominican Americans" OR "Venezuelan AND America" OR "Venezuelan-American" OR "Venezuelan American" OR "VenezuelanAmericans" OR "Venezuelan Americans" OR "Nicaraguan AND America" OR "Nicaraguan-American" OR "Nicaraguan American" OR "Nicaraguan-Americans" OR "Nicaraguan Americans" OR "Guatemalan AND America" OR "Guatemalan-American" OR "Guatemalan American" OR "Guatemalan-Americans" OR "Guatemalan Americans" OR "Brazilian AND America” OR "Brazilian-American” OR "Brazilian 
American" OR "Brazilian-Americans" OR "Brazilian Americans" OR "Puerto Rican" OR "Puerto Ricans.”

The following are the terms that were used to identify the age group of interest: “adolescent” OR “adolescents” OR “adolescence” OR “child” OR “children” OR “young adult” OR “young adults.”

The following terms were used to identify marijuana and alcohol use: "Alcohol Drinking” OR “Drinking, Alcohol” OR “Alcohol Consumption” OR “Consumption, Alcohol” OR “alcoholic” OR “alcoholics” OR “alcoholism” OR “alcohol addiction” OR “addiction, alcohol” OR "liquor” OR "liquors" OR “Alcohol Dependence” OR “Alcohol Abuse” OR "Problem Drinking” OR “cannabis” OR “cannabis” OR “marihuana” OR “marihuana” OR “marijuana” OR “marijuana” OR "ganja” OR "granjas” OR "hashish" OR "hashish” OR “hemp” OR "hemps” OR “bhang” OR “bhangu” OR “substance abuse" OR "substance abuser" OR "substance abusers."

All combinations of race/ethnicity/country of origin, age, and marijuana and alcohol use search terms were combined. Relevant papers were sought and reviewed for potential inclusion in this review. Only the most relevant peer-reviewed papers that were published within the past 5 years (June 2012-June 2017) and select, relevant papers cited within these publications were included in the literature review. The dissertation committee members provided additional suggestions of seminal studies to include in the literature review. 
Appendix 2 - Tests for Muticollinearity 
Variance Inflation Factors for the Independent Variables

\begin{tabular}{|l|l|l|}
\hline & $\begin{array}{l}\text { VIF (before Latino } \\
\text { cultural value Respect } \\
\text { was removed) }\end{array}$ & $\begin{array}{l}\text { VIF (after Latino cultural } \\
\text { value Respect } \text { was } \\
\text { removed) }\end{array}$ \\
\hline Country of Birth & 1.217 & 1.224 \\
\hline Gender & 1.306 & 1.264 \\
\hline Age & 1.143 & 1.116 \\
\hline Living with both parents & 1.102 & 1.087 \\
\hline GPA Dummy Variable 1 & 1.178 & 1.167 \\
\hline GPA Dummy Variable 3 & 1.208 & 1.203 \\
\hline GPA Dummy Variable 4 & 1.204 & 1.193 \\
\hline $\begin{array}{l}\text { Socioeconomic status dummy } \\
\text { variable 1 }\end{array}$ & 1.107 & 1.107 \\
\hline $\begin{array}{l}\text { Socioeconomic status dummy } \\
\text { variable 3 }\end{array}$ & 1.203 & 1.137 \\
\hline Cultural Value Familism & 2.543 & 1.417 \\
\hline Cultural Value Respect & 2.759 & 1.453 \\
\hline Cultural Value Religion & 1.498 & 1.398 \\
\hline $\begin{array}{l}\text { Cultural Value Traditional } \\
\text { Gender Roles }\end{array}$ & 1.510 & 1.277 \\
\hline $\begin{array}{l}\text { Cultural Value Independence } \\
\text { and Self Reliance }\end{array}$ & 1.280 & \\
\hline
\end{tabular}


Correlation Coefficients (with Latino Cultural Value Respect)

\begin{tabular}{|l|l|l|l|l|l|l|l|l|l|l|l|l|l|l|}
\hline & COB & Gen & Age & Both & GPA1 & GPA3 & GPA4 & SES1 & SES3 & Fam & Res & Rel & Tra & Ind \\
\hline COB & 1.00 & -0.07 & -0.19 & -0.01 & -0.03 & 0.09 & -0.10 & 0.20 & 0.07 & -0.09 & 0.03 & -0.12 & 0.17 & -0.09 \\
\hline Gen & -0.07 & 1.00 & 0.20 & -0.01 & -0.14 & -0.04 & 0.03 & -0.00 & 0.13 & 0.12 & -0.17 & -0.13 & 0.35 & -0.17 \\
\hline Age & -0.19 & 0.20 & 1.00 & -0.09 & 0.10 & 0.06 & 0.08 & -0.02 & -0.03 & 0.05 & -0.16 & 0.10 & 0.11 & -0.03 \\
\hline Both & -0.01 & -0.01 & -0.09 & 1.00 & 0.07 & 0.05 & -0.06 & 0.03 & 0.20 & 0.11 & -0.05 & -0.06 & 0.00 & 0.09 \\
\hline GPA1 & -0.023 & -0.14 & 0.10 & 0.07 & 1.00 & 0.30 & 0.13 & 0.01 & -.02 & -0.03 & 0.06 & 0.05 & -0.01 & 0.08 \\
\hline GPA3 & 0.09 & -0.04 & 0.06 & 0.05 & 0.30 & 1.00 & 0.16 & 0.19 & -0.02 & -0.08 & 0.05 & -0.09 & 0.14 & 0.25 \\
\hline GPA4 & -0.10 & 0.03 & 0.08 & -0.06 & 0.13 & 0.16 & 1.00 & 0.07 & -0.11 & 0.07 & -0.08 & 0.20 & -0.11 & 0.23 \\
\hline SES1 & 0.20 & -0.00 & -0.02 & 0.03 & 0.01 & 0.19 & 0.07 & 1.00 & 0.07 & 0.05 & -0.03 & 0.05 & 0.03 & -0.01 \\
\hline SES3 & 0.07 & 0.13 & -0.03 & 0.20 & -0.02 & -0.02 & -0.11 & 0.07 & 1.00 & 0.11 & -0.23 & 0.09 & -0.05 & -0.02 \\
\hline Fam & -0.09 & 0.12 & 0.05 & 0.11 & -0.03 & -0.08 & 0.07 & 0.05 & 0.11 & 1.00 & -0.66 & -0.17 & 0.20 & -0.12 \\
\hline Res & 0.03 & -0.17 & -0.16 & -0.05 & 0.06 & 0.05 & -0.08 & -0.03 & -0.23 & -0.66 & 1.00 & -0.17 & -0.28 & -0.00 \\
\hline Rel & -0.12 & -0.13 & 0.10 & -0.06 & -0.12 & 0.14 & 0.20 & 0.05 & 0.09 & -0.17 & -0.17 & 1.00 & -0.27 & 0.15 \\
\hline Tra & 0.17 & 0.35 & 0.11 & 0.00 & -0.01 & -0.09 & -0.11 & 0.03 & -0.05 & 0.20 & -0.28 & -0.27 & 1.00 & -0.21 \\
\hline Ind & -0.09 & -0.17 & -0.03 & 0.09 & 0.08 & 0.09 & 0.23 & -0.01 & -0.02 & -0.21 & -0.00 & 0.15 & -0.21 & 1.00 \\
\hline
\end{tabular}

COB: country of birth; Gen: gender; Both: living with both parents; SES: socioeconomic status; Fam: Familism; Res: Respect; Rel: Religion; Independence and Self-Reliance 
Correlation Coefficients (without Latino Cultural Value Respect)

\begin{tabular}{|l|l|l|l|l|l|l|l|l|l|l|l|l|l|}
\hline & COB & Gen & Age & Both & GPA1 & GPA3 & GPA4 & SES1 & SES3 & Fam & Rel & Tra & Ind \\
\hline COB & 1.00 & -0.05 & -0.19 & 0.01 & -0.02 & 0.10 & -0.10 & 0.21 & 0.08 & -0.09 & -0.13 & 0.20 & -0.08 \\
\hline Gen & -.05 & 1.00 & 0.16 & 0.02 & -0.14 & -0.03 & 0.01 & -0.01 & 0.09 & 0.02 & -0.17 & 0.32 & -0.18 \\
\hline Age & -0.19 & 0.16 & 1.00 & -0.10 & 0.11 & 0.07 & 0.06 & -0.02 & -0.07 & -0.08 & 0.07 & 0.07 & -0.03 \\
\hline Both & 0.01 & -0.02 & -0.10 & 1.00 & 0.06 & 0.05 & -0.07 & 0.03 & 0.19 & 0.10 & -0.06 & -0.02 & 0.07 \\
\hline GPA1 & -0.02 & -0.14 & 0.11 & 0.06 & 1.00 & 0.30 & 0.14 & 0.01 & -0.01 & 0.01 & 0.07 & 0.00 & 0.07 \\
\hline GPA3 & 0.20 & -0.03 & 0.07 & 0.05 & 0.30 & 1.00 & 0.17 & 0.19 & -0.01 & -0.07 & 0.15 & -0.08 & 0.08 \\
\hline GPA4 & -0.10 & 0.01 & 0.06 & -0.07 & 0.14 & 0.17 & 1.00 & 0.07 & -0.13 & 0.02 & 0.19 & -0.14 & 0.22 \\
\hline SES1 & 0.21 & -0.01 & -0.02 & 0.03 & 0.01 & 0.19 & 0.07 & 1.00 & 0.07 & 0.05 & 0.05 & 0.02 & -0.02 \\
\hline SES3 & 0.08 & 0.09 & -0.07 & 0.19 & -0.01 & -0.01 & -0.13 & 0.07 & 1.00 & -0.07 & 0.05 & -0.12 & -0.02 \\
\hline Fam & -0.09 & 0.02 & -0.08 & 0.10 & 0.01 & -0.07 & 0.02 & 0.05 & -0.07 & 1.00 & -0.38 & 0.02 & -0.29 \\
\hline Rel & -0.13 & -0.17 & 0.07 & -0.06 & 0.07 & 0.15 & 0.19 & 0.05 & 0.05 & -0.38 & 1.00 & -0.33 & 0.16 \\
\hline Tra & 0.20 & 0.32 & 0.07 & -0.02 & 0.00 & -0.08 & -0.14 & 0.02 & -0.12 & 0.02 & -0.33 & 1.00 & -0.23 \\
\hline Ind & -0.08 & -0.18 & -0.03 & 0.07 & 0.07 & 0.08 & 0.22 & -0.02 & -0.02 & -0.29 & 0.16 & -0.22 & 1.00 \\
\hline
\end{tabular}

COB: country of birth; Gen: gender; Both: living with both parents; SES: socioeconomic status; Fam: Familism; Res: Respect; Rel: Religion; Independence and Self-Reliance 
Appendix 3 - Latino Cultural Values 
Figure 10: Latino Adolescents' Identification with Latino Cultural Value: Familism Support, Miami-Dade County, Florida 2016-2017

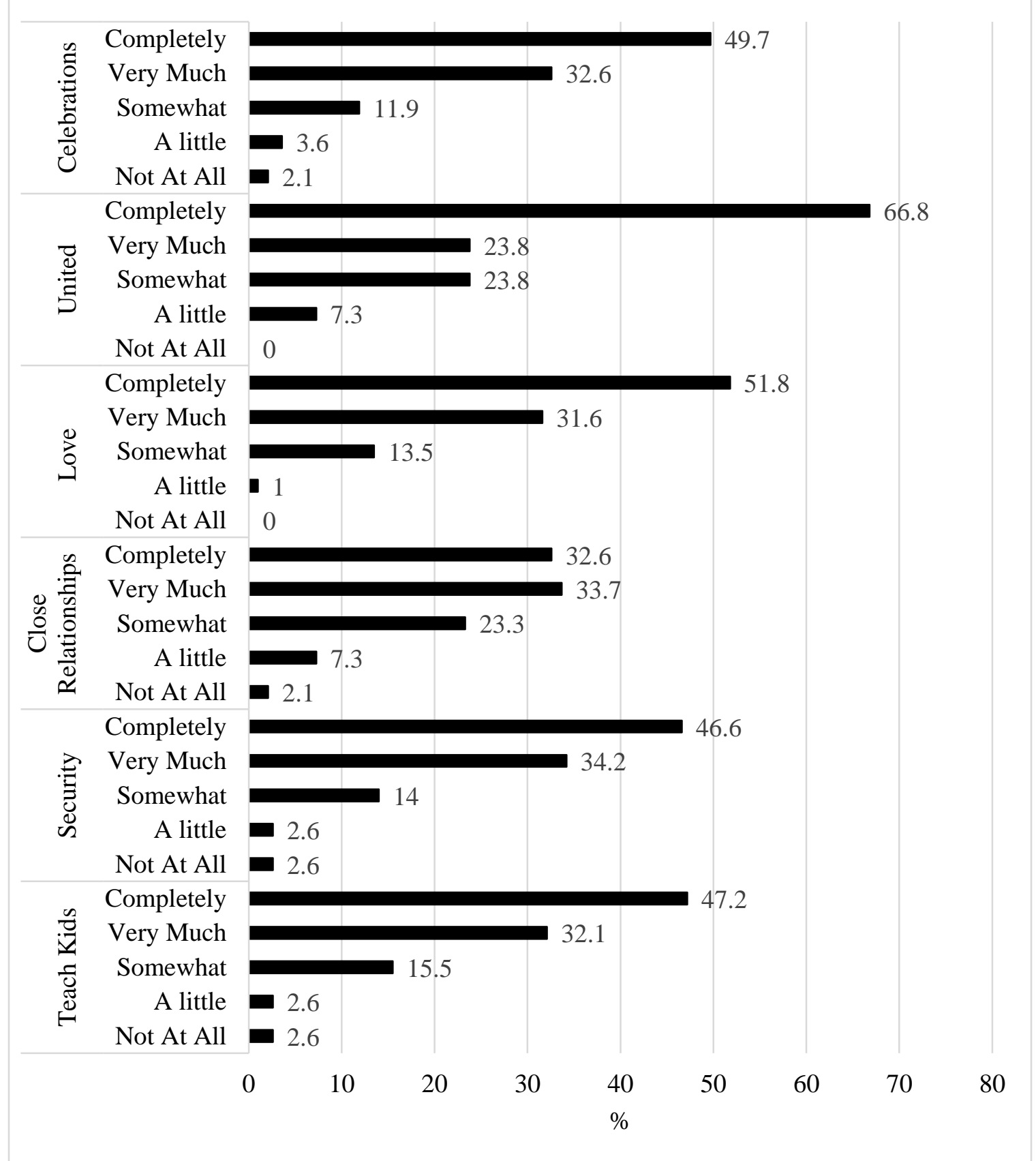

Teach Kids: Parents should teach their children that the family always comes first; Security: Family provides a sense of security because they will always be there for you; Close Relationships: It is important to have close relationships with aunts/uncles, grandparents, and cousins; Love: It is important for family members to show their love and affection to one another; United: It is always important to be united as a family; Celebrations: Holidays and celebrations are important because the whole family comes together. 
Figure 11: Latino Adolescents' Identification with Latino Cultural Value: Familism Obligations, Miami-Dade County, Florida 2016-2017

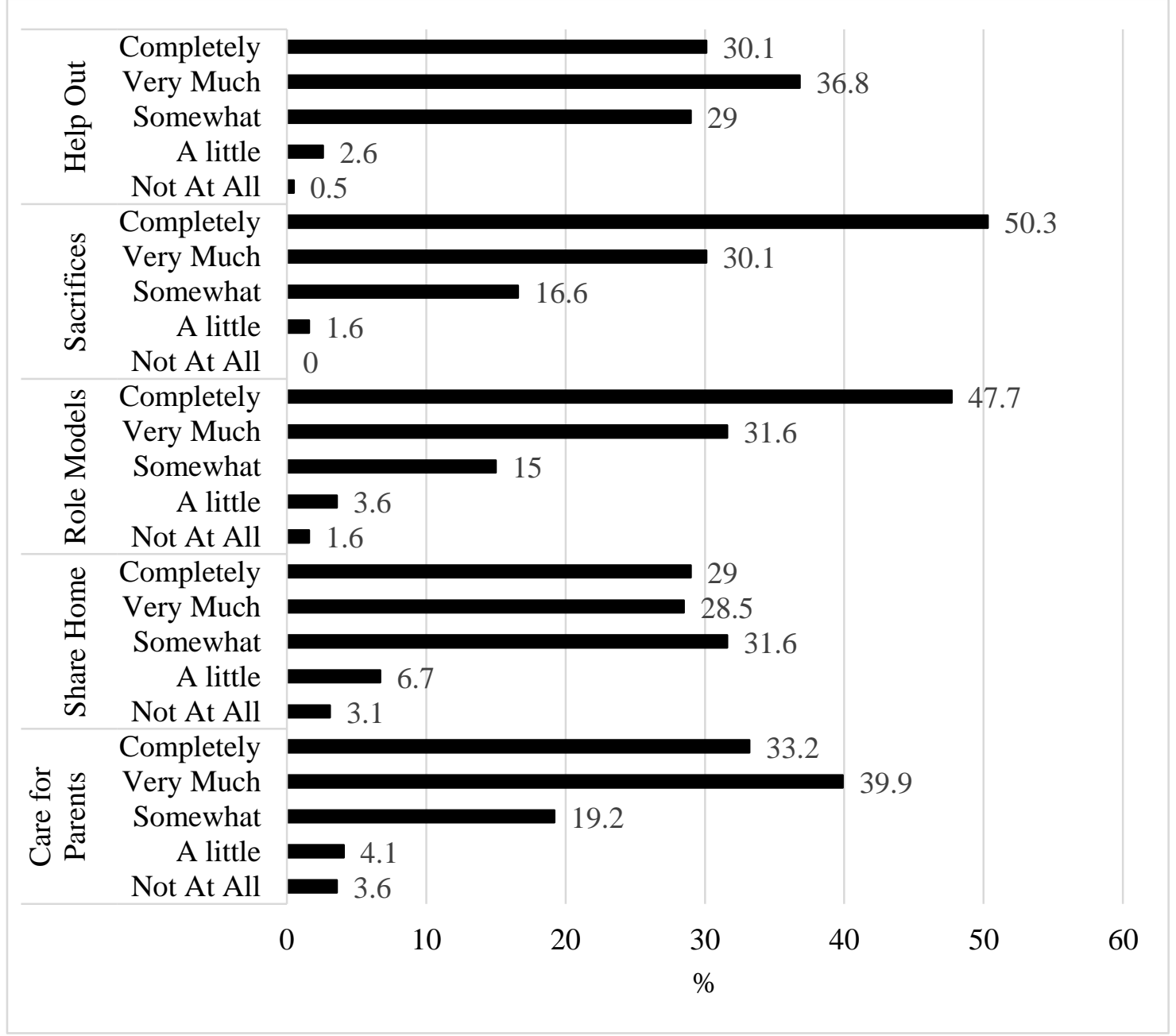

Care for Parents: Children should be taught that it is their duty to care for their parents when their parents get old; Share Home: A person should share their home with relatives if they need a place to stay; Role Models: Older kids should take care of and be role models for their younger brothers and sisters; Sacrifices: Parents should be willing to make great sacrifices to make sure their children have a better life; Help Out: If a relative is having a hard time financially, one should help them out if possible. 
Figure 12: Latino Adolescents' Identification with Latino Cultural Value: Familism Referents, Miami-Dade County, Florida 2016-2017

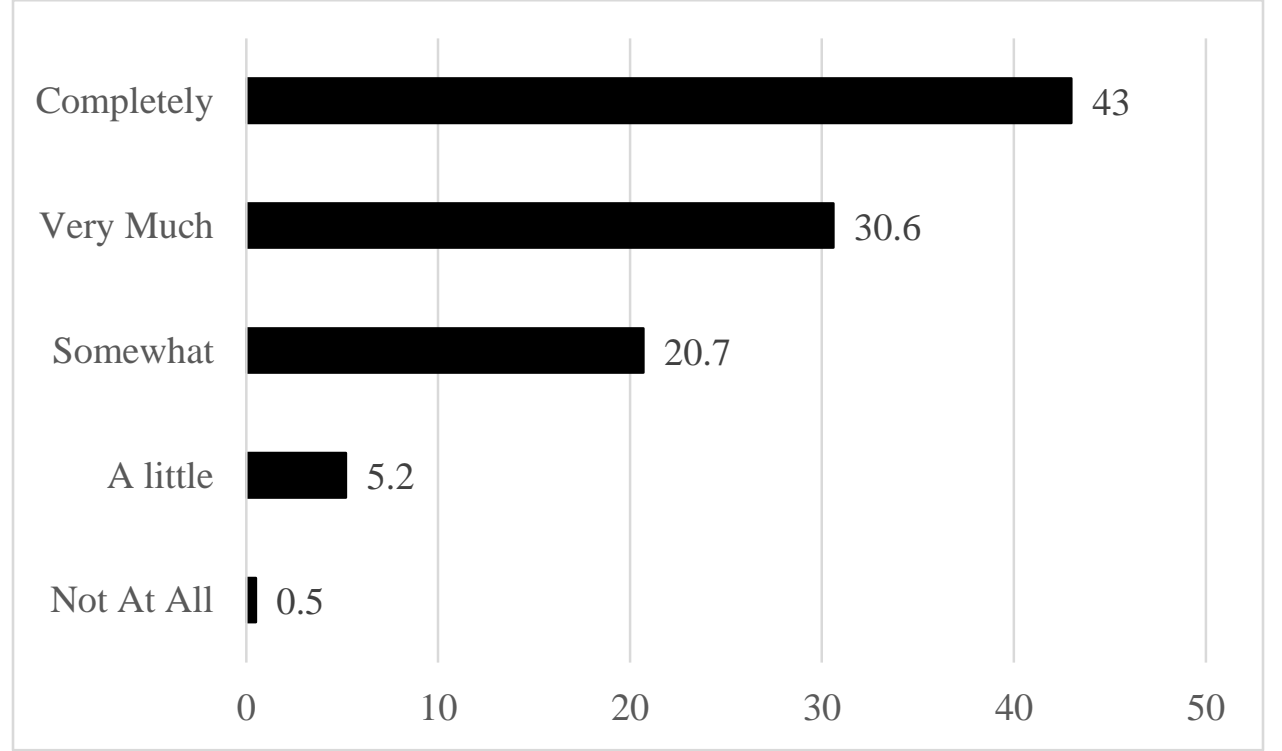

A person should always think about their family when making important decisions. 
Figure 13: Latino Adolescents' Identification with Latino Cultural Value: Respect, Miami-Dade County, Florida 2016-2017

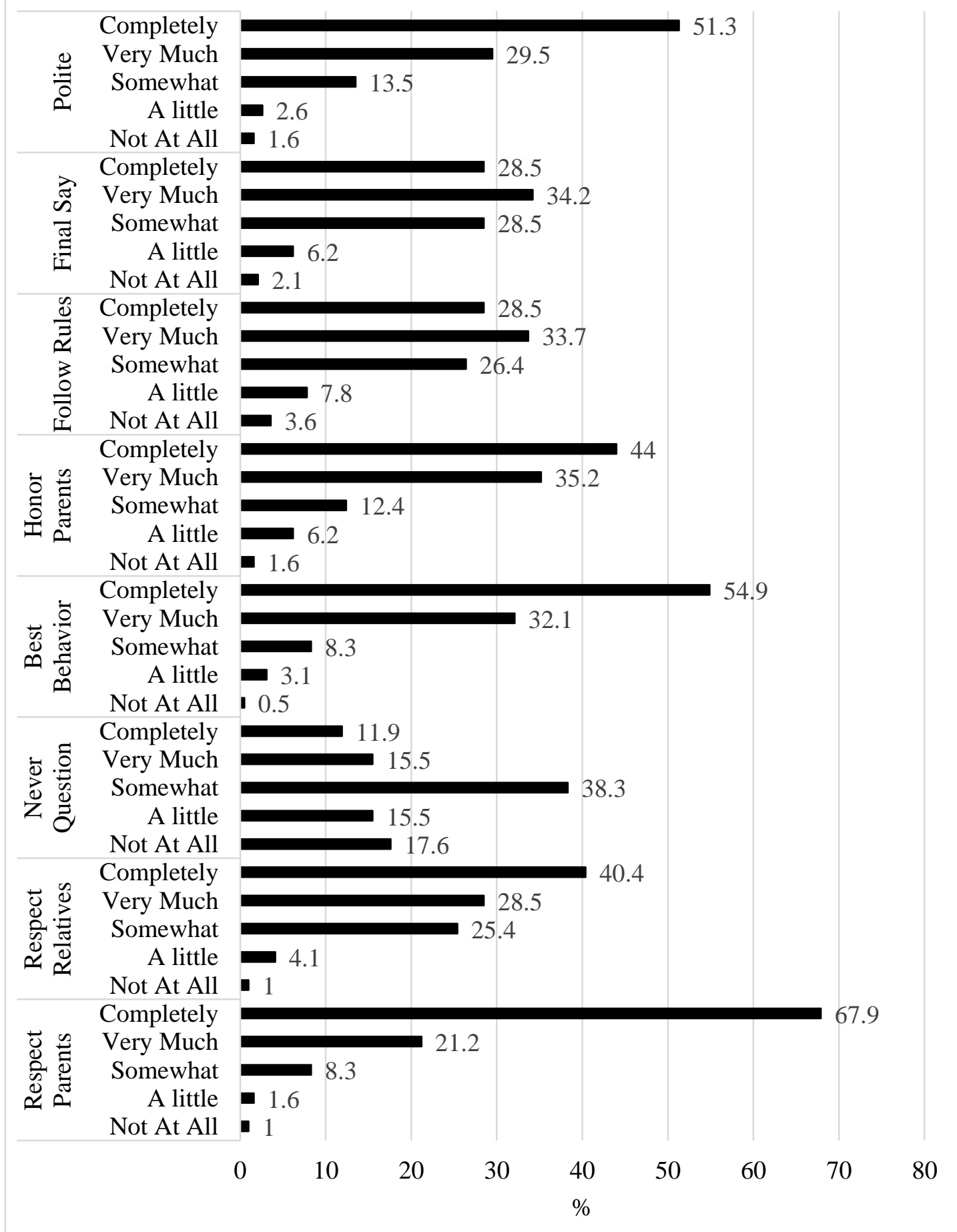

Respect Parents: No matter what, children should always treat their parents with respect; Respect Relatives: Children should respect adult relatives as if they were parents; Never Question: Children should never question their parent; Best Behavior: Children should be 
on their best behavior when visiting the homes of friends or relatives; Honor Parents: Children should always honor their parents and never say bad things about them; Follow Rules: Children should follow their parents' rules, even if they think the rules are unfair; Final Say: It is important for children to understand that their parents should have the final say when decisions are made in the family; Polite: Children should always be polite when speaking to any adult. 
Figure 14: Latino Adolescents' Identification with Latino Cultural Value: Religion, Miami-Dade County, Florida 2016-2017

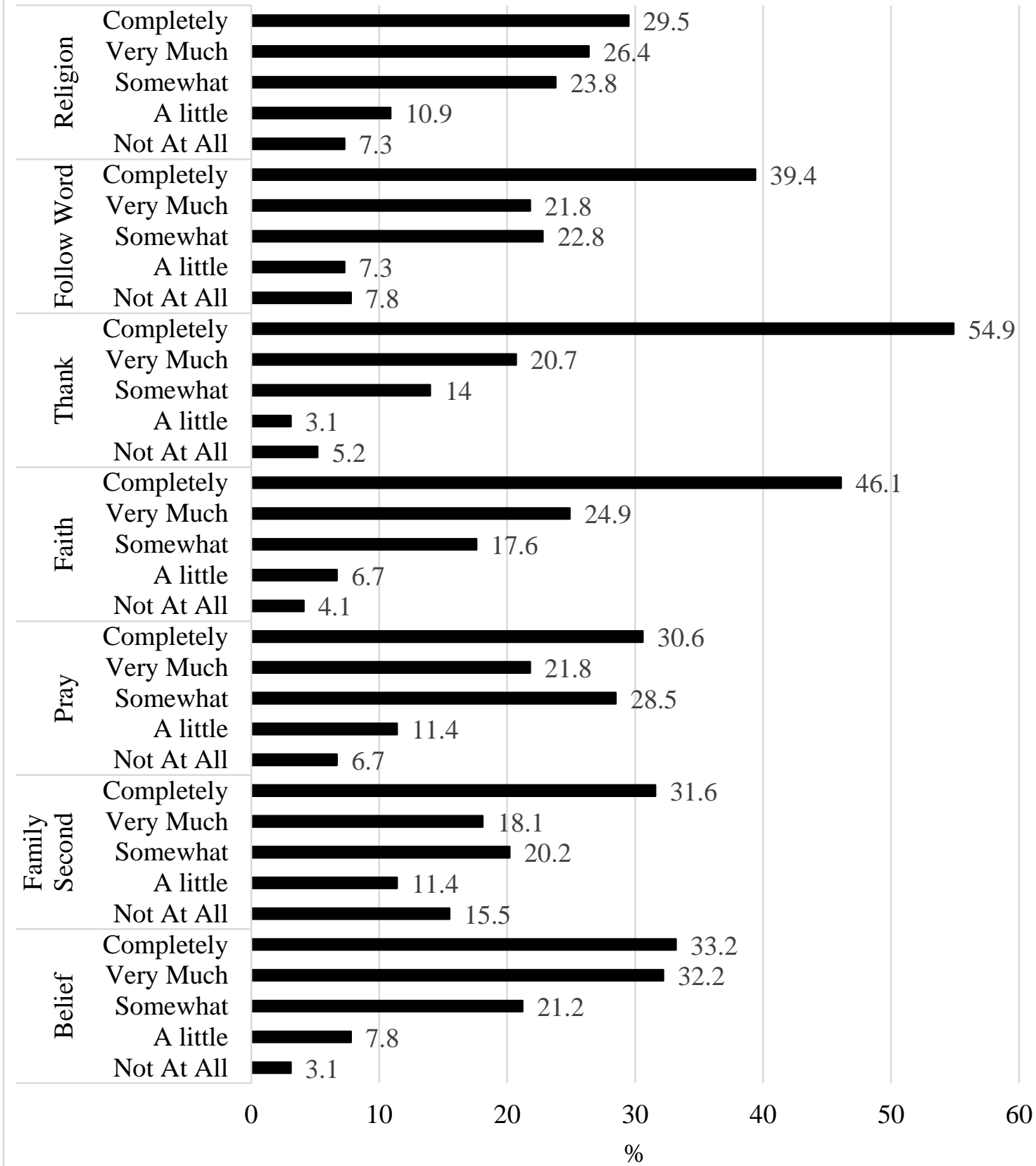

Belief: One's belief in God gives inner strength and meaning to life; Family Second: God is first; family is second; Pray: Parents should teach their children to pray; Faith: If everything is taken away, one still has their faith in God; Thank: It is important to thank God every day for all one has; Follow Word: It is important to follow the Word of God; Religion: Religion should be an important part of one's life. 
Figure 15: Latino Adolescents' Identification with Latino Cultural Value: Traditional Gender Roles, Miami-Dade County, Florida 2016-2017

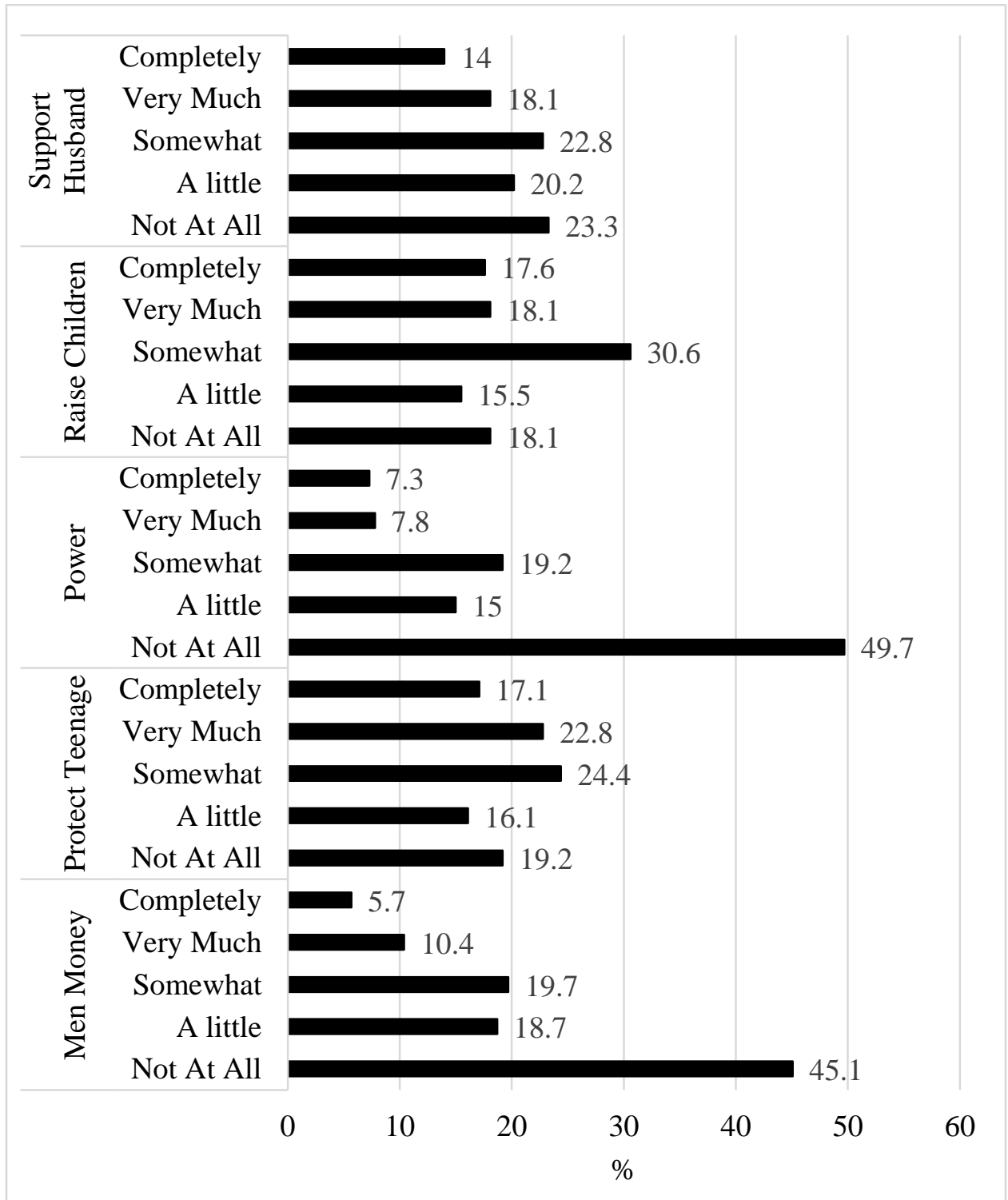

Men Money: Men should earn most of the money for the family so women can stay home and take care of the children and the home; Protect Teenage: Families need to watch over and protect teenage girls more than teenage boys; Power: It is important for the man to have more power in the family than the woman; Raise Children: Mothers are the main people responsible for raising children; Support Husband: A wife should always support her husband's decisions, even if she does not agree with him. 
Figure 16: Latino Adolescents' Identification with Latino Cultural Value: Independence and Self-Reliance, Miami-Dade County, Florida 2016-2017

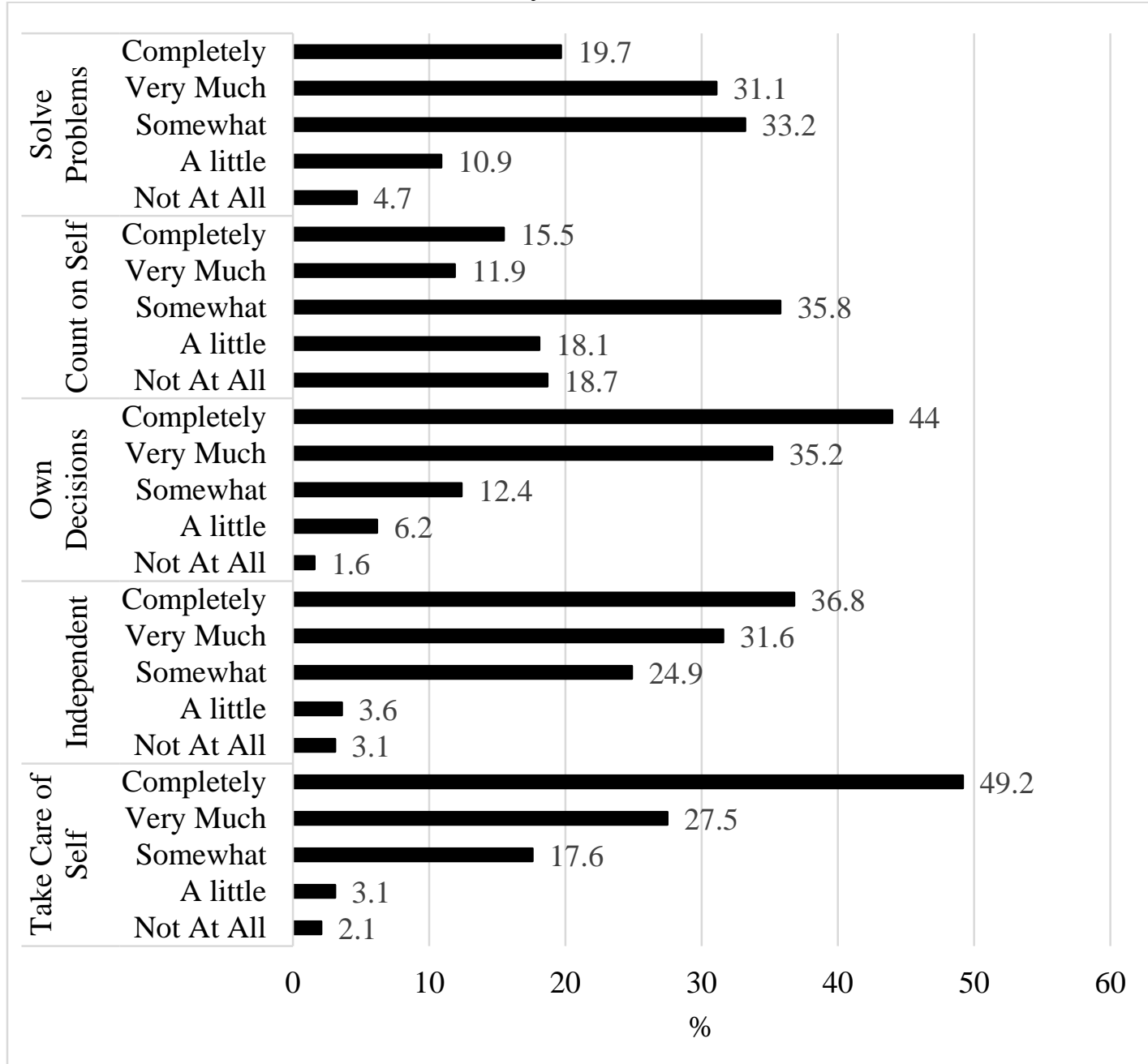

Take Care of Self: People should learn how to take care of themselves and not depend on others; Independent: The most important thing parents can teach their children is to be independent from others; Own Decisions: As children get older their parents should allow them to make their own decisions; Count on Self: When there are problems in life, a person can only count on him or himself; Solve Problems: Parents should encourage children to solve their own problems. 
VITA

JESSICA WEISSMAN

\section{EDUCATION AND AWARDS/SCHOLARSHIPS}

2018: PhD, Public Health, Florida International University, Miami, FL

2010: MS, Dietetics and Nutrition, Florida International University, Miami, FL

2008: BSE, Exercise Science and Health Promotion, Florida Atlantic University, Boca Raton, FL

2017: Presidential Award from the Division of Student Affairs' Annual Outstanding Student Life Awards at Florida International University: recognizes one "Worlds Ahead" student who has significantly impacted the FIU community above and beyond any oneaward category.

2017: PATH Science Prize from Robert Stempel College of Public Health \& Social Work at Florida International University: recognizes a current doctoral student or doctoral graduate who has had a paper accepted for publication as first author

2016: Leadership Challenge Annual Meeting Scholarship from American Public Health Association-Student Assembly: travel fund for registration and flight to travel to the 2016 American Public Health Association Annual Conference \& Expo.

2016: Campus Liaison of the Year Award from the American Public Health AssociationStudent Assembly.

2016: Presidential Award from the Florida Public Health Association.

\section{PUBLICATIONS AND PRESENTATIONS}

Weissman, J., Kanamori, M., Dévieux, J., Trepka, M. J., De La Rosa, M. (2017). HIV risk reduction interventions among substance-abusing reproductive-aged women: A systematic review. Submitted to AIDS Education and Prevention, 29(2), 120-138.

Kanamori, M., De La Rosa, M., Diez, S., Weissman, J., Trepka, M. J., Sneij, A., Schmidt, P., Rojas, P. . (2016). A Brief Report: Lessons Learned and Preliminary Findings of Progreso en Salud, an HIV Risk Reduction Intervention for Latina Seasonal Farmworkers. International Journal of Environmental Research and Public Health, 14(32).

Kanamori, M., Weissman, J., De La Rosa, M., Melton, J., Sanchez, M., Rojas, P., Trepka, M. J. (2016). Women's Perception of Adolescent Marijuana Use in a Hispanic Seasonal 
Farm Worker Community: A Qualitative Study. Journal of Ethnicity and Substance Abuse, 16, 1-11.

Weissman, J., Preston, S., Sebekos, E., Latorre, W., Alsaif, B., Krupp, K., Darrow, W. (2016). Associations Between Health and Academic Success at a Florida University: An Exploratory Cross-Sectional Study. Florida Public Health Review, 13, 91-98.

Kanamori, M., De La Rosa, M., Weissman, J., Rojas, J., Villar, M. E., Trepka, M. J., Dillon, F., Jaramillo, M. (2016). Associations between drug/alcohol use and emotional abuse: Who perpetrates emotional abuse against Latina women? Journal of Epidemiological Research, 2 (1), 95-101.

Kanamori, M., Weissman, J., De La Rosa, M., Trepka, M. J., Rojas, P., Cano, M. A., Melton, J., Unterberger, A. (2015). Latino mother/daughter dyadic attachment as a mediator for substance use disorder and emotional abuse. Journal of Immigrant and Minority Health, 18 (4), 896-903.

Weissman, J., Magnus, M., Niyonsenga, W., Roofe Sattlethight, A. (2013). Sports nutrition knowledge and practices of personal trainers. Community Medicine and Health Education, 3(7). Doi: 10.4172/2161-0711.1000254.

Weissman, J., Merten, J., McCoy, H. V., Bhatt, C., France, R., Waskovich, J., Edwards, E., Jordahl, L., Salfinger, Y., \& Hughes, S. (November 4-8, 2017). Florida Public Health Association Membership Initiative for Millennials and Beyond. American Public Health Association, Atlanta, GA; Poster Presentation.

Weissman, J., \& Darrow, W. (Oct 29-Nov 2016). Marriage Equality and Public Health: Ethical Considerations. American Public Health Association (APHA) Annual Meeting, Denver, CO; Oral Presentation.

Weissman, J., McMillan, M., Edwards, E., Akonkhai, L., McCoy, H.V., Hughes, S., Magyar, S., Pekovic, V., Jordahl, L. (Oct 29-Nov 2 2016). South Florida's 2016 regional conference: A Florida Public Health Association collaborative event. American Public Health Association (APHA) Annual Meeting, Denver, CO; Poster Presentation.

Weissman, J., Preston, S., Sebekos, E., Latorre, W., Alsaif, B., Krupp, K., Darrow, W. (May 31-June 4 2016). Can an on-campus medical home improve academic performance in college students?: An exploratory cross-sectional study. American College Health Association (ACHA) Annual Meeting, San Francisco, CA; Poster Presentation.

Weissman J,. Magnus, M. (September 24-27, 2011). Validity and reliability of an instrument on sports nutrition knowledge and practices of personal trainers. Academy of Nutrition and Dietetics, Food \& Nutrition Conference \& Expo (FNCE), San Diego, CA; oral presentation; Oral Presentation. 